\title{
Earning-by-Learning.Investigating the Performance Benefits of Customer Knowledge Development
}

Citation for published version (APA):

van Beuningen, J. W. A. (2009). Earning-by-Learning.Investigating the Performance Benefits of Customer Knowledge Development. [Doctoral Thesis, Maastricht University]. Datawyse / Universitaire Pers Maastricht. https://doi.org/10.26481/dis.20090417jb

Document status and date:

Published: 01/01/2009

DOI:

10.26481/dis.20090417jb

Document Version:

Publisher's PDF, also known as Version of record

\section{Please check the document version of this publication:}

- A submitted manuscript is the version of the article upon submission and before peer-review. There can be important differences between the submitted version and the official published version of record.

People interested in the research are advised to contact the author for the final version of the publication, or visit the DOI to the publisher's website.

- The final author version and the galley proof are versions of the publication after peer review.

- The final published version features the final layout of the paper including the volume, issue and page numbers.

Link to publication

\footnotetext{
General rights rights.

- You may freely distribute the URL identifying the publication in the public portal. please follow below link for the End User Agreement:

www.umlib.nl/taverne-license

Take down policy

If you believe that this document breaches copyright please contact us at:

repository@maastrichtuniversity.nl

providing details and we will investigate your claim.
}

Copyright and moral rights for the publications made accessible in the public portal are retained by the authors and/or other copyright owners and it is a condition of accessing publications that users recognise and abide by the legal requirements associated with these

- Users may download and print one copy of any publication from the public portal for the purpose of private study or research.

- You may not further distribute the material or use it for any profit-making activity or commercial gain

If the publication is distributed under the terms of Article $25 \mathrm{fa}$ of the Dutch Copyright Act, indicated by the "Taverne" license above, 


\section{EARNING-BY-LEARNING}

INVESTIGATING THE PERFORMANCE BENEFITS OF CUSTOMER KNOWLEDGE DEVELOPMENT

Jacqueline van Beuningen 
The cover shows a successful partnership found in nature, namely between bees and plants. Both depend on each other for survival, creating a highly effective cooperation or symbiosis. Honeybees are effective learners who communicate with each other to find new flowers quickly. The plant on the other hand offers self-service by providing nectar in return for pollination.

Both partners benefit in contrast to so-called parasitic relationships in which one species benefits by harming the other. Similar symbiotic and parasitic relationships exist between customers and companies; these are studied in this dissertation.

(c) 2009, Jacqueline van Beuningen, Maastricht

All rights reserved. No part of this publication may be reprinted or utilized in any form or by any electronic, mechanical, or other means, now known or hereafter invented, including photocopying and recording or in any information storage retrieval system, without written permission of the copyright owner.

ISBN: 978-90-5278-813-5

Cover design: Jacqueline van Beuningen

Printed by: Datawyse Maastricht 


\title{
EARNING-BY-LEARNING
}

\section{INVESTIGATING THE PERFORMANCE BENEFITS OF CUSTOMER KNOWLEDGE DEVELOPMENT}

\author{
PROEFSCHRIFT \\ Ter verkrijging van de graad van doctor \\ aan de Universiteit Maastricht, \\ op gezag van de Rector Magnificus, Prof. Mr. G. P. M. F. Mols \\ volgens het besluit van het College van Decanen, \\ in het openbaar te verdedigen \\ op vrijdag 17 april 2009 om 12.00 uur \\ door \\ Jacoba Wilhelmina Anna van Beuningen
}

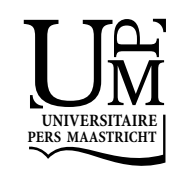




\section{Promotores}

Prof. dr. J. C. de Ruyter

Prof. dr. M. G. M. Wetzels

\section{Beoordelingscommissie}

Prof. dr. J. G. A. M. Lemmink (Voorzitter)

Prof. dr. A. de Grip

Prof. dr. A. Th. H. Pruyn (Universiteit Twente)

This research has received financial support from the Sheth Foundation. 
Voor mijn ouders,

Geer en Wilhelmien van Beuningen 



\section{ACKNOWLEDGEMENTS}

Ruim vier jaar geleden kreeg ik tot mijn stomme verbazing als reactie op mijn sollicitatiebrief een uitnodiging voor een gesprek in Maastricht. Onder het mom van een dagje uit naar Maastricht toog ik naar het zuiden. Toen ik later een telefoontje van Ko de Ruyter kreeg of ik bij het marketing departement in Maastricht wilde promoveren, hoefde ik niet lang na te denken. Terugkijkend op een leuke tijd heb ik geen spijt gekregen van mijn beslissing om in Maastricht een promotie te doen.

Een belangrijke succesfactor daarbij is Ko de Ruyter, mijn promotor, geweest. Ko, bedankt dat je altijd voor me klaar stond als ik weer eens vastzat. Je niet-aflatende stroom ideeën en enthousiasme waren zeer motiverend en je kritische houding pushte mij om harder te werken en stukken steeds weer te verbeteren. Je bood mij tevens de kans om naar het buitenland en conferenties te gaan en zorgde voor samenwerking met bedrijven. Verder wil ik Martin Wetzels, mijn copromotor, bedanken. Door jou durfde ik mijn tanden te zetten in complexe statistische methoden. Als ik problemen had, kon ik bij je langs komen voor hulp en advies. Je relativeringsvermogen is legendarisch.

Furthermore, I am very grateful for the opportunity to work with Christine Moorman. Because of you I do not see problems as obstacles anymore, but as challenges. Our collaboration does not feel like work, but like a fun adventure in which we hunt for conceptual treasure. Thank you for teaching me and making me feel welcome when I visited Duke.

Ik wil ook graag Sandra Streukens bedanken. Hoewel we helaas maar een jaar samen hebben gewerkt, ben je voor mij heel belangrijk geweest. Je hebt me mentaal gesteund en door het eerste jaar gesleurd. I would also like to thank my co-author and company contact, David Cox. Thank you for patiently dealing with all my information and data requests. You have helped me look at our project through a practitioner lens.

Tevens wil ik mijn commissieleden, Jos Lemmink, Andries de Grip, en Ad Pruyn bedanken voor de moeite en tijd die zij gestoken hebben in het lezen en becommentariëren van mijn proefschrift. lk wil Andries bedanken voor het in mij gestelde vertrouwen en de sponsoring van mijn postdoc. In het bijzonder wil ik Ad bedanken voor zijn vertrouwen in mij tijdens mijn studie en afstuderen in Twente. Hierdoor durfde ik te geloven dat een promotie misschien voor mij ook weggelegd was. Ik hoop dat je me inmiddels hebt vergeven dat ik dit in Maastricht in plaats van Twente ben gaan doen.

I would like to thank my roommates over the years for the fun times in the office. A special thank you goes to Clemens Köhler, Jeroen Bleijerveld, and Roos Hoogeboom. You have supported me by listening, reading, answering questions and brainstorming with me. Our coffee breaks, episodes of PhD's the series, forbidden words, "foute" top-40 on Fridays, and tomato competition I 
will never forget. I would like to thank my (former) colleagues at the Marketing department for the pleasant work environment and their helpfulness. I also thank Stephan, Niek, Roos, Jeroen, and Tom for reading through and commenting on my dissertation.

I would like to thank the people from the companies, namely IBM, CiCreate, FatFish, and Merscient, I have worked with for their trust and cooperation. I thank Ryan Faithfull and Matt Browne in particular for their patience and helpfulness.

Verder wil ik mijn ouders, Stefan, familie, en vrienden uit Beuningen, Enschede, Maastricht, en Roermond bedanken voor het zorgen voor de broodnodige afleiding tijdens de promotie. Mijn ouders bedank ik in het bijzonder voor hun onvoorwaardelijke steun bij alles wat ik doe. Jullie staan altijd voor me klaar en zorgen ervoor dat ik werk kan relativeren en geniet van het leven.

Jaap, last but not least, jij begrijpt mij beter dan wie ook. Jouw optimisme en positieve kijk op het leven zorgen ervoor dat problemen zich als vanzelf oplossen. Je bent onmisbaar voor mij!

Jacqueline van Beuningen 


\section{TABLE OF CONTENTS}

Chapter 1 Introduction

1.1 Research Problem 2

1.2 Theoretical Background 3

1.2.1 Partnering with Customers and Sales Agents 5

$\begin{array}{ll}1.3 \text { Theoretical Contributions } & 6\end{array}$

$\begin{array}{ll}\text { 1.3.1 Self-Efficacy in Services } & 7\end{array}$

1.3.2 Agency Challenges in Marketing Partnerships 7

1.4 Dissertation Outline 8

Chapter 2 Customer Self-Efficacy in Technology-Based Self-Service 11

$\begin{array}{ll}2.1 \text { Introduction } & 12\end{array}$

2.2 Conceptual Framework 14

$\begin{array}{ll}\text { 2.2.1 Customer Self-Efficacy } & 14\end{array}$

2.2.2 Customer Self-Efficacy and TBSS 15

$\begin{array}{ll}2.3 \text { Hypotheses Development } & 16\end{array}$

$\begin{array}{ll}\text { 2.3.1 Role Engagement } & 18\end{array}$

2.3.2 Outcomes of Self-Efficacy 20

2.4 Method 22

2.4.1 Research Context 22

2.4.2 Participants and Procedure 22

2.4.3 Measures 23

2.4.4 Measurement Model 24

2.5 Results 26

2.5.1 Multilevel Effects on Self-Efficacy 26

2.5.2 Effects of Self-Efficacy 31

2.6 Discussion 31

2.6.1 Theoretical Implications 32

2.6.2 Managerial Implications 33

2.6.3 Limitations 34 
Chapter 3 Consumers' Self-Efficacy Updating during Information $\quad 37$ Search

3.1 Introduction 38

3.2 Conceptual Background $\quad 40$

3.2.1 Belief Updating during Information Search 40

3.2.2 Explaining Updating Patterns 41

3.2.3 Divergent Consequences 43

3.2.4 Consumer Characteristics 44

$\begin{array}{ll}3.3 \text { Method } & 45\end{array}$

3.3.1 Sample 45

3.3.2 Procedure $\quad 45$

3.3.3 Measures 46

$\begin{array}{ll}\text { 3.3.4 Measurement Model } & 47\end{array}$

3.3.5 Analysis Strategy 50

3.4 Results 51

3.4.1 Identifying Multiple Self-Efficacy Updating Patterns 51

3.4.2 Drivers of Class Membership 53

3.4.3 Divergent Consequences $\quad 55$

3.4.4 Consumer Characteristics $\quad 55$

3.5 Discussion 56

3.5.1 Managerial Implications $\quad 57$

3.5.2 Limitations 58

$\begin{array}{ll}\text { Chapter } 4 \text { The Training-Agency Dilemma } & 61\end{array}$

$\begin{array}{ll}4.1 \text { Introduction } & 62\end{array}$

4.2 The Training-Agency Dilemma 63

$\begin{array}{ll}4.3 \text { Predictions } & 65\end{array}$

4.3.1 The Effect of Partner Exclusivity on Sales Return on Training 65 Investments

4.3.2 When Non-Exclusive Partners' Training Pays Off for the Firm 65

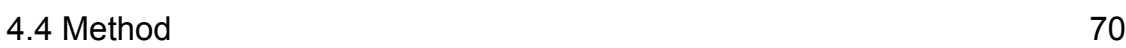

4.4.1 Study Context and Design $\quad 70$

$\begin{array}{ll}4.4 .2 \text { Sample } & 71\end{array}$ 
$\begin{array}{ll}\text { 4.4.3 Independent Variables } & 74\end{array}$

$\begin{array}{ll}\text { 4.4.4 Dependent Measures } & 75\end{array}$

$\begin{array}{ll}4.4 .5 \text { Covariates } & 76\end{array}$

4.4.6 Measurement Model $\quad 77$

$\begin{array}{ll}4.4 .7 \text { Selection Correction } & 79\end{array}$

4.4.8 Multilevel Model 80

$\begin{array}{ll}4.5 \text { Results } & 81\end{array}$

4.5.1 Partner Exclusivity and Sales Return on Training Investments: $\quad 81$ Perceived Sales Performance

4.5.2 Partner Exclusivity and Sales Return on Training Investments: $\quad 83$ Actual Sales Performance

$\begin{array}{ll}4.6 \text { Discussion } & 87\end{array}$

$\begin{array}{ll}\text { 4.6.1 Summary of Findings } & 87\end{array}$

4.6.2 Theoretical and Managerial Implications 88

4.6.3 Limitations and Issues for Further Research 90

4.7 Conclusion 91

Chapter 5 Conclusion $\quad 93$

5.1 Introduction $\quad 94$

5.2 Discussion 94

5.3 What Learning Was Earned? 95

$\begin{array}{ll}5.4 \text { Directions for Future Research } & 97\end{array}$

5.5 A Final Thought 98

$\begin{array}{lr}\text { Appendix A } & 99\end{array}$

$\begin{array}{ll}\text { Appendix B } & 102\end{array}$

$\begin{array}{ll}\text { Appendix C } & 106\end{array}$

$\begin{array}{ll}\text { Appendix D } & 108\end{array}$

$\begin{array}{ll}\text { Appendix E } & 109\end{array}$

References 112

$\begin{array}{ll}\text { Samenvatting } & 125\end{array}$

$\begin{array}{lr}\text { Curriculum Vitae } & 129\end{array}$ 

Chapter 1

Introduction 


\subsection{Research Problem}

Contemporary firms increasingly rely on actors outside the firm, i.e., customers or other firms, to contribute to their service and sales processes (Anderson, Håkansson, and Johansson 1994; Prahalad and Ramaswamy 2004). As such, firms no longer operate as isolated entities, providing standardized services to their customers. Customers cooperate with firms to create their preferred customized product or service experience, whereas specialized partnerships enable firms to respond more adequately to dynamic customer or market demands. The unique services that result provide sustainable competitive advantage through binding and bonding (Prahalad and Ramaswamy 2004). As such, firms can earn by inducing customer learning. For example, Zillow.com provides home-owners with free advice and exposure when they sell their house themselves, and Bank of America lets customers manage their investment portfolio by providing "online capabilities [ . . . ] to help you choose the right investments." In addition, firms team up with their downstream channel partners; distributors sell the firm's products, logistics companies handle transport to customers, and independent call centers are hired to handle customer complaints. In general, these arrangements focus on jointly producing services or core business processes, such as sales, with (an) external actor(s). However, in spite of these advantages, joining forces with customers give rise to more problems and service failures (J.D. Power 2006; Tax, Colgate, and Bowen 2006). In addition, it has been reported that almost half of firm partnerships fail (Dyer, Kale, and Singh 2001). So how can firms make these partnerships successful?

A key requirement for fulfilling the potential of partnerships is effective education and knowledge development. In the marketing literature, Vargo and Lusch (2004, p. 11) note that "for these services [i.e., services associated with goods] to be delivered, the customer still must learn to use, maintain, repair, and adapt the appliance to his or her unique needs, usage situation, and behaviors." Especially in B2B services the need for education has been voiced; Deborah NippesMena of Lucent Technologies (1997) notes: “Lucent won't leave our customers high and dry. Training and support are just as important to us as selling and installing our equipment in the first place." Alan Shipman, editor of Finance Week (2007) notes: "They [the customers] simply didn't realize it was there, was downloadable, and could be analyzed by them at will . . . we should really be running training on how to use what we produce." Forrester Research (2002) recognizes online learning of customer service agents as an effective and efficient way to decrease turnover. In addition, customers' self-confidence, or efficacy, is necessary for them to achieve high performance. Managerial practice suggests that a lack of consumer confidence, or self-efficacy, inhibits successful partnering strategies especially for complex services (Boyle, Clarke, and Burns 2006). 
The internet works as a catalyst by creating a platform for firms and customers to exchange information and develop knowledge. Julyette Jacobs of the Financial Literacy Center (FLC) states that the Internet has the potential to improve customer education, but current practice has some caveats: "Right now, I think there are tons of financial information out there. But I don't think most of it is real simple, or easy for the customer to understand" (1999, p. 15).

Many business-to-business (B2B) firms are developing extensive online education or training programs which include reward systems, whereas business-to-consumer (B2C) firms primarily focus on providing online information to customers. Hence, these firm tactics can be classified as institutionalized or formal versus individualized or informal. This dissertation focuses on online information and education of customers and business partners in particular, since these are actors with which B2C and business-to-business B2B firms frequently collaborate. Our overall aim is to find out how information and knowledge development can make customers more effective in their service and selling roles. In general, effective adjustment of newcomers has been put forward as a requirement for successful performance in organizations (e.g., Bauer et al. 2007). But how information provision can facilitate this process for customers has received little attention. In addition, while firms are educating partner firms' employees to facilitate coproduction role adjustment, research has not studied how partners need to be taught to increase their performance for the firm most effectively. Research sofar has failed to assess whether employees are equally effective in transforming training into higher sales performance.

In general, the issue of how to effectively educate customers or partner employees in service contexts remains unresolved. This dissertation attempts to fill this gap in the marketing literature by investigating how knowledge development by providing online information and training can increase the actor's performance. The overall research question of this dissertation is therefore: What mechanisms account for the effectiveness of customer knowledge development for facilitating external parties' performance?

Both customers and business partners are investigated, which enables us to draw from a diverse body of sources in the academic marketing literature. Specifically, we assess how information affects customers' self-efficacy, or taskspecific self-confidence, and, in turn, how self-efficacy influences performance and service evaluations (study 1 and 2). In addition, study 3 investigates conditions under which manufacturer training increases sales partner performance. The remainder of this chapter discusses the relevant literature, the contributions we aim to make, and the dissertation outline. Finally, we elaborate on these study objectives.

\subsection{Theoretical Background}

In general, information provision should result in effective role adaptation by an external party and, in turn, lead to favorable outcomes such as high 
performance. How exactly effective adaptation occurs, has remained unresolved. Bauer et al. (2007) note that the literature is unclear about the role of adjustment in newcomer or novice socialization. To study information effectiveness on external party performance, we make use of social cognitive theory, learning literature, and agency theory to understand the mechanisms that influences this process.

Social cognitive theory states that self-efficacy affects what actions people choose to pursue, how much effort they will put in task execution, how long they will persevere, and the performance level they will achieve (Bandura 1997). Selfefficacy is conceptualized as: "beliefs in one's capabilities to organize and execute the courses of action required to produce given attainments" (Bandura 1997 , p. 3). Meta-analysis has shown that self-efficacy is an important performance predictor (Stajkovic and Luthans 1998). The theory does not negate the importance of cognitive ability, but assumes that "people's level of motivation, affective states, and actions are based more on what they believe than on what is objectively true" (Bandura 1997, p. 2). Especially when learning about new and complex services and subsequently producing services, building customer self-efficacy might be an important criterion for success. Knowledge development should be distinguished from service performance to understand how self-efficacy impacts these processes. During knowledge development (e.g., while reading new information and updating self-efficacy) some self-doubt is beneficial for people to invest effort in acquiring knowledge; self-efficacy should not be too high as overconfidence will result (Bandura 1997). However, when customers are required to perform service tasks, wrestling with self-doubt hinders use of developed skills; hence, the higher customers' self-efficacy, the better (Bandura 1997). Study 1 of this dissertation focuses on self-efficacy as a predictor of performance and examines how it is formed on the basis of different sources of information, whereas study 2 addresses self-efficacy change during learning. Bandura (1997) distinguishes four general sources of self-efficacy: enactive mastery or prior experience, vicarious experience or modeling others, verbal persuasion or social influences, and physiological or affective states. Task information provided by the firm helps customers execute their task. Hence, when customers perceive information to be credible and of high quality, they will in turn feel more efficacious. In this case information acts as a signal associated with verbal persuasion as it conveys the consumers' ability to produce the service.

Information search by newcomers (within the context of organizations) has been classified as a socialization process, which emphasizes adaptation of newcomers to their roles (Ashforth and Saks 1996). On the one hand, newcomers search information and, on the other hand, the firm employs socialization tactics to familiarize newcomers with role requirements (Bauer et al. 2007). Feldman (1976) identifies initiation to the task and role definition as two essential processes during newcomer adaptation. Further, the socialization literature has identified information search as a predictor of adjustment, which 
includes self-efficacy (Bauer et al. 2007). Traditionally, socialization theory has been applied to employees, but not to customers or business partners. Since firms are now involving external parties in their service processes, these become partial employees or agents to the firm (Ross, Anderson, and Weitz 1997; Kelley, Skinner, and Donnelly 1992). Hence, it becomes important for firms to effectively socialize external parties to their service and selling roles.

Furthermore, consumer learning and information search literature shows that customers do not search information similarly depending on the individual's characteristics. For example, experience determines how information is processed and which information is remembered and used to execute a task (Alba and Hutchinson 1987). Besides ability-related factors, motivation directs learning and amount of search as well (Beatty and Smith 1987; Moorthy, Ratchford, and Talukdar 1997). Hence, it is important to take customer heterogeneity into account by investigating different response patterns, relevant individual characteristics, and types of business partners.

Finally, cooperating with an external party gives rise to specific challenges, which are discussed in agency theory literature. Agency theory describes relationships in which the firm relies on an agent, often an independent firm or individual, to perform some task for the firm (Bergen, Dutta, and Walker 1992). In this case firms are less able to monitor and control these external parties (Bergen et al. 1992). Many firms invest substantially in training programs to train sales agents, because they rely on these agents to sell their products and services. However, due to divided loyalties to manufacturers and self-interests, these independent sellers might not use training knowledge or use it to sell for competitors. Hence, although firms require customers or partners to learn to perform service tasks, they might not be motivated to work hard. In contrast to traditional agency literature, this dissertation focuses on non-contractual solutions and not on financial incentives, which facilitate role adjustment and performance of external parties.

The first two studies (i.e., chapter 2 and 3) focus on the link between customer information search and customer self-efficacy, which is an important indicator of newcomer adjustment, and its performance implications. In addition, in the third study (i.e., chapter 4) this dissertation investigates the effectiveness of manufacturer training, a firm tactic, on partner performance.

\subsubsection{Partnering with Customers and Sales Agents}

Current B2C research on services in which customers participate in service production has mainly focused on inducing consumers to adopt this particular type of service (Meuter et al. 2005), the existence of self-attribution bias (Bendapudi and Leone 2003), and the description of customer roles (Bitner et al. 1997). For instance, Meuter et al. (2005) show that perceived ability, or selfefficacy, increases customer's trial of self-service technologies, in which customers are responsible themselves for service production. Self-efficacy has also 
been used as a moderator, impacting the effect of perceived benefits on service attitudes (Dabholkar and Bagozzi 2002).

Although previous literature investigates how to attract customers to these types of services, it has not considered how sufficient customer performance can be ensured during service production. For example, increasing customer performance through improving self-efficacy has not been studied so far. This dissertation attempts to fill this gap by investigating how customers' self-efficacy is formed during information search, and how this self-efficacy, in turn, affects customers' performance and service evaluations in chapter two and three.

Secondly, a large body of B2B research exists on interfirm relationships in marketing. As Heide (1994, p. 71) notes: "the design of interfirm relationships is becoming a strategic decision variable in its own right." This dissertation focuses on partnerships of one manufacturer with several sales partners (e.g., resellers, distributors, integrators, and consultants), where the partner firm resells products and provides augmented services to other firms or consumers. Dependence on other firms is often viewed as something negative that should be avoided. However, in practice, it is often unavoidable to cooperate. Outsourcing the sales function to partners who collaborate with several manufacturers simultaneously is most of the time a necessity, which results in agency problems (Heide and John 1988; Sengupta 1995). The problem arises because of incongruent firm objectives. Hence, the fact that partners are independent and collaborate with multiple suppliers causes tension (Celly and Frazier 1996). Thus, dealing with a multitude of diverse sales partners is for most firms a reality.

Chapter four of this dissertation focuses on how these partners should be managed. Bettencourt et al. (2002) highlight the role of training in B2B partnerships as one of the strategies for creating high partner performance. Therefore, the focus is on sales partner training. Instead of analyzing the amount of learning from training, we are interested in knowledge application to find out if training pays off for the manufacturer. We account for partner diversity by using exclusive and non-exclusive partners as meaningful partner classifications.

\subsection{Theoretical Contributions}

According to recent marketing theorizing, knowledge is becoming a key resource for firms to sustain competitive advantage (Lusch, Vargo, and O'Brien 2007). Lusch and colleagues distinguish a second facilitator for firms' survival, namely their ability to form enduring relationships with customers and strategic partners. Although both knowledge development and relationship marketing have been studied extensively, relatively little is known about mechanisms which facilitate or inhibit pay-offs from customer knowledge development. We propose that these mechanisms include self-efficacy formation and agency challenges. In the three empirical studies we study consumers' as well as employees' knowledge development and try to make various theoretical contributions to selfefficacy and agency theory in particular. These are discussed in the next section. 


\subsubsection{Self-Efficacy in Services}

In general, the identification of self-efficacy antecedents has received little research attention. Gist and Mitchell (1992) note that few attempts have been made to identify the specific information cues that could affect self-efficacy and that little understanding exists on how cues are used to form self-efficacy. Study 1 of this dissertation tests whether specific information source evaluations can form self-efficacy, and how these effects differ across sources. A recent metaanalysis does not provide evidence that the amount of information seeking can be linked to self-efficacy (Bauer et al. 2007). Therefore, this study investigates whether self-efficacy is affected by customers' evaluation of the information source, instead of the amount of information sources considered.

In addition, recent literature calls for more research on the dynamic nature of motivational processes such as self-efficacy (Yeo and Neal 2008). A few studies have already examined self-efficacy changes over time (Bandura and Jourden 1991; Shea and Howell 2000), however self-efficacy change has always been conceptualized as a result of performance. In study 2 we extend this body of research by investigating dynamics of self-efficacy formation prior to performance. Specifically, the study shows that self-efficacy change can occur while receiving information during information search. In addition, not all customers seem to respond similarly to information, resulting in a variety of selfefficacy change patterns during search.

\subsubsection{Agency Challenges in Marketing Partnerships}

When a firm collaborates, it depends on the other party to execute certain (sales) tasks. Agency theory is concerned with these types of relationships in which a principal (either a firm or individual) depends on an agent to act on its behalf (Arrow 1985; Basu, Lal, Srinivasan, and Staelin 1985). Information asymmetry and lack of control result in agency problems in these relationships because the agent is assumed to pursue self-interests rather than the principal's interests (Bergen, Dutta, and Walker 1992).

Current agency research has identified the design of formal governance mechanisms (e.g., compensation schemes and monitoring) as solutions to agency problems with partners (Bergen, Dutta, and Walker 1992). In contrast to economics literature, study 3 investigates non-contractual solutions to agency problems. We focus specifically on non-exclusive versus exclusive sales partners. The former sells a portfolio of brands for various manufacturers, whereas the latter exclusively sells for one manufacturer. Study 3 shows that specific contextual conditions related to partner socialization and selection can alleviate agency problems for non-exclusive sales partners in particular.

Furthermore, current partnership research focuses on knowledge acquisition and sharing (e.g., Dyer and Hatch 2006; Selnes and Sallis 2003). Although learning from training is a requirement for successful training, the application of 
this new knowledge to partnership activities is important as well. This issue has been virtually neglected in the marketing literature thus far. Study 3 looks at the effect of learning from training on partner sales performance. In particular, conditions are identified related to individual, firm, and cultural characteristics, which impact the effect of learning on performance differently for exclusive and nonexclusive partners.

\subsection{Dissertation Outline}

This dissertation consists of three empirical studies in B2C and B2B domains. Data was collected using surveys. In addition, behavioral and secondary data were collected. Thus, multi-source methods were used to collect subjective and objective data. The data in chapter 4 was collected in close collaboration with several companies, including one of the leading computer technology manufacturers in the world. Furthermore, several analysis strategies, including multilevel modeling, growth mixture modeling, and growth modeling, were employed.

Chapter 2 introduces a multi-level model of self-efficacy formation from information source evaluations to gain insight into how self-efficacy is built during information search. Specifically, the study investigates how evaluations of different sources (i.e., source credibility and argument quality) are integrated into a self-efficacy judgment. It also includes role engagement, a consumer characteristic, which impacts the self-efficacy formation process. Finally, relevant selfefficacy outcomes are assessed by investigating its effect on performance and service evaluations, such as value and usage intentions.

Chapter 3 focuses on differential customer responses in terms of selfefficacy updating during search. Our research distinguishes three segments based on variance in updating patterns studied by a growth mixture modeling approach. Next, we explain why these patterns exist, how they are related to consumer characteristics, and what the consequences are in terms of customers' performance. Experience and effort explain customers' updating patterns, which show an increasing, maintaining, or decreasing pattern. The study offers detailed insight into how motivation and search behavior relate to the development of self-beliefs, such as self-efficacy, during search.

Chapter 4 investigates the effectiveness of sales partner training in terms of knowledge application. Using a multi-level analysis approach, we address how sales partners can be induced to apply training knowledge for the firm. Specifically, the distinction between exclusive and non-exclusive sales partners proves useful. Besides training and individual characteristics we are able to integrate firm and cultural characteristics to provide a detailed understanding of the conditions which impact knowledge application on perceived sales performance increase after training. In addition, we analyze actual sales performance change from December 2006 to November 2007 in a growth model to validate previous results. 
Finally, chapter 5 presents the conclusions of the dissertation and provides an answer to the overall research question. This chapter will also discuss general limitations and suggestions for future research. Table 1.1 offers a summary of the empirical studies.

TABLE 1.1 Overview of Empirical Studies

\begin{tabular}{|c|c|c|c|c|}
\hline Chapter & Study & Objective & $\begin{array}{l}\text { Analysis } \\
\text { Strategy }\end{array}$ & $\begin{array}{l}\text { Research } \\
\text { Context }\end{array}$ \\
\hline 2 & $\begin{array}{l}\text { Study 1: Cus- } \\
\text { tomer Self- } \\
\text { Efficacy in Self- } \\
\text { Service Tech- } \\
\text { nology }\end{array}$ & $\begin{array}{l}\text { Explore antece- } \\
\text { dents and con- } \\
\text { sequences of } \\
\text { customer self- } \\
\text { efficacy. }\end{array}$ & HLM & $\begin{array}{l}\text { Survey about } \\
\text { online invest- } \\
\text { ment, subjec- } \\
\text { tive and objec- } \\
\text { tive data. }\end{array}$ \\
\hline 3 & $\begin{array}{l}\text { Study 2: Con- } \\
\text { sumers' Self- } \\
\text { Efficacy Updat- } \\
\text { ing during } \\
\text { Information } \\
\text { Search }\end{array}$ & $\begin{array}{l}\text { Investigate } \\
\text { customer self- } \\
\text { efficacy updating } \\
\text { during search } \\
\text { and performance } \\
\text { differences } \\
\text { between seg- } \\
\text { ments. }\end{array}$ & $\begin{array}{l}\text { GMM } \\
\text { ANOVA }\end{array}$ & $\begin{array}{l}\text { Survey about } \\
\text { online invest- } \\
\text { ment, subjec- } \\
\text { tive and objec- } \\
\text { tive data. }\end{array}$ \\
\hline 4 & $\begin{array}{l}\text { Study 3: The } \\
\text { Training-Agency } \\
\text { Dilemma? }\end{array}$ & $\begin{array}{l}\text { Offer a frame- } \\
\text { work to under- } \\
\text { stand the condi- } \\
\text { tions under which } \\
\text { training invest- } \\
\text { ments in non- } \\
\text { exclusive part- } \\
\text { ners pay off for } \\
\text { the manufac- } \\
\text { turer. }\end{array}$ & $\begin{array}{l}\text { HLM } \\
\text { GM }\end{array}$ & $\begin{array}{l}\text { Survey with } \\
\text { sales partners, } \\
\text { in addition to } \\
\text { secondary } \\
\text { data provided } \\
\text { by the manu- } \\
\text { facturer, com- } \\
\text { bining subjec- } \\
\text { tive and objec- } \\
\text { tive data. }\end{array}$ \\
\hline
\end{tabular}

Note. HLM stands for hierarchical linear modeling, GMM for growth mixture modeling, ANOVA for analysis of variance, and GM for growth modeling. 



\section{ChAPTER 2}

\section{Customer Self-Efficacy in Technology-Based Self-Service Assessing Between- and Within-Person Differences ${ }^{1}$}

Firms increasingly offer customers the opportunity to coproduce self-service using online technologies. This requires novice customers to adopt a new role and engage in information search. This is particularly challenging in complex, high-risk services, such as online investment trading. Actively managing customers' task-specific self-confidence, or self-efficacy, in these types of technology-based self-service (TBSS) may convert novice customers into regular users and thereby increase return on investments. The authors show that self-efficacy increases novice customers' financial performance perceptions, service value evaluations, and future usage intentions. During online information search, novices focus on credibility and argument quality cues to determine their selfefficacy. The effects differ across information sources; third-party credibility and firm argument quality are most influential. Moreover, when consumers are highly engaged in their self-service role, the impact of credibility is strengthened, whereas that of argument quality is attenuated.

\footnotetext{
${ }^{1}$ This chapter is based on Van Beuningen, Jacqueline, Ko de Ruyter, Martin Wetzels, and Sandra Streukens, "Customer Self-Efficacy in Technology-Based Self-Service: Assessing Between- and Within-Person Differences," Journal of Service Research, forthcoming.
} 


\subsection{Introduction}

Across service industries, firms have extended their range of online service delivery options and are involving customers more extensively in the service production process. Technology-based self-service (TBSS) requires higher effort from customers than traditional full-service, whereas service providers invest substantially in the development and implementation of the self-service. Further, although no direct, face-to-face interaction takes place, the use of TBSS frequently requires coproduction and new service behaviors (Bendapudi and Leone 2003; Meuter et al. 2005). Despite that coproduction through self-service implies higher cognitive costs for customers, it also offers the potential of increased customization and a more satisfying experience (Prahalad and Ramaswamy 2004).

Firms invest heavily in interactive technologies that offer access to a wide range of information sources to support customers' decision making during online services. Bank of America (2007), for example, offers "tools and independent research to help you choose the right investments," and ING provides decision-support tools that assist clients in designing their financial retirement plans. At Zillow.com, customers search for and sell real estate using their access to local market reports, analyses by professionals, and peer-based pricing benchmarks.

Yet industry reports and academic research consistently indicate that coproduced services also result in a considerably higher incidence of customer problems than their full-service counterparts (J.D. Power 2006; Tax, Colgate, and Bowen 2006). Such problems are particularly worrisome in an online environment with its low switching barriers (Johnson, Bellman, and Lohse 2003). As a consequence, companies face the challenge of ensuring that novice customers can adjust to their new role. Effective adjustment, in turn, contributes to maximizing the likelihood that they become loyal customers, thus gaining acceptable returns on TBSS investments. Managerial practice suggests that a lack of consumer confidence, or self-efficacy, inhibits successful coproduction strategies especially for complex services (Boyle, Clarke, and Burns 2006). Moreover, customers who perceive their new role as engaging (i.e., interesting, rewarding, and challenging) may be more likely to invest energy in developing self-efficacy and learning to coproduce (Goodwin 1988). However, not all customers will be equally engaged. Therefore, self-efficacy and engagement seem to represent key success factors for effective TBSS coproduction by novice consumers. Specifically, Meuter et al. (2005) show that self-efficacy is one of the key factors inducing TBSS trial. We extend this work by investigating how self-efficacy is formed during consumer information search and its effects on performance and service evaluations.

Recent theory suggests that self-efficacy, or confidence in one's ability to execute a specific task, marks people's adjustment to new roles (Bauer et al. 
2007). Furthermore, self-efficacy has been identified as a robust performance predictor across a wide variety of domains (Stajkovic and Luthans 1998; Vancouver, Thompson, and Williams 2001). Evidence suggests that self-efficacy is formed as the result of an inferential process from information search (Bandura 1997). When confronted with online self-service options, customers often need to deal with multiple information sources (Steckel et al. 2005; Zauberman 2003), including those that extend beyond the information provided by the firm, such as online magazines and consumer communities (Klein and Ford 2003). However, even though consumers may not perceive all information as equally valuable, research on how people weigh and integrate task or role information obtained from different sources is virtually nonexistent. A notable exception is the work of Murray (1991), who finds that consumers use sources distinctively to evaluate services. We extend this research to self-efficacy formation and demonstrate that novice consumers also use source evaluations selectively to build their selfefficacy. Furthermore, self-efficacy may be determined by the interplay between information and an individual's cognitive processes, because the ability to weigh and integrate self-efficacy information should improve with high engagement (Bandura 1997). Extant research has yet to consider how varying levels of consumer role engagement influence the impact of source perceptions during selfefficacy formation. Therefore, this study adds to existing literature on TBSS by examining two important theoretical and empirical issues that have not been addressed conclusively.

First, we construct a theoretical framework that incorporates information source credibility and argument quality as key predictors of self-efficacy beliefs in complex TBSS. These are known determinants of consumers' product beliefs (Petty, Cacioppo, and Schumann 1983), but might also affect self-beliefs. Furthermore, as the range of sources broadens, consumers' evaluations will vary among different online information sources according to their perceived credibility and quality. Typical information search literature studies predictorcriterion relationships at the between-person level; we develop a framework that also includes a within-person assessment of variance in credibility and argument quality perceptions across different information sources as these perceptions will be interrelated for each person. We explore the outcomes of self-efficacy in TBSS by investigating the effects on customers' performance in their new role as coproducer, the value of the service, and intentions to use the service again.

Second, we posit that an exclusive focus on direct predictor-criterion relationships may mask divergent consumer valuations of information sources and thus inhibit a rich understanding of self-efficacy. Moreover, dual processing theorists note that motivational variables, such as engagement, should moderate source evaluation effects on attitudes by inducing differences in cognitive processing (Petty, Cacioppo, and Goldman 1981; Sanbonmatsu and Kardes 1988). Therefore, we examine whether a consumer's role engagement influences the effects of source evaluations on self-efficacy and how the information sources are related to these effects. 


\subsection{Conceptual Framework}

\subsubsection{Customer Self-Efficacy}

Despite Bendapudi and Leone's (2003) recognition of the relevance of psychological processes during coproduction for understanding service evaluations, these processes have received relatively little research attention. We investigate how self-efficacy forms during pre-purchase information search and how it drives service evaluations. Self-efficacy is conceptualized in this context as the belief in one's capabilities to specify and produce a service, as required in the service delivery process (Bandura 1997). As a domain-specific motivational belief, selfefficacy can be classified as a situational variable, setting it apart from more enduring personality traits (Bandura 1997). The proposed self-efficacy antecedents stem from verbal persuasion, which is identified as one of the self-efficacy sources (Bandura 1997). With verbal persuasion, people are persuaded that they possess necessary capabilities to execute an action. Source credibility and knowledgeableness or argument quality are properties associated with verbal persuasion, which determine the persuasiveness of a source (Bandura 1997). Although previous research states that these cues are critical for the persuasiveness of feedback information (Gist and Mitchell 1992), we test whether the same holds for task information. Thus, the assumption has been in previous research that the source should provide information about one's abilities; this study aims to test whether source evaluations related to sources providing task information affects self-efficacy in a similar way. Presumably, our self-concepts are shaped by what we think we know. Inevitably, we compare our own knowledge with information from other sources. Previous research has shown that people spontaneously infer self-beliefs from (social comparison) information (Stapel and Blanton 2004). Therefore, it seems reasonable that self-efficacy is also influenced by source evaluations from sources giving task information, as these signal the amount of task support the source provides. Thus, the better the source is evaluated, the more confident consumers will be about their ability to coproduce and to make a satisfactory purchase decision by using that source. We discuss two relevant conceptualization issues: (1) the level of specificity and (2) the dynamic nature of the construct.

A task-specific measure of self-efficacy directly increases performance, unlike more general measures (Chen et al. 2000). However, it remains unclear how specific the conceptualization should be. Bandura (1997) states that selfefficacy interpretations differ when people must consider a wider range of activities and situational demands, which results in response biases. Therefore, we focus on the customer behavior required to coproduce successfully rather than on service use in general, as discussed by McKee, Simmers, and Licata (2006).

Second, Yeo and Neal (2006), conceptualize self-efficacy as a multilevel construct that varies between and within individuals. For a TBSS, consumers may search a variety of information sources, each of which influences their self- 
efficacy uniquely, depending on the person and the source. As Sanbonmatsu and colleagues (2003) note, each consumer combines information from multiple sources differently, because stimuli are weighed inconsistently. That is, although individuals differ in self-efficacy based on their characteristics, self-efficacy also varies because of information sources the consumer encounters. Morrison and Vancouver (2000) recommend studying within-person patterns of information seeking in general. Because we are interested in how individuals use credibility and argument quality across an array of sources to form self-efficacy, variance across sources is just as relevant as variance across individuals. Thus, a person views multiple information sources, each with a different rating of credibility and argument quality, and we test how each is correlated with self-efficacy. Using only a between-person approach to test this particular part of the model would be erroneous, as the objective is also to test whether variance in these evaluations relates to variance in self-efficacy across sources.

\subsubsection{Customer Self-Efficacy and TBSS}

Previous research has addressed how TBSS trial can be enhanced, what determines satisfaction with TBSS, and the effect of individual characteristics on TBSS usage (e.g., Meuter, Ostrom, and Roundtree 2000; Meuter et al. 2003; Meuter et al. 2005). TBSS literature has also studied factors that influence behavioral intentions to use TBSS before trial has occurred. These mainly relate to service perceptions, such as ease of use, and consumer characteristics, such as technology attitudes (Bobbitt and Dabholkar 2001; Dabholkar 1996; Dabholkar and Bagozzi 2002). In this study we focus on consumers' self-perceptions instead.

Several findings in the TBSS literature point towards the relevance of customers' self-efficacy during usage. First, self-efficacy stimulates self-service trial (Meuter et al. 2005). Second, it has been added to the theory of trying, designed to explain the execution of difficult behaviors, as an important intention predictor in coproduction settings (Xie, Bagozzi, and Troye 2008). And third, it has been shown that self-efficacy is an important consumer characteristic, which affects to what extent favorable service attributes contribute to TBSS attitudes (Dabholkar and Bagozzi 2002). In addition, technology anxiety (i.e., lack of customer confidence) decreases TBSS usage and the likelihood to reuse the service (Meuter et al. 2003). Finally, the confidence to perform service behavior has been associated with perceived behavioral control, which is one of the most important motivations to use TBSS (Dabholkar 1996; Dabholkar, Bobbitt, and Lee 2003; Bobbitt and Dabholkar 2001). We examine how this confidence, or self-efficacy, is formed during pre-purchase information search, and whether it affects various service evaluations.

As customers become partial employees during coproduction, they require a new skill set tailored to the service's demands (Kelley, Donnelly, and Skinner 1990). Building self-efficacy through information search may increase role ad- 
justment and service performance of novice consumers, because they contribute information and effort resources (Bauer et al. 2007; Kelley et al. 1990; Kelley, Skinner, and Donnelly 1992).

In his social cognitive theory, Bandura (1997) states that people construct self-efficacy beliefs on the basis of various information sources. The underlying assumption is that information should be relevant for judging personal capabilities and is translated into self-efficacy beliefs through cognitive processing (Bandura 1997). Especially novice customers cannot rely on previous experience, which has been established as the most important self-efficacy predictor (Bandura 1997). Therefore, novices have to rely on other external sources to form self-efficacy. These customers consciously search for information to select a product while, often unconsciously, they also build self-efficacy by monitoring information sources (Stapel and Blanton 2004). Therefore, we investigate whether source evaluations, namely source credibility and argument quality, affect self-efficacy. If customers are able to use highly credible, high quality sources, they should feel more confident about their ability to make a purchase decision. Investigating whether in fact this is the case is highly relevant in a TBSS setting in which customers do not receive any direct feedback about their coproduction efforts from employees.

\subsection{Hypotheses Development}

Experienced TBSS customers rely mainly on their internal knowledge and less on external messages, whereas novices are more likely to use attributespecific evaluations (Zhu et al. 2007). Thus, experienced users tend to rely on pre-existing beliefs and look for confirming evidence when searching information, whereas novices are more likely to take new information into account when forming beliefs (Alba and Hutchinson 1987; Russo, Meloy, and Medvec 1998). Hence, because of our interest in studying the effects of information sources on self-efficacy, a focus on novice users is appropriate. Research indicates that consumers generally use three main types of information sources: retailer or firm information, third-party information, and peer resources (Beatty and Smith 1987; Steckel et al. 2005; Zauberman 2003). In addition, socialization theory posits that information seeking should positively affect self-efficacy and result in newcomer role adjustment (Bauer et al. 2007). However, it remains unclear what informational properties account for this effect. As Seijts et al. (2004) show, amount of information search may not predict self-efficacy. Literature suggests that consumers prefer to use information sources that fit their needs, which is determined by monitoring source characteristics or cues, such as credibility and argument quality (Murray 1991). The content of a source will either confirm or disconfirm one's own knowledge; however, any effects on self-efficacy will occur because the source is credible or of high quality and therefore helpful for executing the service task. These evaluations determine how much the customer can rely on the external information when executing the task. Similarly, credibility and argu- 
ment quality are known to affect persuasion because they determine the confidence in an ad (Petty and Wegener 2006). We test whether credibility and argument quality also affect confidence in the self while controlling for effects of amount of search. Hence,

$\mathbf{H}_{1}$ : On a between-person level, (a) information source credibility and (b) argument quality positively affect self-efficacy.

An important related question is whether the effect of credibility and argument quality is the same across information sources. In general, novices expend high cognitive effort when searching for information, which makes it likely that these customers are forced to use information selectively (Alba and Hutchinson 1987). Previous research shows that consumers in general rely differentially on firm, third-party, or peer information sources (Bearden, Netemeyer, and Teel 1989; Furse, Punj, and Stewart 1984).

The cue diagnosticity framework suggests that the extent to which a cue is used depends on its predictive value (Slovic and Lichtenstein 1971). Diagnosticity refers to the extent to which a cue can be used to form a judgment, such as self-efficacy (Menon, Raghubir, and Schwarz 1995). In addition, Purohit and Srivastava (2001) show that cue utilization also depends on the value of other available cues. Thus, the cue diagnosticity framework predicts that sources do not contribute equally to the credibility or argument quality effect on self-efficacy. The most diagnostic source(s) will contribute most. That is, the source which is most helpful for estimating self-efficacy from credibility or argument quality will be most influential. For example, peer credibility might be more helpful when forming self-efficacy than firm or third-party credibility.

Research suggests that consumers generally prefer to rely on peer sources (i.e., friends and family) especially for services (e.g., Jolson and Bushman 1978; Murray 1991). These studies conceptualize peer sources as personal and independent, in other words, these peers are well-known by the consumer in an offline context. In the online context, however, consumers exchange information with people who are unknown to them (e.g., in a virtual community or user forums). Mathwick, Wiertz, and de Ruyter (2008) note that this may erode trust in peer sources. However, Bickart and Schindler (2001) show that consumers still find online peer-to-peer information more credible and relevant than corporate information. This is because peer sources are less susceptible to commercial motives, more similar to the consumer, and include emotional personal stories which are more appealing than product specifications. Thus, we propose that novices will evaluate a peer source as highly credible and primarily rely on this source when forming self-efficacy from credibility. Therefore, we hypothesize that effects of source evaluations differ across sources in general, and that customers will mainly rely on peer credibility to form self-efficacy in an online TBSS since this is considered to be the most useful source in terms of its credibility. 
$\mathbf{H}_{2 \mathrm{a}}$ : On a within-person level, effects of information source credibility on self-efficacy differ across information sources, such that peer credibility exerts the strongest influence.

In contrast to source credibility, Smudde (2005) suggests that the quality of online consumer information is low, since peer sources are open to virtually anyone who wishes to voice their opinion. It is contended that since expression of opinion is the main focus, standards of quality are not always maintained. In addition, consumers are more likely to scrutinize argument quality for sources that are low in credibility, hence focus on firm information when forming selfefficacy from argument quality (Priester and Petty 1995).

Moreover, novices generally find it difficult to evaluate argument quality, because of their unfamiliarity with the service (Alba and Hutchinson 1987). Hence, novices will not easily assess the information sources' accuracy, will be insecure about these quality evaluations, and consider the evaluations not very useful. Quality uncertainty might induce the customer to revert to known information sources, such as information provided by the financial service provider. For instance, Pechmann and Ratneshwar (1992) show that when consumers have difficulty evaluating quality they tend to use prior beliefs for these evaluations. These prior beliefs, which only exist for familiar sources, in turn decrease argument quality uncertainty and increase its usefulness. Hence, we propose that customers will mainly use firm argument quality instead of third-party or peer argument quality.

$H_{2 b}$ : On a within-person level, effects of argument quality on self-efficacy differ across information sources, such that firm argument quality exerts the strongest influence.

\subsubsection{Role Engagement}

Customers' role engagement is particularly important in complex TBSS, because these services require a substantial amount of effort. Engagement is likely to increase task effort, because it incorporates enthusiasm and challenge (Salanova, Agut, and Peiró 2005). Engagement also plays an important role in information processing in general, because it facilitates purchase decisions (Wang 2006). Role engagement has been conceptualized as the employment and expression of a preferred self in task behaviors and is considered a motivational construct (Kahn 1990; Salanova et al. 2005). It is broader than customer involvement, as it also encompasses enjoyment and challenge (Salanova et al. 2005). Engagement allows for effective adaptation of the self-image to the new service role, hence it facilitates learning and the application of relevant skills (Goodwin 1988).

A situational variable that raises motivation, such as engagement, also increases the level of cognitive processing (Petty et al. 1981; Sanbonmatsu and Kardes 1988). Customers, who are highly engaged in TBSS, employ more 
cognitive processing, whereas others invest less effort in processing (Zhu et al. 2007). Therefore, engaged customers should rely more on available information source evaluations in general, because they are more willing to scrutinize external information and form self-efficacy from this information. Dual processing research suggests that high cognitive processing leads to more central (i.e., indepth) instead of peripheral (i.e., superficial) processing (Petty et al. 1981; 1983). This implies that highly engaged customers focus more on argument quality. However, novices focus more on peripheral cues, such as credibility, than central cues when cognitive effort requirements are too high (Alba and Hutchinson 1987). In addition, Petty and Wegener (2006) recently proposed that any variable, i.e., credibility or argument quality, can serve as a central as well as a peripheral cue depending on how much it is scrutinized. In this case, credibility and argument quality can both be perceived as additional message arguments when scrutinized extensively. Therefore, we propose that customers should rely more on both credibility and argument quality when they experience high role engagement.

$\mathbf{H}_{3}$ : On a between-person level, high role engagement strengthens the effects of (a) information source credibility and (b) argument quality on self-efficacy.

Further, we predict that highly engaged customers will be less sensitive to the type of information source, as it has been shown that engagement increases message involvement (Wang 2006). Message involvement induces customers to spend more effort on processing information (Laczniak and Muehling 1990). Higher processing might diminish discrimination across sources, because customers are motivated to consider less credible and lower quality sources in addition to the most useful sources ${ }^{2}$. Highly engaged customers will still find some sources more useful than others. However, they will be more willing to consider those less useful sources. Hence, there will be less of a trade-off between information sources. In general, Hawkins and Hoch (1992) show that under low involvement customers are less likely to evaluate information. Moreover, involvement facilitates attention and comprehension processes (Celsi and Olson 1988). Thus, whereas customers would generally focus on peer credibility only, highly engaged customers might also take firm and third-party credibility into account. In other words, relative to customers with low engagement, customers with high engagement will consider firm and third-party credibility more.

$\mathbf{H}_{4 \mathrm{a}}$ : On a within-person level, the impact of role engagement on the relationship between information source credibility and self-efficacy differs across information sources, such that engagement will strengthen the effects of firm and third-party credibility.

\footnotetext{
${ }^{2}$ We thank an anonymous reviewer for this suggestion.
} 
Following the same reasoning of the previous hypothesis, engaged customers will also trade off less when using argument quality to form self-efficacy. Thus, highly engaged customers will focus more on third-party and peer argument quality compared to customers with low engagement, which focus primarily on firm argument quality.

$\mathbf{H}_{4 \mathrm{~b}}$ : On a within-person level, the impact of role engagement on the relationship between argument quality and self-efficacy differs across information sources, such that engagement will strengthen the effects of third-party and peer argument quality.

\subsubsection{Outcomes of Self-Efficacy}

Self-efficacy research in psychology provides empirical evidence that selfefficacy increases performance for a wide range of tasks that require skill acquisition, such as air traffic control simulations, analytic games, and computer software mastery (Eyring, Johnson, and Francis 1993; Gist, Schwoerer, and Rosen 1989; Vancouver, Thompson, and Williams 2001). According to services research, employee job self-efficacy increases employees' service performance and links to service evaluations (Ahearne, Mathieu, and Rapp 2005; Hartline and Ferrell 1996). The reasoning for these effects is that higher self-efficacy leads to beneficial outcomes through increased effort and persistence (Gist 1987). Because customers contribute to service outcomes as "partial employees" in coproduction (e.g., Bendapudi and Leone 2003; Kelley et al. 1990), their selfefficacy should increase their perceived service performance. In this study, we focus specifically on customers' assessments of their own stock investment performance, because we are interested in assessing the effect of self-efficacy on service outcomes.

$\mathbf{H}_{5}$ : Self-efficacy positively affects customer perceived financial performance.

With regard to customer service evaluations, McKee, Simmers, and Licata (2006) show that customer self-efficacy increases perceived value. According to these authors, self-efficacy influences value because customers with high selfefficacy should be able to maximize value, which enables them to take full advantage of service benefits. De Jong, de Ruyter, and Wetzels (2006) further show that self-efficacy among service employees increases customers' service quality evaluations. When firms assist customers during coproduction by providing information, the customers might develop higher self-efficacy (Brown, Jones, and Leigh 2005). Therefore, since customers are better able to use the service, they should also perceive higher service value because of their increased ability to maximize received benefits.

$\mathbf{H}_{6}$ : $\quad$ Self-efficacy positively affects perceived value. 
Adoption research finds a positive relationship between self-efficacy and behavioral intentions (Hill, Smith, and Mann 1987; Pavlou and Fygenson 2006). Meta-analytic organizational research shows that self-efficacy among newcomers increases their intentions to remain with the organization (Bauer et al. 2007). In addition, information technology research indicates that self-efficacy increases computer usage (Compeau and Higgins 1995). Further, consumer lock-in research shows that perceived ease of use, instead of actual ease of use, directly affects intentions to remain with the online service (Murray and Häubl 2007). TBSS research suggests that self-efficacy may be especially important for explaining usage intentions when TBSS services are unfamiliar (Oyedele and Simpson 2007). Hence, self-efficacy is likely to be a relevant predictor of novices' usage intentions. In light of these findings we investigate whether there is a self-efficacy effect on usage intentions.

$\mathbf{H}_{7}$ : Self-efficacy positively affects usage intentions.

Indirect effects of self-efficacy on intentions through value have been found in service research (McKee, Simmers, and Licata 2006). Further, perceived performance has also been associated with behavioral intentions through customer satisfaction (Burton, Sheather, and Roberts 2003). We extend these findings to the TBSS context and investigate whether effects of self-efficacy on usage intentions are mediated by either perceived financial performance, perceived value, or both.

$\mathbf{H}_{8}$ : The effect of self-efficacy on future usage intentions is mediated by (a) customer perceived financial performance, and (b) perceived value.

Figure 2.1 represents our conceptual framework including hypotheses.

FIGURE 2.1 A Conceptual Model of the Role of Self-Efficacy in TBSS

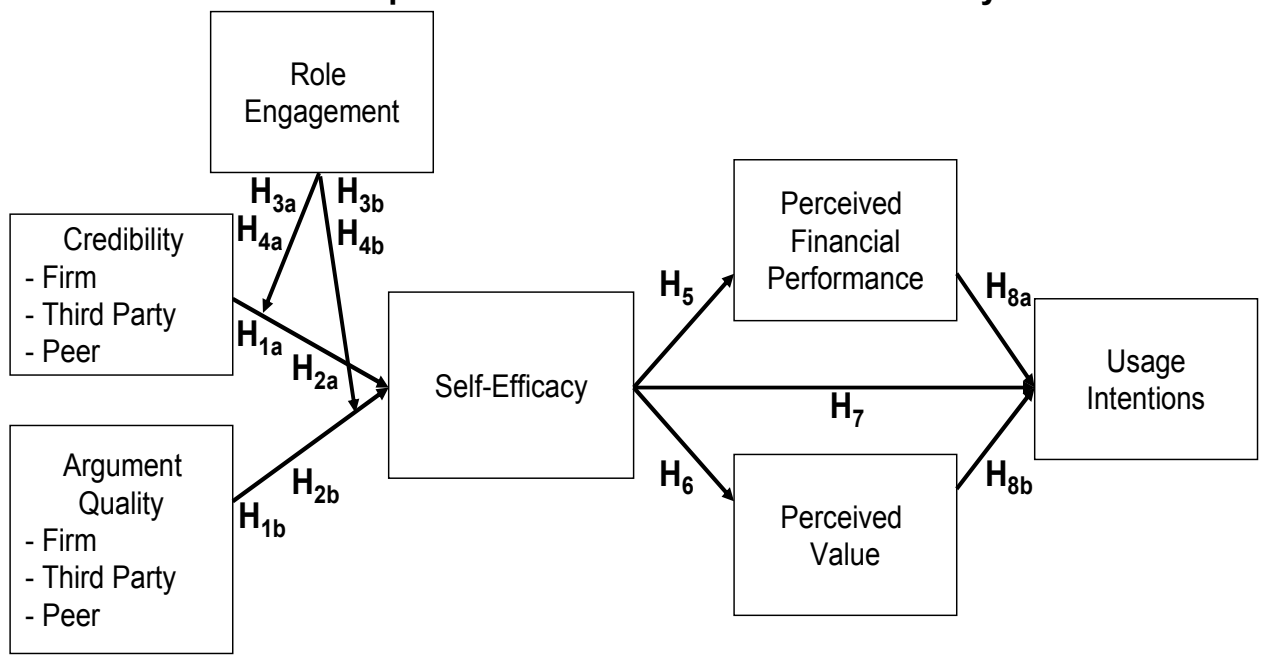




\subsection{Method}

\subsubsection{Research Context}

We use online stock investment as the context for this study, because this represents a complex, long-term TBSS that, though relatively new, is experiencing rapid adoption (Konana and Balasubramanian 2005; Meuter et al. 2005). Because of our focus on effective role adjustment from self-efficacy development, our sample frame consists of young, novice consumers. Financial service providers increasingly target this segment of prospective investors (i.e., 20-25 year age group) (BusinessWeek 2007). In addition, novice consumers are less likely to form their self-efficacy from prior experience, but to focus on other, external information. Therefore, this young, relatively inexperienced consumer segment provides an appropriate context to study how self-efficacy is affected by information search. Finally, one of the activities associated with this service consists of online information collection about stocks and firms, and the target consumers frequently consult various information sources to obtain advice.

\subsubsection{Participants and Procedure}

Two hundred seventy-one business students, with a mean age of 22 years $(S D=2.76)$, participated in our study in exchange for a dinner coupon at a medium-sized Dutch university. We deem a student sample appropriate, because this group is still relatively unfamiliar with investing (i.e., the investment experience of respondents who had invested before, or $26.6 \%$ of the sample, averages 3.1 years online and 3.8 years offline), but their potential revenues are high. Indeed, Schwarzkopf (2007) shows that business students are frequently involved with investing or planning to do so in the future. In addition, it has been shown that TBSS adopters are usually relatively young, highly educated consumers (Meuter et al. 2003). Therefore, it is realistic to ask respondents to search for stock investment information, as most of them would have to engage in a skill acquisition process and form self-efficacy.

In cooperation with a large international bank, we invited respondents to explore information sources offered on the bank's Web site. Before viewing the actual Web site, each respondent imagined that he or she had received $€ 1500$ from an inheritance and decided to invest it in stocks using XYZ online investment. Each information source on the bank's Web site, available through hyperlinks, contained company and stock information. The firm source clarified that stock analysts provided the site's content. The third-party source was a link to an online magazine that proclaimed its independence, but did not indicate any specific editor expertise. Finally, the peer source consisted of a private investor forum where investors and would-be investors exchange information. Screen prints of each source's homepage can be found in Appendix A. Presenting three online information sources is a realistic representation of consumer search on 
the Internet (Johnson et al. 2003; Steckel et al. 2005; Zauberman 2003). Respondents rated the credibility and argument quality of each source. In addition, we measure role engagement and perform a median split to identify low and high engaged groups (i.e., between-subjects factor). According to realism checks, incorporated on a seven-point scale from Dabholkar (1994), the respondents found the situation realistic $(M=5.0 ; S D=1.13, \mathrm{Cl}=[4.86 ; 5.14])$. A professional investment expert also checked the information sources to ensure clarity. Respondents did not actually use the service, because trial usage serves as an additional information source (Kempf and Smith 1998) and we wanted to exclude this confounding effect. Instead respondents made an investment decision in the survey by selecting the stock(s) they wanted to invest in from an unordered list and decided, based on the predetermined amount given in the instructions, how much they would invest in the stocks they selected.

\subsubsection{Measures}

All measures in our study consist of seven-point scales. Argument quality employs a semantic differential scale, whereas all the others are Likert scales. We measure role engagement with respect to the overall task (i.e., searching for information and deciding in which stocks to invest) on the basis of Kahn's (1990) and Salanova and colleagues' (2005) conceptualizations. The five items combine cognitive, affective, and physical elements by focusing on perceived interest, challenge, satisfaction, enjoyment, and energy expended. Source credibility, which distinguishes trustworthiness and expertise, relies on a scale developed by Newell and Goldsmith (2001). To measure argument quality a scale from Bailey and Pearson (1983) is adopted. Respondents provide three assessments of credibility and argument quality, that is, for each information source. To measure self-efficacy, a scale adapted from Webster and Martocchio (1992) is used. This scale relates to working with computer software and takes the difficulty of estimating one's confidence when learning complex and abstract features into account. We measure participants' perceived financial performance using a measure from Singh (1993) and ask how respondents rate themselves on the stock trading task. Perceived value is adapted from Harris and Goode (2004) and usage intentions from Agarwal and Karahanna (2000). Experience, identified as the most important self-efficacy predictor (Bandura 1997) is controlled for even though it is relatively low in our sample, by measuring the number of years respondents had invested in stocks online and offline (Balasubramanian, Konana and Menon 2003). In addition, amount of information search was controlled by measuring the number of seconds respondents spent viewing the web sites. We also control for prior online and offline stock trading experience. Finally, the source order was counterbalanced, and it had no significant effect on selfefficacy; therefore, it was excluded from further analyses. All study items can be found in Appendix B. 


\subsubsection{Measurement Model}

To address our hypotheses regarding the within-person effects, we conduct a confirmatory factor analysis of the three constructs (i.e., credibility, argument quality, and self-efficacy) across the three information sources. Normality violations are tested by investigating skewness and kurtosis (Bollen 1989), which can bias tests of variances and covariances (DeCarlo 1997). Skewness and kurtosis scores reveal that both are not serious problems in our data (skewness ranges from -.79 to .09 , kurtosis ranges from -.53 to 1.78 ). Multivariate kurtosis is also inspected using the normalized estimate of Mardia's coefficient, which indicates the presence of significant multivariate kurtosis $(z=16.91, p<.001)$ (Mardia and Foster 1983).

To estimate the model, we fix the loadings and errors of the indicators across sources in Mplus 4.0 and use the Satorra-Bentler (SB) correction to control for non-normality (Satorra and Bentler 1988). We allow the errors and loadings to correlate to control for the fact that we essentially use the same measurement items across information sources. We exclude constructs with single-item measures (i.e., online and offline experience, and information search). The fit indices indicate a reasonable fit of the data $\left(S B X^{2}(1478)=\right.$ 2474.99, $p<.001$, RMSEA $=.050$, SRMR $=.048, \mathrm{TLI}=.91, \mathrm{CFI}=.92)$. In addition, the factor structure of the between-person constructs (i.e., role engagement, perceived financial performance, value, and usage intentions) is investigated, which also reveals a good fit $\left(S B X^{2}(59)=110.99, n s, \operatorname{RMSEA}=.058\right.$, SRMR $=.056, \mathrm{TLI}=.97, \mathrm{CFI}=.98$ ). All factor loadings can be found in Appendix B. The correlation matrix with means and standard deviations of this study's constructs are displayed in Table 2.1. Although means of source evaluations are in the same direction across sources, credibility and argument quality for each source do not pose multicollinearity problems (i.e., variance inflation factors range from 1.64 to 2.07 ). 


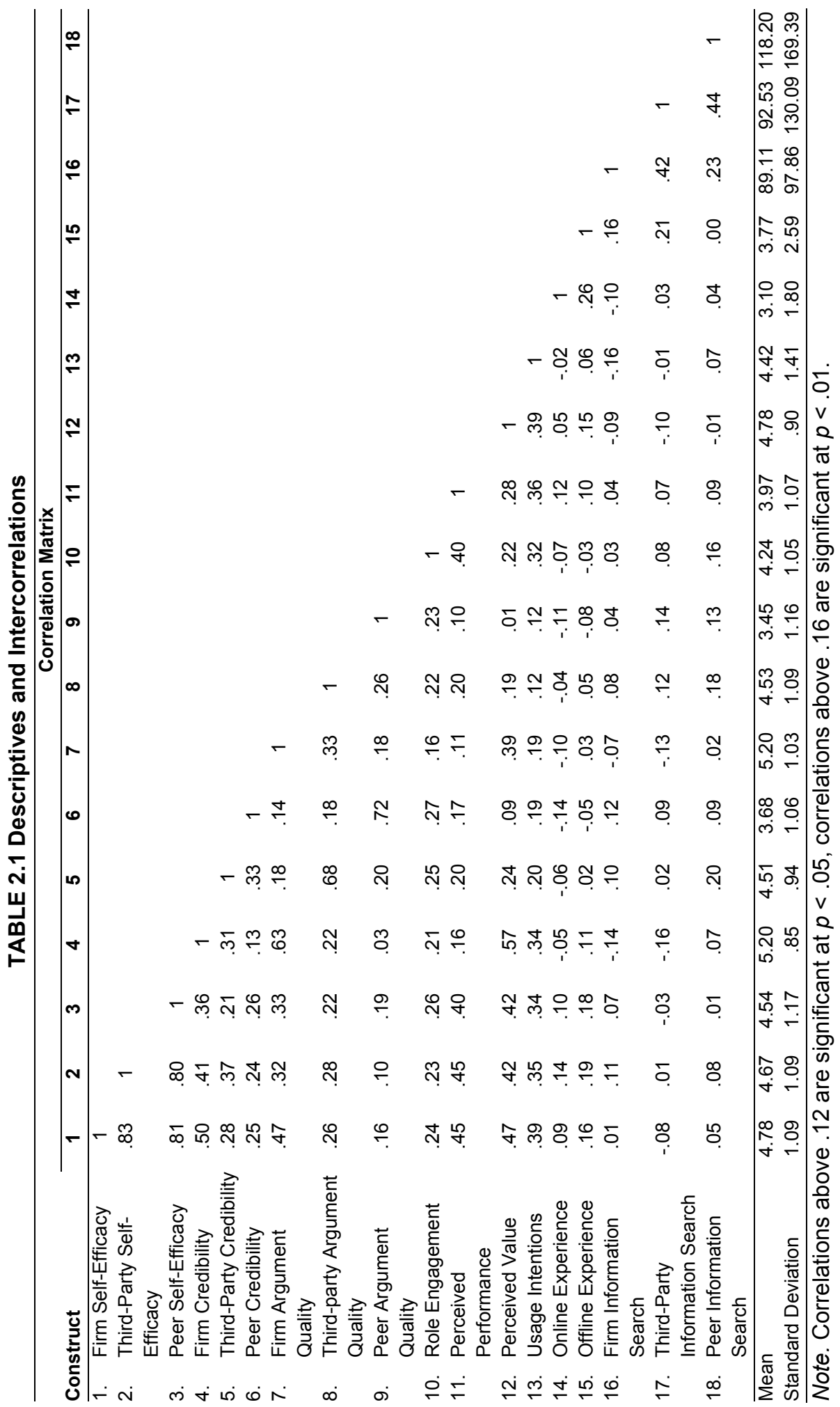




\subsection{Results}

\subsubsection{Multilevel Effects on Self-Efficacy}

The observations across information sources are nested within respondents, but repeated measures analyses would not enable us to estimate the cross-level interactions of role engagement. By using hierarchical linear modeling (HLM), we allow for missing data in repeated measures and can specify the between- and within-subjects heterogeneity simultaneously (Raudenbush and Bryk 2002). Noortgate and Onghena (2006) list several additional advantages of HLM compared with traditional repeated measures analyses (e.g., Lorch and Myers procedure, ANOVA), including information about how effects vary across respondents, comprehensible and economical descriptions of complex models, the simultaneous estimation of regression coefficients on different hierarchical levels, and the flexibility to include more levels, use unbalanced designs, or model within-person residuals. In addition, nested data may lead to heteroskedastistic error terms, because of correlated observations. Thus, regression analysis may lead to biased estimates (Raudenbush and Bryk 2002). Particularly, HLM calculates individual regression equations, so source perception slopes may vary across individual respondents (Morrison and Vancouver 2000). We employ HLM with maximum likelihood estimation (Raudenbush and Bryk 2002).

$\mathrm{H}_{1}-\mathrm{H}_{4}$ are tested using SAS PROC MIXED (Littell et al. 2006), starting with a base model that includes online experience, offline experience, and information search as control variables (Model 1 ), followed by a model with only the main effects of level-1 and level-2 predictors (Model 2), and a full model including cross-level interactions (Model 3). Thus, in model 2 the source evaluations and role engagement are included in addition to the covariates, whereas in model 3 the interactions of role engagement with the source evaluations are added. To reduce multicollinearity issues and increase interpretability, we grand mean-center the predictors (Raudenbush and Bryk 2002) and use KenwardRoger's adjusted F-tests, because the default Welch-James procedure inflates type I error (Kowalchuk et al. 2004). Level-1 is analyzed by specifying information source interactions in the MODEL statement instead of including the REPEATED statement, as recommended by Overall and colleagues (1999). This is because the source order is counterbalanced and does not impose a structure on the data, such as a time variable in a traditional growth model. Instead, a RANDOM statement is included. The model is specified as follows:

Level 1:

$S E_{\mathrm{ij}}=\beta_{00}+\beta_{10}\left(S E A R C H_{\mathrm{ij}}\right)+\beta_{20}\left(C R E D_{\mathrm{ij}}\right)+\beta_{30}\left(A Q_{\mathrm{ij}}\right)+\beta_{40}\left(S O U R C E_{\mathrm{i}}\right)+$ $\beta_{50}\left(C R E D_{i \mathrm{ij}}{ }^{*} S O U R C E_{\mathrm{i}}\right)+\beta_{60}\left(A Q_{\mathrm{ij}}{ }^{*} S O U R C E_{\mathrm{i}}\right)+\beta_{70}\left(S E A R C H_{\mathrm{ij}}{ }^{*} S O U R C E_{\mathrm{i}}\right)+r_{\mathrm{ij}}$ 
Level 2:

$$
\begin{aligned}
& \beta_{00}=\mathrm{y}_{00}+\mathrm{y}_{01}\left(R E_{\mathrm{j}}\right)+\mathrm{y}_{02}\left(O N L E X_{\mathrm{j}}\right)+\mathrm{y}_{03}\left(O F F E X_{\mathrm{j}}\right)+\mathrm{Y}_{04}\left(C R E D_{\mathrm{j}}\right)+\mathrm{Y}_{05}\left(A Q_{\mathrm{j}}\right)+ \\
& \mathrm{Y}_{06}\left(S E A R C H_{\mathrm{j}}\right)+\mathrm{Y}_{04}\left(R E_{\mathrm{j}}{ }^{*} C R E D_{\mathrm{j}}\right)+\mathrm{Y}_{05}\left(R E_{\mathrm{j}}{ }^{*} A Q_{\mathrm{j}}\right)+u_{0 \mathrm{j}} \text {; } \\
& \beta_{20}=\mathrm{\gamma}_{10}+\mathrm{\gamma}_{11}\left(R E_{\mathrm{j}}\right)+u_{1 \mathrm{j}} \\
& \beta_{30}=\gamma_{20}+\gamma_{21}\left(R E_{\mathrm{j}}\right)+u_{2 \mathrm{j}} \\
& \beta_{40}=\gamma_{30}+\gamma_{31}\left(R E_{\mathrm{j}}\right)+u_{2 \mathrm{j}} \text {; } \\
& \beta_{50}=\gamma_{40}+\gamma_{41}\left(R E_{\mathrm{j}}\right)+u_{1 \mathrm{j}} \\
& \beta_{60}=\gamma_{50}+\gamma_{51}\left(R E_{\mathrm{j}}\right)+u_{1 \mathrm{j}}
\end{aligned}
$$

where SE corresponds to self-efficacy, SEARCH indicates the amount of information search, CRED is credibility, $A Q$ is argument quality, ONLEX stands for online investment experience, OFFEX is offline investment experience, RE indicates role engagement, and SOURCE denotes a general information source effect. Error terms specify measurement error on the individual (i.e., $u_{0 \mathrm{j}}$ ) and within-person level (i.e., $r_{\text {ij }}$ ), separately. Equation 1 specifies the within-person effects, whereas equations 2 to 7 focus on between-person effects. The subscripts "i" and "j" denote the within-person (i.e., information source) and betweenperson (i.e., individual) levels of analysis respectively. For clarity, all main and interaction effects are included as they are in the analysis even though some are not conceptually relevant. Means on level-1 variables are included on level-2 of the analysis, so the overall effects as well as the deviation around the mean associated with each source are included in the analysis as suggested by Hedeker and Gibbons (2006). The source variable is used to specify within-person effects and the peer source is used as reference category against which effects of the other two sources are compared.

After experience and information search are controlled for, model 1 indicates that differences among persons accounts for $78 \%$ of the variance in selfefficacy; therefore, it is meaningful to investigate between-person effects and level-2 interactions (the Intraclass Correlation Coefficient is .78). The random residual is also significant $\left(s^{2}{ }_{\text {wg }}=.25\right.$, Wald $\left.Z=12.61, p<.001\right)$; that is, information source evaluations across information sources explain additional variance in self-efficacy, which warrants a within-person investigation. When we estimate a model with only main effects (i.e., model 2 ), we find that third-party credibility and firm argument quality significantly increase self-efficacy, whereas information search does not. The log-likelihood ratio test also shows a significant improvement in comparison to model $1\left(\Delta \mathrm{x}^{2}(11)=84.50, p<.001\right)$. Inspection of the studentized residual plots shows no indication of non-normality.

Finally, the full model results in significant improvement over model 2 $\left(\Delta \mathrm{x}^{2}(13)=30.90, p<.01\right)$. In general, credibility $\left(\mathrm{Y}_{04}=.22, p<.01\right)$ and argument quality $\left(\gamma_{05}=.16, p<.05\right)$ significantly increase self-efficacy. Thus, the findings support $\mathrm{H}_{1 \mathrm{a}}$ and $\mathrm{H}_{\mathrm{b}}$. In addition, these effects differ across information sources. First, the effect of third-party credibility is significantly stronger than the credibility 
effects of the other two sources $\left(\beta_{50}=.25, p<.01\right)$. Thus, for building selfefficacy using credibility cues, novice consumers rely mainly on the third-party source. Hence, we reject $\mathrm{H}_{2 \mathrm{a}}$, predicting that peer credibility would be used most. Second, the effect of firm argument quality is significantly stronger than the argument quality effects of the other sources $\left(\beta_{60}=.24, p<.01\right)$, supporting $\mathrm{H}_{2 \mathrm{~b}}$. For argument quality, the positive effect on self-efficacy is mainly due to the firm source, since it has a stronger effect relative to the other sources.

Furthermore, model 3 indicates significant cross-level effects. The interaction shows that effects of credibility and argument quality differ across levels of role engagement; under high engagement the effect of credibility is strengthened $\left(\mathrm{Y}_{04}=.22, p<.01\right)$, whereas the effect of argument quality is attenuated $\left(\mathrm{Y}_{05}=-\right.$ $.25, p<.01)$. Therefore, $\mathrm{H}_{3 a}$ is supported, whereas $\mathrm{H}_{3 \mathrm{~b}}$ is rejected. Contrary to our expectation, highly engaged consumers rely less on argument quality to build self-efficacy than low engaged consumers. In addition, highly engaged consumers consider the argument quality of the three sources equally for selfefficacy formation compared to low engaged consumers, rejecting $\mathrm{H}_{4 \mathrm{~b}}$. That is, third-party and peer credibility are not considered more under high engagement. The moderator effect of engagement and credibility does differ across sources; highly engaged consumers mainly focus on third-party and peer credibility, as the effect of firm credibility is significantly lower than that of the other two sources $\left(\mathrm{V}_{41}=-.20, p<.05\right)$. Hence, $\mathrm{H}_{4 \mathrm{a}}$ is partially supported, because peer and third-party credibility are considered more by highly engaged consumers than by low engaged consumers, but not firm credibility. In Table 2.2, the relevant results of the multilevel analysis are shown. 


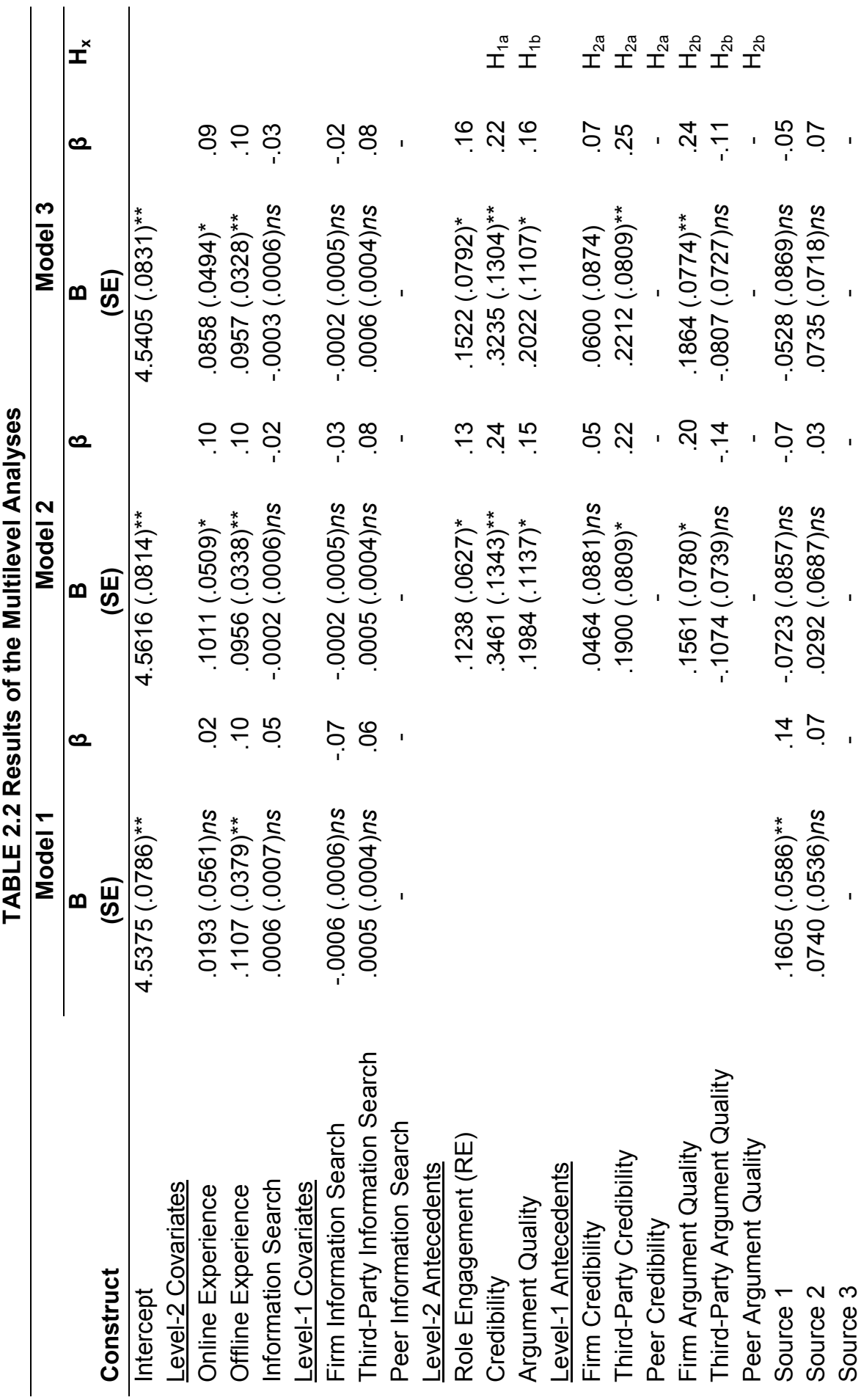




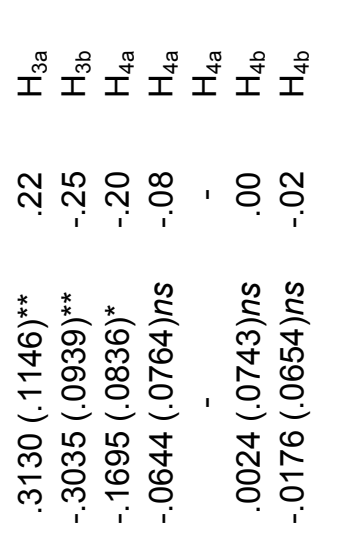

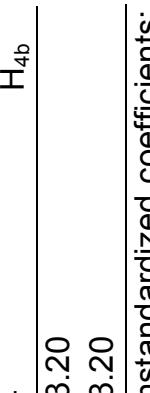

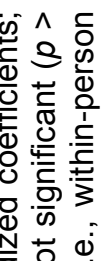




\subsubsection{Effects of Self-Efficacy}

We use ordinary least squares (OLS) to check the effects of aggregated self-efficacy evaluations (i.e., the average self-efficacy rating after the information sources were viewed) on the outcomes. For the mediation tests, we follow Baron and Kenny's (1986) procedure. Self-efficacy increases customer perceived financial performance $(\beta=.46, p<.05)$ and perceived value $(\beta=.76, p<$ .05). Thus, $\mathrm{H}_{5}$ and $\mathrm{H}_{6}$ are supported. Perceived financial performance and value in turn increase usage intentions $\left(\beta_{\text {performance }}=.26, p<.01, \beta_{\text {value }}=.31, p<.01\right)$. Self-efficacy has a direct effect on intentions $(\beta=.39, p<.01)$, which decreases when we include perceived financial performance or value, indicating partial mediation $(\beta=.18, p<.05)$. Inspection of the standardized residuals does not show indications of non-normality; hence the Sobel test is appropriate. The Sobel test indicates that perceived financial performance and value both significantly mediate self-efficacy effects on intentions $\left(z_{\text {performance }}=5.02, p<.01, z_{\text {value }}\right.$ $=5.05, p<.01)$. Thus, we also find support for $\mathrm{H}_{7}$ and $\mathrm{H}_{8 \mathrm{a}}$ and $\mathrm{b}_{\mathrm{b}}$. Table 2.3 shows the results of the mediation analysis.

TABLE 2.3 Results of Mediation Analysis

\begin{tabular}{|c|c|c|c|}
\hline \multirow[b]{2}{*}{$\begin{array}{l}\text { Independent } \\
\text { Variable }\end{array}$} & \multicolumn{3}{|c|}{ Dependent Variable } \\
\hline & $\begin{array}{c}\text { Perceived } \\
\text { Performance } \beta\end{array}$ & $\begin{array}{c}\text { Perceived Value } \\
\beta\end{array}$ & $\begin{array}{c}\text { Usage } \\
\text { Intentions } \beta\end{array}$ \\
\hline Self-efficacy & $.46^{*}$ & $.76^{*}$ & $\begin{array}{l}.39^{* * a} \\
.18^{* b}\end{array}$ \\
\hline $\begin{array}{l}\text { Perceived } \\
\text { Performance }\end{array}$ & & & $.26^{* *}$ \\
\hline Perceived Value & & & $.31^{* *}$ \\
\hline $\begin{array}{l}\text { Note. } \beta \text { refers to sta } \\
\text { refers to a direct ef } \\
\text { performance and valu } \\
\text { performance and valu }\end{array}$ & $\begin{array}{l}\text { dized regressio } \\
\text { of self-efficacy } \\
\text { re excluded, }{ }^{b} \text { re } \\
\text { e included. }\end{array}$ & $\begin{array}{l}\text { oefficients. }{ }^{*} p< \\
\text { usage intention } \\
\text { to the direct effe }\end{array}$ & $\begin{array}{l}5,{ }^{* *} p<.01 \\
\text { then perceivec } \\
\text { when perceivec }\end{array}$ \\
\hline
\end{tabular}

\subsection{Discussion}

The key objective of this study has been to analyze the antecedents and consequences of novice customers' self-efficacy during TBSS. Therefore, we develop this construct and empirically demonstrate its important role in predicting customer performance and service evaluations, which results in three major findings. First, source evaluations, such as credibility and argument quality, serve as informational cues and influence novice customers' self-efficacy during information search. It is important to note that this process is mainly applicable to novice consumers, as these consumers will not be able to rely on previous 
experience to form self-efficacy judgments. Both credibility and argument quality increase self-efficacy, whereas amount of information search does not.

The results also show that consumers differentiate among information sources and weigh associated evaluations differently when developing their selfefficacy. Interestingly, consumers focus on different sources when forming selfefficacy using credibility or argument quality. This lends support to the predictions of the cue diagnosticity framework, which implies that some sources will be more useful than others depending on the available cues the consumer focuses on. Specifically, third-party credibility and firm argument quality affect selfefficacy more than the other sources. Especially for novice consumers it is difficult to verify the usefulness of unknown peers giving trading advice, thus it makes sense to make less use of the peer source than of the other sources.

Second, role engagement affects how source credibility and argument quality form self-efficacy. Specifically, under high role engagement, credibility has a stronger effect on self-efficacy, whereas argument quality has less effect. Highly engaged customers seem to put in more effort to integrate credibility evaluations of different sources to build self-efficacy, as peer and third-party credibility are now used equally to inform self-efficacy. The attenuated effect of argument quality seems counterintuitive, given that it is often conceptualized as a central cue. However, it can be explained by the lack of experience of novice consumers. Highly engaged consumers apparently realize that they are less able to evaluate argument quality and use it as a meaningful cue to build self-efficacy. It's not possible for these consumers to rely on central cues, so they revert to heuristic cues. This is in line with a statement made by Chen and Chaiken (1999, p. 74): "systematic forms of processing in a given judgmental domain are less likely to be seen among perceivers who possess little knowledge in the domain." The authors note that systematic processing requires cognitive ability and capacity. Since novices lack ability to appropriately assess argument quality of the source's content in addition to lacking capacity to process several argument quality cues centrally, this finding is in line with the ELM. Highly engaged consumers use the information sources equally in terms of argument quality compared to low engaged consumers. This implies that they do not utilize more information sources to build self-efficacy from argument quality.

Third, customers' self-efficacy beliefs increase customer perceived financial performance, service value, and future usage intentions. Because self-services rely on customers' inputs, these findings imply that firms must find ways to increase customer confidence and in order to reap the full benefits of enhanced customer experiences.

\subsubsection{Theoretical Implications}

This study aims to contribute to TBSS research, social cognitive theory and dual processing research. First, previous TBSS literature has generated extensive insight into reasons for adopting these new services and stimulating service 
trial. This study investigates what happens after the trial decision has been made. We focus specifically on the role of information search on enhancing consumers' confidence to use the TBSS.

Second, previous research has pointed towards the relevance of customers' self-efficacy in this service setting, however as far as we know, research has not assessed how self-efficacy is formed and its impact on a combination of service evaluations. Although extensive studies address self-efficacy in educational and organizational settings, the performance implications of self-efficacy have been virtually unexplored in relation to services. Evidence of the relevance of selfefficacy is provided, because this construct predicts service evaluations, which are important for firms.

Third, the research contributes to a better understanding of the factors that influence self-efficacy of novice consumers. Whereas most self-efficacy research uses prior performance and previous experience as important self-efficacy antecedents, this study offers insight into antecedents when experience and prior performance are lacking. In this case, informational cues that facilitate task execution are used by novices to form self-efficacy. Although previous research has assumed that amount of search as such increases self-efficacy, these findings indicate that source evaluations rather than search are responsible for this effect. In addition, consumers use information sources selectively when forming self-efficacy. Importantly, we find that source relevance switches when consumers focus on other informational cues (credibility vs. argument quality). We expand on Murray's (1991) findings, which show that consumers use sources distinctively to evaluate services, and demonstrate that consumers also use source attributes selectively to build their confidence. These findings have implications for the information search literature, which traditionally focuses on attribute effects of a single message or compares effects of information sources in general without distinguishing different informational cues related to individual sources.

Finally, engagement is a relatively new factor that is shown to be important in building self-efficacy. This differentiator impacts what informational properties consumers use when forming self-efficacy. Engagement increases the impact of external information and decreases differentiation across sources.

\subsubsection{Managerial Implications}

The findings also suggest several managerial implications for service providers offering complex online services requiring customer information search. When consumers search information online, they are likely to consult several information sources. We show that these multiple information sources are combined into self-efficacy judgments by novice consumers, which, in turn, affect service evaluations such as usage intentions. Converting novices to loyal customers by building their confidence is crucial to the service's future success. 
Firms, therefore, should incorporate additional information sources to control this process, perhaps through partnerships with information providers. Including a hyperlink on the firm Web site that provides access to an online investment magazine introduces an expert perspective. Findings by independent research agencies featured on the Web site may also help shape investor selfefficacy perceptions and perhaps decrease the chance that prospective customers search the web for information sources that are beyond the control of the firm, which creates the inherent risk that views expressed by third parties do not reflect the firm's standpoints or policies. When the firm's objective is to build novice customers' self-efficacy, credibility of the external partner should be the most important selection criterion. Service providers other than online investment services, for example Zillow.com offering real estate online, can include an online real estate guide featuring ins and outs on buying, selling, and owning real estate. In addition, this service provider could connect to US state sites (such as http://www.visitnc.com giving information about North Carolina) offering information about the region. This facilitates the buying process and helps buyers select the region where they want to live.

Furthermore, firm-provided information quality drives self-efficacy, so firms should pay special attention to the content of their web site and employ site editors to ensure high content quality. Authenticity, consistency, clarity of content and style, and an explicit and transparent service recovery strategy are the key ingredients for presenting high-quality information on the firm's Web site. Finally, measuring engagement can help firms segment their customers to predict what type of information source will be most effective to bolster their self-confidence for using a service.

\subsubsection{Limitations}

There are some limitations of this study to consider. Only one type of service was included in the study, namely online stock investment. Although this may limit the generalizability of the findings and future research should address this limitation, it seems intuitive that credibility and arguments quality can predict self-efficacy in any complex service where pre-purchase information search is required. In addition, a student sample was used. Although our results are specific to novice consumers, one could argue that students do not resemble the typical novice consumer. Due to statements made by Schwarzkopf (2007) about the fact that students often invest or are considering to invest, and those made and by Meuter et al. (2003) that this highly educated group in particular is drawn to TBSS, we believe that this is not a major problem.

Third, a sample from a single country was used, which implies that replication of this research in cross-national settings might be useful. Further, given our focus on consumers' information search before trial we have not incorporated service attributes, such as ease of use or enjoyment, which have been shown to affect usage intentions as well. Future studies could investigate effects of pre- 
purchase information search in relation to service features on usage intentions. This study could also be extended by incorporating additional consumer characteristics besides engagement related to technology readiness, risk attitudes, and goal orientations. Finally, formal causal relationships cannot be established, as the study was conducted using a cross-sectional survey approach instead of an experiment. However, theory has informed the direction of the linkages included in the model. This study has traded off this limitation to an increase in external validity as it included real online information sources thus describing realistic variance in source evaluations. Future research could replicate these findings in an experimental setting by manipulating credibility and argument quality of information that is provided to subjects and subsequently having them assess selfefficacy and indicate purchase intentions. 



\section{Chapter 3}

\section{Consumers' Self-Efficacy Updating during Information Search}

\section{Examining Unobserved Heterogeneity}

This study examines differences in self-efficacy updating during consumers' information search. Without specifying groups a priori, the authors determine whether consumer segments exist based on varying self-efficacy updating patterns (i.e., unobserved heterogeneity). The authors find that consumers respond to information differently by either maintaining, decreasing, or increasing their self-efficacy. This response depends on the interplay between experience and effort. Interestingly, inexperienced consumers who spend high effort increase their self-efficacy and reach a relatively high performance (i.e., investment profits) in contrast to more experienced consumers. Consumer segments differ on time spent on search, credibility evaluations and intrinsic motivation as well. 


\subsection{Introduction}

As the scale and scope of interactivity is evolving, customers are increasingly involved in the delivery of online services, either by serving themselves or co-creating value in cooperation with service providers. For instance, many financial service providers are offering online investors options of joint- or selfservice portfolio management on their web sites. A recent industry report, however, reveals that active customer involvement is more strongly associated with unsatisfactory performance than traditional, do-it-for-me service delivery (J.D. Power 2006). Especially online investment induces self-defeating behaviors, such as excessive trading, which causes profits to plummet presumably because of investors' overconfidence in their stock-trading abilities (Barber and Odean 2002). These behaviors are particularly problematic during online coproduction or self-service, since customers tend to attribute service failures more to the firm rather than to themselves (Bendapudi and Leone 2003), share these bad experiences effortlessly with online peers (Ward and Ostrom 2006), and can seamlessly switch to a competitor's web site (Johnson, Bellman, and Lohse 2003). So far, investigators know little about the mechanisms that predict online customers' transition and adjustment to their coproducer role and ultimately successful selfservice performance.

One of these mechanisms that may be used to account for differential performance levels is the development of consumers' self-confidence, or selfefficacy, during pre-purchase information search. Recent theorizing suggests that self-efficacy is a driver of people's adjustment to new roles and responsibilities, and it has been shown to influence performance (Bandura and Jourden 1991; Bauer 2007). The purpose of this study is to investigate consumer selfefficacy updating during search, identify the factors driving variance in updating, relate the updating patterns to performance (i.e., actual profits), and characterize the various groups in terms of search and motivation. Thus, multiple consumer segments may exist based on self-efficacy updating patterns during search. This study examines unobserved heterogeneity in self-efficacy updating and attempts to explain found patterns using literature on consumer learning. Substantively, we focus on three issues that have not been conclusively addressed so far.

First, we approach self-efficacy patterns from a belief updating perspective, which suggests that consumers update beliefs after receiving information (Hogarth and Einhorn 1992). It has been found that consumers typically search information from multiple sources (Steckel et al. 2005). Especially during online service encounters, consumers seamlessly switch between web sites. Therefore, we support the theoretical argument that consumers reevaluate their self-efficacy beliefs on the basis of seeking information from different sources. However, the assumption in belief updating research is that all individuals update their belief the same way when asked to state it after reading information, because of a similar information integration process (Hogarth and Einhorn 1992). Yet, in the 
case of self-efficacy it seems intuitive that for some customers new information builds the confidence they have in their ability to serve themselves, resulting in an upward self-efficacy trend. In contrast, other customers may conclude that they are not as capable as they thought they were, resulting in a downward adjustment of self-efficacy. We question and test the general assumption by exploring unobserved heterogeneity in updating patterns and find distinct updating segments.

Second, the dynamics in efficacy belief formation have been studied within the context of efficacy-performance spirals in self-efficacy literature (Lindsley, Brass, and Thomas 1995). Previous studies demonstrate that there is considerable heterogeneity in self-efficacy over time as well as across people, as a result of different feedback and repeated performance (Bandura 1997; Bandura and Jourden 1991; Shea and Howell 2000). We contend that consumers can also form self-efficacy beliefs using information sources, instead of previous performance or performance feedback. This is relevant in an online environment in which switching barriers are extremely low; a series of trials may never occur because of initial disappointing performance. Recently, scholars called for intra-individual research on motivational processes such as selfefficacy, and note that "this work is still in its infancy" (Yeo and Neal 2008, p. 617). We extend this body of research by investigating dynamics of self-efficacy formation in the absence of performance, and compare performance differences between segments only after search.

Third, we focus on experience and effort to explain heterogeneity in efficacy adjustment patterns from literature on consumer learning. Experience and effort expenditure have been identified as key requirements for learning and have been shown to be related to confidence (Barber and Odean 2002; Hoch and Deighton 1989). Moreover, consistent with theories of behavioral choice, people differ in their valuation and integration of information across multiple sources (Morrison and Vancouver 2000). This study tests whether varying experience and effort expenditure during search results in different self-efficacy change patterns. Specifically, we show that high effort can compensate for a lack of experience, as inexperienced investors reach relatively high performance or actual profits, and that this is reflected in self-efficacy adjustment. In addition, we relate effort to search behavior and intrinsic motivation, and experience to information credibility to provide a more detailed picture of the segments.

Thus, the article is structured as follows. We start by developing hypotheses on the basis of belief updating, self-efficacy, and learning literatures. Subsequently, we report on the results of an empirical study in which growth mixture modeling is used to reveal efficacy-adjustment patterns. We also determine factors that drive updating patterns, and ANOVA is used to delineate performance differences between segments and to characterize these groups. We conclude by discussing our findings and their theoretical and practical implications. 


\subsection{Conceptual Background}

\subsubsection{Belief Updating during Information Search}

According to belief updating theory, information is generally received a piece at a time and integrated into a continuously evolving impression (Hogarth and Einhorn 1992). This theory has been applied to explain development of perceived ease of use, usefulness, usage intentions, relationship value, and market beliefs about new products (Bolton 1998; Biyalogorsky, Boulding, and Staelin 2006; Kim and Malhotra 2005). Updating is proposed to occur because of changes in uncertainty, which should also be reflected in beliefs in one's abilities. Thus far, researchers have not examined self-efficacy updating during information search, which refers to these ability beliefs.

Belief updating has been conceptualized as experiential learning in a seminal article by Hoch and Deighton (1989). More specifically, these authors suggest that consumers adapt their beliefs to make sense of new data and note that "consumers often [. .] form internal attributions about personal efficacy" (Hoch and Deighton 1989, p. 2). Accordingly, our basic assumption is that consumers adjust their level of self-efficacy as a function of the way they interpret new information related to the decision-making task. Since this is an individual process, we do not assume that each consumer updates similarly, but that so-called unobserved heterogeneity may exist, resulting in various updating segments.

Self-efficacy has been defined as "beliefs in one's capabilities to organize and execute the courses of action required to produce given attainments" (Bandura 1997, p. 3). Moreover, self-efficacy has been conceptualized as a dynamic state that changes over time as information or experience is acquired. There is some empirical evidence supporting the existence of different patterns in the context of so-called self-efficacy-performance cycles in which efficacy beliefs are updated on the basis of performance feedback loops. Implicit feedback derived from achieved performance and explicit performance feedback both cause people to adjust their self-efficacy (Bandura and Jourden 1991; Chiou and Wan 2007). In this article we set out to extend this emerging body of knowledge by examining whether varying efficacy formation patterns also occur during prepurchase information search when performance feedback is absent.

Self-efficacy theory suggests that self-efficacy updating during search occurs through three processes: analysis of task requirements, attributional analysis of experience, and assessment of situational resources and constraints (Gist and Mitchell 1992). In case people underestimate required abilities and necessary cognitive resources and constraints, they are likely to overestimate their initial self-efficacy and subsequently should decrease or correct this to some extent during search. The opposite may occur when required abilities and cognitive resources are overestimated. Self-efficacy will be maintained if abilities and resources are correctly estimated in the first place. This is in line with recent 
efficacy theorizing which posits that there are three different updating patterns of self-efficacy; namely, maintenance or no change, increasing and decreasing self-efficacy (Bandura 1997). Therefore, we hypothesize that;

$\mathbf{H}_{1}$ : Three self-efficacy change patterns will exist during consumer information search. Therefore, three segments will exist; those experiencing relatively little change in self-efficacy (i.e., a maintaining pattern), those experiencing self-efficacy increases (i.e., an increasing pattern), and those experiencing self-efficacy decreases (i.e., a declining pattern).

Next, hypotheses are developed that may account for aforementioned updating patterns.

\subsubsection{Explaining Updating Patterns}

The assumption, which underlies variety in updating patterns, states that initial self-efficacy is sometimes specified incorrectly; this creates a need to update when the consumer realizes this during search. Although over- and underestimation of self-efficacy has been addressed in the literature (Bandura 1997), it has not been empirically examined why these misjudgments occur. It has been argued that people may under- or overestimate their capabilities due to, for example, limited experience with the new activity (Bandura 1997). Additionally, Hoch and Deighton (1989) propose that experiential consumer learning is influenced by experience, effort, and ambiguity of the information environment. In relation to information search, ambiguity is inherent in the search task, as information is equivocal and difficult to evaluate prior to service usage. Ambiguity is a reason why different updating patterns should exist, but in itself would not offer an explanation for the occurrence of any specific pattern. Experience and effort are consumer characteristics which may affect the likelihood of the occurrence of specific patterns. In recent theorizing, these factors respectively represent cognitive ability and motivational resources consumers draw upon to form self-efficacy (Bandura 1997; Vancouver, More, and Yoder 2008). Furthermore, both factors have also been identified as precursors to increasing performance levels (Bell and Kozlowski 2002).

The Role of Experience. Cervone and Palmer (1990) state that prior experience may influence the degree to which self-efficacy changes, because of its effect on task uncertainty. Experience also affects initial self-efficacy, as consumers will systematically differ on initial self-efficacy because of differences in experience (Bandura 1997). In addition, Johar, Sengupta, and Aaker (2005) suggest that belief updating is especially likely to occur when there are no strong initial beliefs, which is generally the case for inexperienced consumers. Also, according to Hoch and Deighton (1989), experience should result in more stable beliefs in general because experienced consumers have more detailed 
knowledge structures. Alternatively, experienced consumers are more inclined to look for confirming evidence when reading information and may not update their beliefs because they already feel certain (Russo, Meloy, and Medvec 1998). In contrast, novice consumers are more likely to be influenced by point-of-purchase information (Alba and Hutchinson 1987). Therefore, we propose that self-efficacy should change more for inexperienced consumers as soon as information about task demands becomes available. In contrast, experienced consumers should be less likely to adjust their beliefs, because they have a more established initial self-efficacy. Thus,

$\mathbf{H}_{2}$ : Consumer experience accounts for differential self-efficacy development during information search. Experienced consumers are more likely to maintain self-efficacy (i.e., not update) than inexperienced consumers.

The Role of Effort. Because of its motivational nature, self-efficacy reflects both the understanding of one's ability and effort allocation intentions (Mitchell et al. 1994). For example, Wang and Netemeyer (2002) show that learning effort increases salesperson's job self-efficacy. In addition, Bandura (1997) states that effort not only shapes efficacy beliefs, but also determines how information impacts self-efficacy development. This is because effectively integrating information sources to form self-efficacy requires substantial cognitive effort. In previous self-efficacy literature effort has also been conceptualized as a consequence instead of an antecedent of self-efficacy (Debowski, Wood, and Bandura 2001; Stone 1994). Notably, these studies have been cross-sectional instead of longitudinal. Here, we do not conceptualize effort as a self-efficacy antecedent or consequence, but as a factor that impacts the patterns of self-efficacy change as part of the feedback loop occurring during updating. This way, initial self-efficacy impacts effort expenditure, whereas effort impacts subsequent self-efficacy change and so on. Literature shows that consumers expend effort because they are highly motivated (Beatty and Smith 1987). Highly motivated consumers should generate and test more hypotheses about their beliefs (Hoch and Deighton 1989), implying that high motivation increases the likelihood of updating because of effort expenditure. Less motivated consumers may not see the point of generating hypotheses, resulting in what is called a "good enough bias" and not much effort expended (Hoch 1984). These processes reflect the differences in information integration. Thus, the theory suggests that differences in effort may help to explain self-efficacy patterns. We propose that effort affects selfefficacy development by inducing self-efficacy change and hypothesize;

$\mathbf{H}_{3}$ : Effort accounts for differential self-efficacy development during information search. Consumers reporting high effort are more likely to increase or decrease their self-efficacy than consumers reporting less effort. 


\subsubsection{Divergent Consequences}

Across several scientific domains, self-efficacy has been shown to be a robust performance predictor (Stajkovic and Luthans 1998). Therefore, selfefficacy misspecifications may have serious consequences and deteriorate customers' performance on tasks (Bandura 1997). Social cognitive theory suggests that high self-efficacy would lead to higher persistence and better performance, implying that overestimation might not be a problem (Gist and Mitchell 1992). In contrast, Bandura and Locke (2003) note that in challenging tasks underestimation, or self-doubt, can be beneficial because it induces skill acquisition. According to the theory, the negative effects of misjudgment of selfefficacy will be strongest in tasks where errors can cause serious consequences, such as financial losses in stock investment (Bandura 1997).

Vancouver et al. (2001) provide some evidence that overestimation leads to negative consequences; the number of errors in their study increased with selfefficacy. In an experimental study, Stone (1994) shows that overestimating selfefficacy can have negative effects on decision making. Over- or underestimation has been studied by correspondence between self-efficacy and performance, and comparisons to other's performance (Bandura 1997; Stone 1994). Overestimation has been addressed in the finance literature as an issue in online selfinvesting especially because of a heightened sense of control, commitment to favorable results as personal wealth is involved, and abstract reference points that make it hard to compare performance across individuals (Barber and Odean 2002). During search consumers are confronted with information that might not match their own knowledge. If so, this most likely results in self-efficacy decrease, because the consumer should become more uncertain about his or her own capabilities. Thus, we propose that initial overestimation, exemplified by a decreasing self-efficacy pattern (i.e., initial overconfidence), is reflected in relatively low performance;

$\mathrm{H}_{4}$ : Consumers who maintain or increase their self-efficacy during search obtain a higher performance than consumers who decrease their selfefficacy.

A remaining question is whether the various updating patterns can be linked to other consumer characteristics. These characteristics are only indirectly related to self-efficacy updating patterns, but provide useful information for marketers. We take a more detailed look at effort by investigating search behavior and intrinsic motivation. We also investigate whether inexperienced consumers' information credibility perceptions are different from those of experienced consumers. 


\subsubsection{Consumer Characteristics}

Locander and Hermann (1979) show that specific self-confidence, that is, self-efficacy, is significantly related to information seeking in contrast to general self-confidence. Information seeking literature proposes that consumers continue searching as long as they perceive higher search benefits, such as expected savings, or when consumers feel they lack the ability to judge products (i.e., selfefficacy underestimation) (Newman and Staelin 1972). Search in general is proposed to reflect cognitive effort (Ratchford, Lee, and Talukdar 2003); thus, individuals who report spending high cognitive effort should search more than individuals who report less effort. In this study, cognitive effort is explicitly distinguished from search effort as the former refers to the degree of information processing and the elaboration on the purchase decision, whereas the latter refers to actual amount of search. This way, we link cognitive with physical effort, and examine whether cognitive effort is best reflected by search time or number of pages. Thus,

$\mathbf{H}_{5}$ : Search, in the form of (a) time spent and (b) number of pages read, will differ across segments, such that consumers, who spend high effort, search more than consumers spending less effort.

Since we argue that intrinsic motivation is the underlying mechanism driving effort expenditure, we also expect differences in motivation between segments. Effort is viewed as the manifestation of motivation in consumer behavior (Cervone and Bandura 1986). Several studies have also shown that intrinsic motivation predicts the level of search effort (Beatty and Smith 1987; Darley 1999). By including motivation in the analysis, we can determine whether intrinsic motivation is a plausible explanation for differences in effort. Specifically, we expect that consumers who spend high effort are also highly motivated. Hence,

$\mathbf{H}_{6}$ : Intrinsic motivation will differ across segments, such that consumers, who spend high effort, display higher motivation than consumers spending less effort.

Information evaluations may differ across segments as well. Experienced consumers are likely to be more critical towards external information, because they can rely on their internal information to some extent and are better able to evaluate complex information (Alba and Hutchinson 1987). In an experimental study, participants with product experience were less convinced by the provided information than participants without experience, and less influenced by credibility when asked about their product attitudes (Wu and Shaffer 1987). Thus, we hypothesize:

$\mathbf{H}_{7}$ : Credibility will differ across segments, such that consumers, who are inexperienced, perceive higher credibility than experienced consumers. 


\subsection{Method}

We examine our theoretical predictions in the context of consumer stock investment, because effects of self-efficacy misspecification seem to be particularly harmful in financial trading and this represents a complex service requiring significant customer participation (Meuter et al. 2005; Odean 1998). Twohundred fifty-seven respondents participated in the online survey for which 1.085 e-mail invitations were sent, which corresponds with a response rate of $24.29 \%$. The opening screen noted that the goal of the study was to investigate online investment decisions.

\subsubsection{Sample}

We focus on a relatively homogeneous sample of business students to control for variance in computer and internet experience. In our sample, $60.8 \%$ of our sample is male, the average age is 22 years $(S D=2.74)$, and online investment experience ranges from zero to seven years. Schwarzkopf (2007) shows that business students are often investing small amounts in stocks or planning to do so in the near future. European and US banks are increasingly targeting young investors by introducing special investment funds (such as the Young Dynamic Fund introduced by the largest bank in the Netherlands at http://www.youngdynamic.nl/, and the Young Investor Fund from Bank of America at http://www.younginvestor.com/). Additionally, roughly $50 \%$ of US households below 25 years own mutual funds (Investment Company Institute 2007). Furthermore, early adopters of these types of complex online services are usually relatively young, highly educated consumers (Meuter et al. 2003). Therefore, focusing on relatively young consumers seems appropriate. Early and late respondents were compared using a median split and independent $t$-tests on all variables (Armstrong and Overton 1977). Means did not differ significantly, indicating that nonresponse bias is not a major issue in our data.

\subsection{Procedure}

Respondents were asked to imagine that they inherited 1500 Euros and had decided to invest this in stocks. Prior to making the investment decision, they were asked to view three information sources in counterbalanced order (i.e., each respondent randomly received one out of six orders). After viewing a new source, they re-estimated their self-efficacy. The information sources included a firm, third-party (i.e., online investment magazine), and peer web site (i.e., virtual community), which is a realistic representation of actual consumer search (Johnson et al. 2003; Steckel et al. 2005). The content of the sources, consisting of company and stock information, was checked by an investment expert to make sure relevant and clear information was available of the sort used to make 
investment decisions in reality. This was done to make sure the respondents received high quality information, which should result in high quality updating (Hoch and Deighton 1989). The stocks were listed on the Amsterdam Exchange Index, and include well-known companies such as Philips, Heineken, ING, and Shell. Company information and purchase advice related to the stocks was given in the information sources. After viewing the three sources, respondents distributed their 1500 Euros by selecting stocks from the list and determining the amount to invest in each. Respondents' instructions and images of the information sources can be found in Appendices A and D.

When considering self-efficacy change patterns during the information search process, it is necessary to set up a reference point to index change direction. Belief updating theory and self-efficacy theorizing suggest that consumers not only reestimate prior beliefs after receiving information, but also that the nature of prior beliefs impact the amount of adjustment (Hogarth and Einhorn 1992; Cervone and Palmer 1990). This prior assessment of self-efficacy is adjusted irrespective of the amount of time that has passed (Bandura 1997). In other words, new information is interpreted relative to the level of current belief, irrespective of whether this information is available after a significant amount of time (i.e., after a performance evaluation) or almost immediately (after consulting an additional source of information). Initial self-efficacy levels (i.e., before the consumer engaged in information search) can be regarded as a reference point. We set the individual's self-efficacy prior to reading any information (i.e., initial self-efficacy) as the reference point so that the incremental impact of information on one's self-efficacy can be analyzed. In this study the time intervals are very short, but respondents view new information each time before re-estimating their self-efficacy. Therefore, we can be reasonably sure that efficacy beliefs are modified because of the information read instead of other environmental changes. The research design resembles a repeated measures design consisting of measures related to different sources instead of similar measures over time.

\subsubsection{Measures}

Self-Efficacy. Self-efficacy was measured as the perceived ability to invest in stocks using the particular service outlined in the introduction of the survey and was adapted from Webster and Martocchio (1992). By using a self-efficacy measure tailored to online investment using the service, we follow the recommendations by Looney et al. (2006). Each measure following an information source related to that source by stating "After reading information from [name of the source], please state your expectations right now". An example item is "I believe that purchasing stocks via $X Y Z$ Investment is a task on which I can perform well". However, because the source order is counterbalanced, selfefficacy relating to source 1,2 , or 3 refers to respectively the first, second, and third source respondents viewed. Thus, self-efficacy related to source 1 as used 
in the analysis is not associated with a specific type of source, because some respondents viewed the firm source first, whereas others viewed the third-party or peer source first.

Performance Consequence. Performance was measured by taking the actual profits in Euros two months after the investment decision was made by the respondents. In addition, the profits were corrected for the overall price development of the available stocks.

Covariates Predicting Class Membership. Experience was measured context-specifically as the number of years one had been investing in stocks, based on Balasubramanian, Konana, and Menon (2003), who also used it in the context of online investment. Effort was measured using the scale from Mohr and Bitner (1995), which reflects the cognitive effort expended by the consumer during the search task. The source order of the three presented sources was included as additional check to ensure that any observed differences are not due to variety in source order.

Source-Varying Covariate. To control for differences in source quality we ask respondents to rate the information presented by each source using a seven-point semantic scale.

Consumer Characteristics. Information search was measured as the number of pages read in total and amount of time spent searching measured in seconds. Intrinsic motivation was measured using a scale adapted from Debowski and colleagues (2001). Credibility of the information was measured using the Newell and Goldsmith (2001) measure. Credibility was measured for each source and subsequently aggregated across sources, because we do not expect any differences in effects when respondents first evaluate credibility compared to the second or third time. Further, we are interested in differences between segments on credibility, therefore taking the average across sources seems most appropriate. All constructs and items used in the study are included in Appendix C.

\subsubsection{Measurement Model}

We conduct confirmatory factor analysis to assess the validity of our measures. Mplus 4.0 was used to analyze the measurement model and estimate the growth mixture model (Muthén and Muthén 1988-2007). We included all constructs except experience, time spent, number of pages, source quality, and performance, which are single-item constructs. First, we test normality violations by investigating skewness and kurtosis (Bollen 1989). Mardia's test of multivariate kurtosis indicates the presence of significant multivariate kurtosis $(z=$ 102.29, $p<.001$ ) (Mardia and Foster 1983); therefore, we correct for nonnormality in the factor analysis using the Satorra-Bentler correction (Satorra and Bentler 1988). We correlate error terms across sources and fix loadings across sources to be equal for self-efficacy and source credibility, because these constructs have to be validated for each type of source separately. Fit indices indi- 
cate a good fit of the data $\left(S B X^{2}(1760)=2896.22, p<.01\right.$, RMSEA $=.050$, SRMR $=.050, \mathrm{TLI}=.91, \mathrm{CFI}=.91)$. Construct reliabilities range from .86 to .95 and are reported in Appendix C. Table 3.1 presents the correlation matrix and its descriptive statistics. 


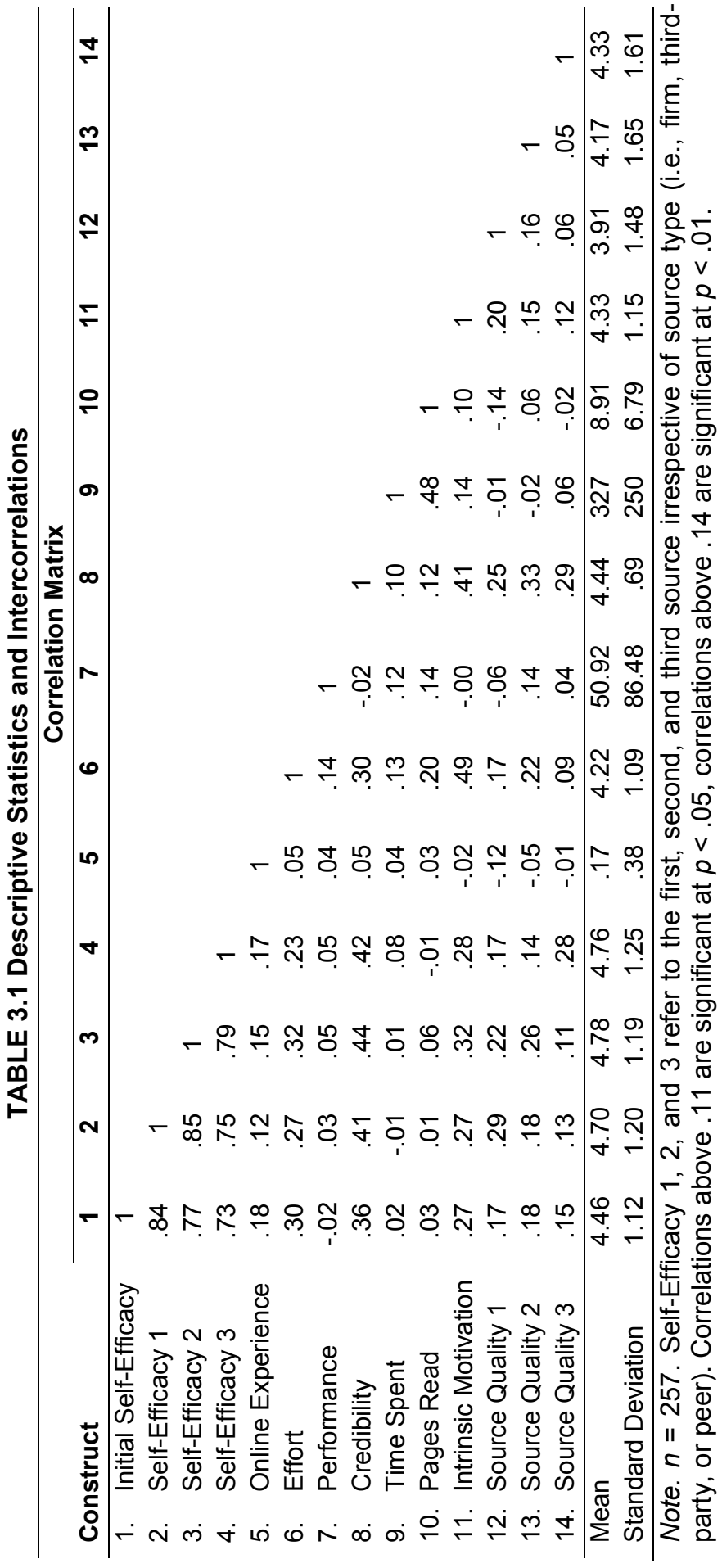




\subsubsection{Analysis Strategy}

Conventional growth modeling assumes that individuals are sampled from a homogeneous population. However, growth mixture modeling infers subpopulations from the data ( $\mathrm{Li}$ et al. 2001). The growth mixture modeling approach assumes that varying individual growth trajectories belong to distinct subgroups (Li et al. 2001). Intuitively, it seems unrealistic to assume that all consumers will interpret novel information similarly because of the unique combination of their characteristics. Mixture models are also more flexible than latent class analysis, latent profile analysis and K-means clustering as group or class variables represent unobserved probabilities of class membership instead of using a priori defined classes. Because characteristics do not have to describe people in one segment uniquely, they allow simultaneous estimation of continuous and categorical variables, and covariates can affect different parts of the model (Lubke and Muthén 2005).

In this study, we take four analytical steps:

1. A finite growth mixture model is estimated, in which the number of segments is determined based on the unobserved heterogeneity in the self-efficacy development. We test whether including more segments in the model significantly improves the correspondence with the data.

2. Class membership probabilities are estimated from several invariant covariates (i.e., consumer characteristics such as experience and effort, and source order during information search). These so-called concomitant variables are regressed onto the latent class variable describing the segments and the self-efficacy intercept and slope. In Figure 3.1 the growth mixture model estimated for step 1 and 2 , is displayed.

3. ANOVA is used to test whether segment membership is associated with different performance outcomes.

4. ANOVA is also used to characterize respondents in the segments according to their search behavior, intrinsic motivation, and credibility evaluations. Unequal group sizes are controlled for in post hoc tests. 
FIGURE 3.1 Representation of the Basic Growth Model for Consumers' Self-Efficacy Change Patterns during Search

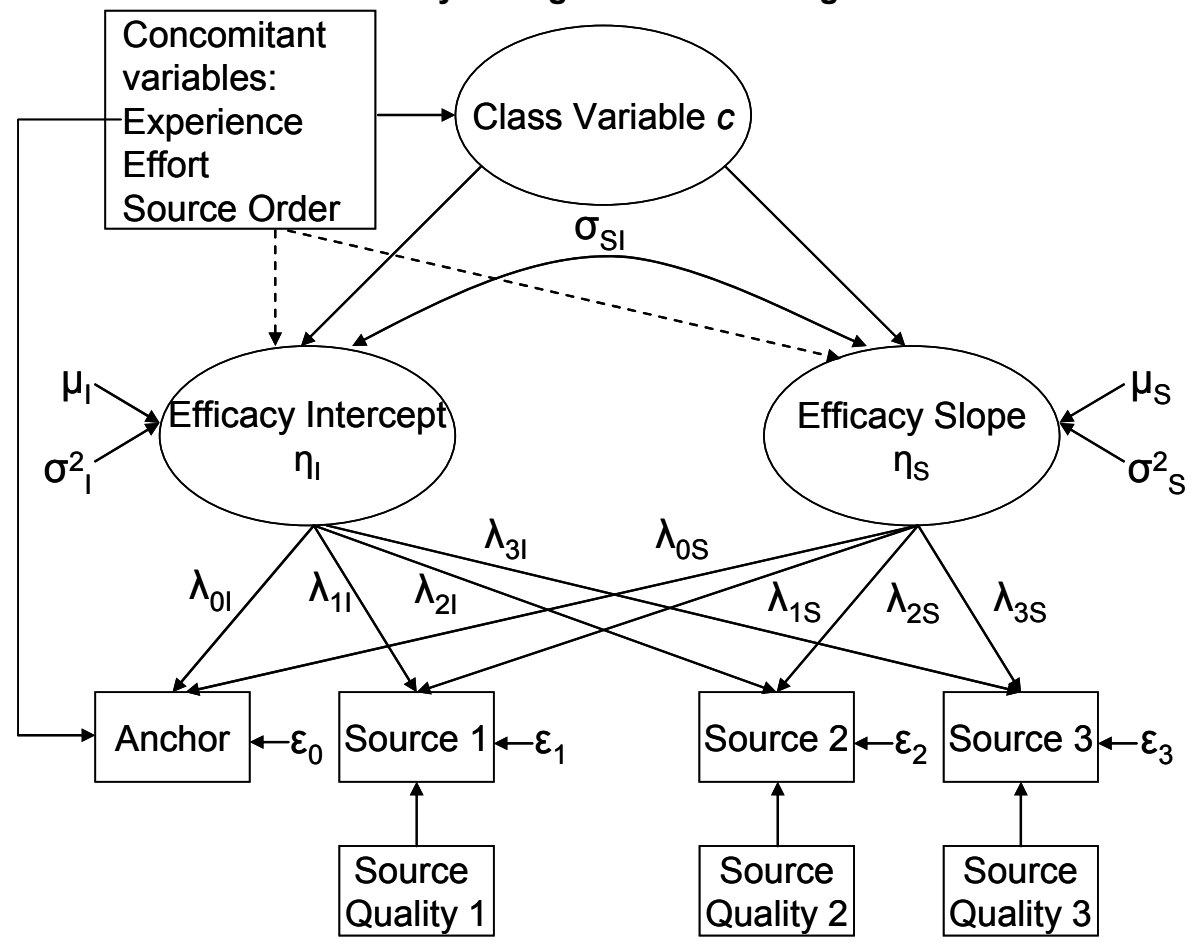

3.4 Results

\subsubsection{Identifying Multiple Self-Efficacy Updating Patterns}

We start with testing hypothesis 1 , which states that there are several updating self-efficacy patterns. A finite-mixture random effects model or growth mixture model (GMM) will be formulated to capture unobserved subgroups described by various change trajectories. Segments are determined based on intercept and slope variance. We use maximum likelihood estimation with an iterative expectation-maximization algorithm which has been deemed appropriate for mixture models (Muthén and Shedden 1999; Wedel and DeSarbo 1995). In order to identify the number of segments based on differences in self-efficacy changes, we test whether including more segments improves the growth mixture model significantly. Besides inspecting log likelihood, information criteria, and entropy, we use the adjusted Lo-Mendell-Rubin likelihood ratio test (i.e., adjusted LRT) (Lo, Mendell, and Rubin 2001; Muthén 2004). This test determines whether the information criteria decrease significantly indicating a substantial improvement in model fit. 
The adjusted LRT test displayed in Table 3.2 yields significant results for the three-segment solution (Adjusted LRT $=76.46, p<.01$ ), but not for the foursegment solution. This indicates that three segments are represented in the sample based on differences in self-efficacy change patterns. These segments are ordered based on their size, starting with the largest segment. The entropy of .87 indicates a high classification accuracy, which implies that between-segment differences are relatively high and within-segment differences low (Muthén 2004).

TABLE 3.2 Goodness-of-fit Statistics, Entropy, and Model Comparisons for GMM

\begin{tabular}{cccccc}
\hline $\begin{array}{c}\text { Growth } \\
\text { Mixture } \\
\text { Model }\end{array}$ & $\begin{array}{c}\text { Log Like- } \\
\text { lihood }\end{array}$ & AIC & SSABIC & Entropy & $\begin{array}{c}\text { Adjusted } \\
\text { LRT }\end{array}$ \\
\hline 1 class & -1401.816 & 2815.631 & 2817.904 & N/A & N/A \\
2 classes & -1270.895 & 2559.790 & 2563.199 & 0.942 & $247.004^{*}$ \\
3 classes & -1230.371 & 2484.741 & 2489.287 & 0.872 & $76.456^{* *}$ \\
4 classes & -1192.968 & 2415.935 & 2421.617 & 0.864 & 70.567 \\
\hline
\end{tabular}

Note. AIC = Akaike information criterion, SSABIC = sample-size-adjusted Bayesian information criterion, Adjusted LRT = Lo-Mendell-Rubin adjusted likelihood ratio test, slope and self-efficacy level 3 variance were fixed to prevent ceiling effects. ${ }^{*} p<.05,{ }^{* *} p<.01$.

Next, we examine the parameter estimates related to each segment (see Table 3.3). This solution is based on the model including covariates as recommended by Muthén (2004). The slope factor mean (i.e., degree of change in selfefficacy) is statistically significant for segments 2 and 3 , but not for segment 1 . That is, people in segment 1 did not adjust their self-efficacy after reading information, whereas people in segments 2 and 3 respectively decreased and increased self-efficacy. The intercepts and residual variances are significant in each segment, indicating that systematic individual differences in self-efficacy existed before search. Specifically, people in segment 3, who increase selfefficacy, start with relatively low self-efficacy compared to other segments, which is in line with the underestimation proposed to occur for this segment. Average class probabilities per segment are .90 or higher, indicating that class membership is predicted very well by the model (Nagin 1999). Overall, the majority of people maintained their self-efficacy (i.e., segment 3), a smaller group of people in segment 3 increased their self-efficacy, and a minority of people was in segment 2 and decreased their self-efficacy. Therefore, $\mathrm{H}_{1}$ is supported. 
TABLE 3.3 Parameter Estimates for 3-Segment Solution

\begin{tabular}{lrccc}
\hline \multicolumn{1}{c}{ Segment } & $\boldsymbol{N}$ & $\begin{array}{c}\text { Mean Intercept } \\
(\mathbf{S E})\end{array}$ & $\begin{array}{c}\text { Mean Slope } \\
(\mathrm{SE})\end{array}$ & $\begin{array}{c}\text { Average Class } \\
\text { Probability }\end{array}$ \\
\hline 1. Maintain & 146 & $4.54(.10)^{*}$ & $.01(.04)$ & .95 \\
2. Decrease & 22 & $4.42(.25)^{*}$ & $-.73(.09)^{*}$ & .99 \\
3. Increase & 89 & $4.10(.16)^{*}$ & $.47(.04)^{*}$ & .90 \\
\hline
\end{tabular}

Note. standard errors are included in parentheses. ${ }^{*} p<.01$.

Figure 3.2 graphically displays the self-efficacy means of the three segments before and during search.

FIGURE 3.2 Self-Efficacy Development Across Segments

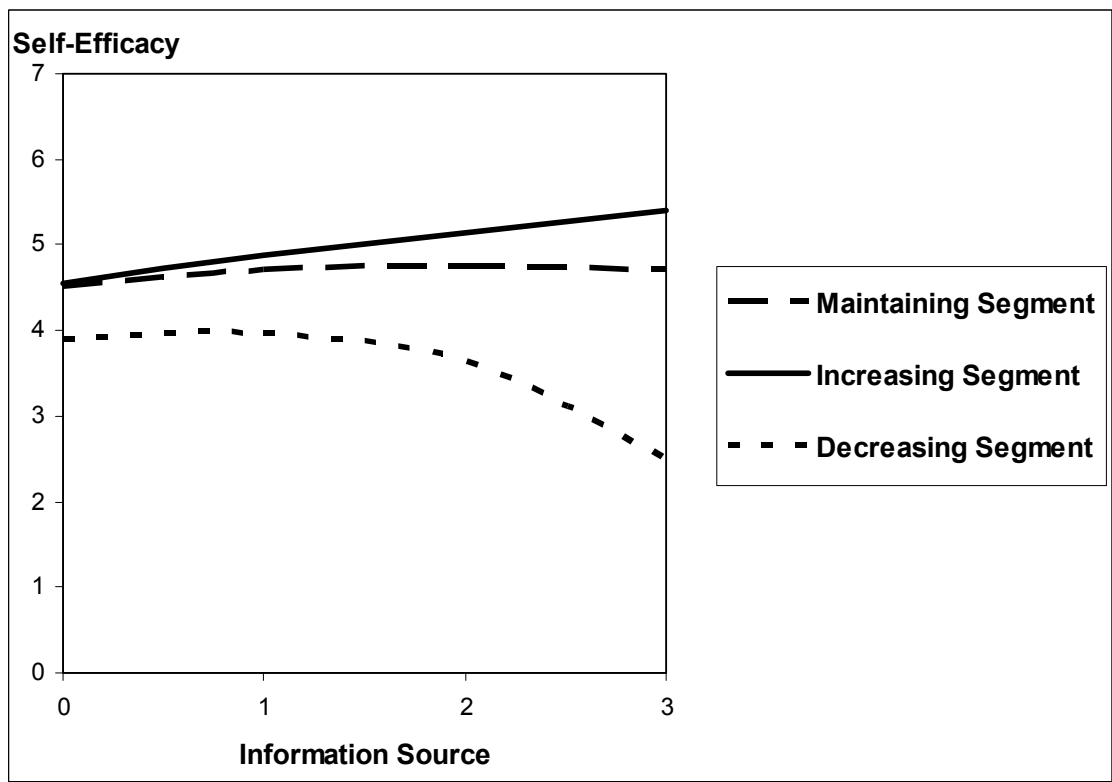

\subsubsection{Drivers of Class Membership}

Next, we test hypotheses 2 and 3, stating that experience and effort predict differences in updating patterns. We assign the source-invariant covariates, namely experience and effort (i.e., the stable consumer characteristics), to the categorical variable which represents class membership for each respondent. In addition, these explanatory variables are regressed onto the intercept and slope of each segment to ensure that spurious effects are excluded (Muthén 2004). Experience is also regressed onto initial self-efficacy (i.e., self-efficacy 0) to control for initial differences between respondents. Experience and effort are included in the GMM, and their effect on class membership is examined by using segment 3 (i.e., the increasing segment) as the reference category. This way, we 
test whether these variables drive class membership of one of the three classes by verifying that class membership probabilities are significantly different. In addition, we include the counterbalanced source order of the three information sources to control for order effects. Source quality related to each source viewed by the respondent on measurement occasion 1,2 , or 3 is regressed onto selfefficacy 1, 2, and 3. An unstructured error structure was used, because autocorrelation is not an issue in the data; each self-efficacy measure is related to a different source.

Table 3.4 shows that experience decreases the likelihood of being assigned to the increasing segment compared to the maintaining or decreasing segments (i.e., segment 1 or 2). In addition, effort increases the likelihood of being in the increasing segment compared to the maintaining or decreasing segments. Information source order does not affect the probability of being assigned to one of the segments. A chi-square test is conducted to check whether source order systematically varies across segments to rule out the possibility that the various orders are not randomly distributed. The test shows that this is not the case $\left(x^{2}(10)=12.19, n s\right)$.

The z-value in the GMM shows whether there are significant differences among segments and therefore tests whether the covariates are appropriate segment descriptors. These results show that experienced investors are mostly in segment 1 or 2, implying that they either maintain or decrease their selfefficacy upon receiving novel information. The mean intercept of self-efficacy is lower for the relatively inexperienced than for the experienced groups, creating more confidence in the conclusion that experience drives updating patterns (as inexperienced consumers should be more uncertain about their capabilities in general and more likely to increase self-efficacy when they read information). Thus, $\mathrm{H}_{2}$ is partially supported; highly experienced consumers either maintain or decrease their self-efficacy during search. In addition, respondents who report spending a lot of effort are more likely to increase their self-efficacy. Therefore, $\mathrm{H}_{3}$ is also partially supported; consumers, who spend high effort, are more likely to increase, but not more likely to decrease self-efficacy.

TABLE 3.4 Parameter Estimates for Class Membership Probabilities

\begin{tabular}{lcccc}
\hline & \multicolumn{2}{c}{ Maintaining Segment 1 } & \multicolumn{2}{c}{ Decreasing Segment 2 } \\
\cline { 2 - 5 } Predictor & Estimate (SE) & z-Value & Estimate (SE) & z-Value \\
\hline Experience & $.43(.25)^{*}$ & 1.69 & $.63(.30)^{*}$ & 2.09 \\
Effort & $-1.95(.57)^{\star *}$ & -3.40 & $-2.80(.73)^{* *}$ & -3.85 \\
Source Order & $.00(.01)$ & -.01 & $-.02(.04)$ & -.43 \\
\hline
\end{tabular}

Note. Increasing Segment (i.e., segment 3 ) is used as reference category. ${ }^{*} p<$ .05. ${ }^{* *} p<.01$. 


\subsubsection{Divergent Consequences}

One-Way ANOVA is used to investigate whether the segments performed differently in terms of investment profits and test hypothesis 4 . Because Levene's test for homogeneity of variances indicates that performance has equal variances across segments $(F(2,253)=.38, n s)$, Hochberg's GT2 post hoc test was used (Toothaker 1993). ANOVA indicates significant differences between segments in terms of corrected profits $(F(2,253)=4.39, p<.05)$. The post hoc test shows that the maintaining and increasing segments do significantly better in terms of obtained profits than the decreasing segment, irrespective of whether profits are corrected for overall market development. The average corrected profits are 52.09, 1.29, and 61.27 Euros for the maintaining, decreasing, and increasing segment respectively. In multinomial logistic regression with segment 3 serving as reference category, performance significantly predicts segment membership for segment $2(\beta=-.01, p<.05)$ when effort and experience are included as covariates. Thus, we can exclude the possibility that effort or experience instead of self-efficacy drives the performance difference between the decreasing segment and the other groups. Therefore, $\mathrm{H}_{4}$ is supported. Interestingly, the decreasing segment does not make any substantial profit after correction for overall market development.

\subsubsection{Consumer Characteristics}

We test hypotheses 5,6 , and 7 using ANOVA to check whether segments differ in search behavior, credibility evaluations, and intrinsic motivation. The Levene's test for homogeneity of variances indicates that variances are equal for time spent, pages read, and credibility $\left(F_{\text {Time }}(2,248)=1.41, n s\right)\left(F_{\text {Pages }}(2,254)=\right.$ $.30, n s)\left(F_{\text {Cred }}(2,254)=1.79, n s\right)$. Therefore, to detect differences between segments, we use ANOVA combined with Hochberg's GT2 post hoc test to correct for unequal group sizes for these tests (Toothaker 1993). However, variances are unequal for intrinsic motivation $\left(F_{\mathrm{mot}}(2,254)=6.14, p<.01\right)$, therefore we use the Games-Howell test combined with the Welch statistic for this test. The amount of information seeking in terms of pages read does not differ across segments but does differ in terms of time spent, supporting $\mathrm{H}_{5 a}$ but not $\mathrm{H}_{5 \mathrm{~b}}$. People in the increasing segment spend more time on search than people in the decreasing segment. Differences between the increasing and maintaining segment are not significant. In addition, segments also differ in terms of intrinsic motivation in the expected direction; the increasing segment, which spends most effort, is also most motivated, followed by the maintaining segment. The decreasing segment, which spends least effort and reaches low performance, is also least motivated. Thus, $\mathrm{H}_{6}$ is supported. Finally, the increasing group rated credibility significantly higher than the other groups, supporting $\mathrm{H}_{7}$. Thus, relatively inexperienced consumers perceive information to 
be more credible than experienced consumers. Results are displayed in Table 3.5 .

TABLE 3.5 Mean Differences in Search and Motivation

\begin{tabular}{|c|c|c|c|c|}
\hline & $\begin{array}{c}\text { Maintaining } \\
\text { Segment } 1\end{array}$ & $\begin{array}{l}\text { Decreasing } \\
\text { Segment } 2 \\
\end{array}$ & $\begin{array}{l}\text { Increasing } \\
\text { Segment } 3 \\
\end{array}$ & F-Value \\
\hline Construct & $M$ & $M$ & $M$ & (df) \\
\hline $\begin{array}{l}\text { Amount of Search: } \\
\text { Number of Pages }\end{array}$ & 8.88 & 7.45 & 9.30 & $\begin{array}{c}.66 \\
(2,254)\end{array}$ \\
\hline $\begin{array}{l}\text { Amount of Search: } \\
\text { Time Spent }\end{array}$ & 318.12 & 199.46 & $364.44^{*}$ & $\begin{array}{c}3.36 \\
(2,248)^{*}\end{array}$ \\
\hline \multirow[t]{2}{*}{ Credibility } & 4.29 & 4.16 & $4.76^{* *}$ & $\begin{array}{c}17.17 \\
(2,254)^{\star *}\end{array}$ \\
\hline & & & & Welch (df) \\
\hline Intrinsic Motivation & $4.15^{*} /^{* *}$ & $3.32^{*} / * *$ & $4.87^{* * / * *}$ & $\begin{array}{c}22.56 \\
(2,55.42)\end{array}$ \\
\hline
\end{tabular}

Note. ${ }^{*} p<.05,{ }^{* *} p<.01$. Mean of segment 3 is significantly different from segment 2 for time spent, and from all other segments for credibility based on Hochberg's GT2 post hoc test with the F-statistic. Intrinsic motivation means are significantly different for each segment based on the Games-Howell post hoc test in combination with the Welch statistic; segment 1 and 2 differ at $5 \%$ significance level, whereas segment 2 and 3 and 1 and 3 differ on $1 \%$ significance level.

\subsection{Discussion}

This study was designed to address the following questions: Do multiple self-efficacy change patterns exist during information search? If so, can these multiple patterns be predicted by consumer characteristics? What are the consumer performance consequences of these patterns? Finally, how do consumers in these segments differ on search behavior, intrinsic motivation and information source evaluations?

First, our results support the hypothesis that multiple change patterns exist. Specifically, three patterns emerged in our sample: a maintaining, a decreasing, and an increasing self-efficacy trajectory. These patterns are consistent with predictions from social cognitive theory (Bandura 1997). By recognizing the existence of these patterns, the current study provides a way to reconcile inconsistencies in previous research. Thus, other repeated measures studies of selfefficacy might have focused on the average self-efficacy updating pattern and dismissed other patterns as outliers. As such, the current study emphasizes the relevance of examining interindividual variability of self-efficacy updating patterns and extends recent work by Vancouver et al. (2008) and Yeo and Neal (2006).

Second, we demonstrate that multiple patterns of self-efficacy updating can be predicted by individual variables. In our sample, we find evidence of overes- 
timation and its harmful consequences, and compensation of inexperience by expending effort, which resulted in beneficial consequences. Inexperienced consumers make up for their lack of experience by devoting higher effort to the search task, and they also do better in terms of performance than their more experienced counterparts. This is reflected in their self-efficacy updating patterns as well; during search the inexperienced individuals who work hard increase selfefficacy. Previous self-service research suggests that novices are more likely to apply effort to understand the service, because they are more curious than experienced consumers (Zhu et al. 2007). Several studies find evidence that self-efficacy decreases performance because of lower effort expenditure (Vancouver and Kendall 2006; Vancouver, Thompson, and Williams 2001). This effect has been explained by perceptual control theory; people who feel they are highly capable to accomplish their goals allocate less effort towards the task, they simply do not see a need to put in effort. In this study we find that this is only a minority of consumers, which adjusts self-efficacy downwards, expends low effort, is unmotivated, and achieves low performance.

Third, we find that segments do not differ in terms of pages read, but on time spent. It seems that time spent is a more appropriate measure of cognitive effort than pages read. In addition, inexperienced consumers who increase selfefficacy during search find the information provided more credible than the other groups. In general, we show that it is inappropriate to investigate self-efficacy development from an aggregate perspective. Instead, we show that individuals respond to information associated with complex tasks differently in terms of their self-efficacy.

\subsubsection{Managerial Implications}

First, this type of analysis can facilitate new methods for market segmentation based on consumers' beliefs and behavior patterns. This way, marketing managers are able to identify consumer groups based on differences in self-efficacy updating, i.e., unobserved belief modification in response to information. Segmenting consumers based on belief modification instead of demographics provides marketers a more direct way to predict consumer performance. In general, this study shows that even inexperienced consumers who invest via online self-service can be successful as long as they exert sufficient effort. This is good news for many online service providers, who have been introducing new self-service formats in the last years. However, experience and effort are largely uncontrollable for marketers. Therefore, we address how segments differ on search variables; providing highly credible information, possibly from independent parties, will be especially beneficial for convincing experienced investors to use information, since they are more critical toward external information than inexperienced investors.

In addition to reaching high performance, which is likely to result in high satisfaction, individuals with high self-efficacy are less likely to quit and switch to 
another service after trial (Bandura 1997). In a real-life setting, consumers with low self-efficacy may choose not to try the service in the first place (Meuter et al. 2005). Our finding that self-efficacy sometimes deteriorates during search has serious implications for marketers; providing more information to customers is not always beneficial. Although the notion of information overload has been discussed in literature, this is unlikely to be the cause of the problem. Consumers in real-life situations generally stop searching before they are overloaded (Jacoby 1984). In addition, this effect occurred for experienced consumers. Most likely, a lack of motivation to spend effort on reading and using information causes the negative effects. Thus, unless investors critically assess the information provided, this information may be useless. This means that overconfident customers are a real problem for service providers, even though this group is relatively small. Setting realistic service expectations before trial is pivotal to ensure service satisfaction. In addition, being able to spend less effort on search while still receiving all required information (e.g., by providing a summary section in addition to more detailed task information) will probably serve these customers better. In general, convincing consumers that spending high effort pays off for them is the biggest challenge service firms face.

\subsubsection{Limitations}

This study has several limitations. First, we do not examine how consumers respond to specific types of information, but only focus on task information in general. The sources included information on firms listed on the stock exchange, buy and sell recommendations, and information on the long-term development of specific shares, which was actual information from the real-life sources. Furthermore, because all respondents viewed the same sources and source order was counterbalanced, all respondents essentially read the same information. Second, we only study one type of service, namely online stock investment. Although this may limit the generalizability of the findings, we believe that the three self-efficacy updating patterns will exist in any complex service type requiring significant customer participation, because over- and underestimation of one's abilities is applicable to any task. Third, we have not examined non-linear relationships when analyzing class membership explanations, because of the limited amount of available self-efficacy data. Johnson and Russo (1984) suggest a non-linear relationship between familiarity (i.e., experience) and learning. However, in relatively new services, such as online investment, there are hardly any highly familiar consumers, which makes testing non-linear relationships impossible. Fourth, respondents were asked to assess their self-efficacy immediately after reading information. This is probably an appropriate approach in online service settings, since consumers can rapidly switch to other web sites looking for new information. It is possible that respondents would have judged their self-efficacy differently if they were asked after a longer period of time, because they would have had more time to interpret 
and reflect on the information. However, other factors would have influenced this judgment as well, therefore, it would be extremely difficult to attribute the observed self-efficacy change to the presented information. Therefore, taking this approach we can be confident that the updating occurs because of the information that was read. Finally, we collect data from a student sample which could limit generalizability of the findings as well. However, by using a relatively homogeneous sample we can be more confident that the segments exist because of variety in self-efficacy updating and not because of other spurious differences between groups. 



\section{ChAPTER 4}

\section{The Training-Agency Dilemma}

\section{When Do Knowledge Investments in Sales Partners Pay Off?}

Manufacturers often rely on sales partners to interact with end-consumers. Hence, it is in the manufacturer's interest to train partners to sell. However, nonexclusive partners selling multiple brands may use manufacturer training investments to help sell competitor products or not use training at all. This paper develops and tests a framework to identify the conditions under which training investments in non-exclusive partners pay off for the manufacturer in terms of product sales. We test our predictions using data from 306 sales partners in 31 countries who have undergone manufacturer-provided sales training. We find that non-exclusive partners can be trusted to apply what they have learned to help the firm when (1) the partner has a learning goal orientation towards selling, (2) the partner is employed by a firm that has a stronger professional affiliation, (3) the partner operates in a collective/embedded national culture; and (4) training is perceived to be idiosyncratic to the manufacturer. These findings help develop theory in the area of training investments and are likely to help firms identify how to maximize training ROI.

This chapter is based on joint work with Christine Moorman. 


\subsection{Introduction}

Firms increasingly use vertical networks to create superior value (Lusch, Vargo, and O'Brien 2007). As a result, manufacturers often rely on partners to interact with end-consumers. For example, IBM collaborates with approximately 110,000 partners in their PartnerWorld Program, whereas Cisco works with 35,000 partners in their Cisco Channel Partner Program. This trend increases the likelihood that firms will need to train not just their own, but also their distributors' employees to sell their products. U.S. firms spend between $\$ 4$ and \$7B per year training their sales force (ES Research Group 2008).

The goal of such training programs is presumably to improve sales partners' knowledge and skills in order to increase manufacturer sales performance. Return on these training investments is uncertain, however, given that sales partners can not be monitored to ensure they apply what they have learned. In fact, Saks and Belcourt (2006) report that, on average, only $47 \%$ of employees apply any knowledge gained from training on their job. Hence, half of all training investments could be wasted.

Another problem manufacturers face is that sales partners often sell competitor products. Hence, non-exclusive partners may use manufacturer training investments to help competitors (Bernheim and Whinston 1985). Thus, the firm faces a classic agency problem that the manufacturer (the principal) must utilize the sales partner (the agent) with nonparallel motives to perform tasks on its behalf (Arrow 1985). This agency problem places the manufacturer in a difficult position with regard to training investments. On the one hand, if the manufacturer wants to increase the likelihood that its non-exclusive sales partners will be successful, the manufacturer should rationally expend resources to train the partners. On the other hand, given divided loyalties, the manufacturer must also accept that some of these investments will be used to help the partner sell competitor products or will not be used at all.

At the most fundamental level, training involves sharing knowledge with partners. There are features associated with knowledge that make the agency problem especially difficult for firms to manage. First, although monitoring agents is always a challenge, attempting to observe or control how partners use knowledge they have been given in training is virtually impossible. The use of knowledge occurs through both its effects on decisions and on behavior, both of which are difficult for a firm to monitor. Second, new knowledge builds on prior knowledge and accumulates over time. Hence, the agent may not be aware he is using knowledge acquired from the manufacturer to help another firm.

The marketing literature has examined the firm's strategic decision to outsource the sales function (Anderson 1985; Sengupta 1995). The literature has offered a number of organizational, incentive, socialization, and selection solutions that resolve the agency problems inherent in outsourcing the sales or distribution function (see Bergen, Dutta, and Walker 1992; Heide and Wathne 
2006; Mishra, Heide, and Cort 1998). Some of these solutions are ex ante strategies that involve selecting sales partners with characteristics that increase the likelihood they will behave in ways that are consistent with manufacturer's motivations. For example, the firm may hire partners with a particular set of personality characteristics or sociocultural background. Other solutions are ex post strategies that involve managing different aspects of the relationship to increase the likelihood the agent will act in the principal's interests (Heide 1994). For example, Heide, Wathne, and Rokkan (2007) suggest that output monitoring, not behavior monitoring, reduces partner opportunism.

We build on this literature to offer a framework to understand the conditions under which marketing training investments in non-exclusive partners pay off for the manufacturer. We focus on conditions associated with the individual partner, the sales partner's professional status, the larger sociocultural environment surrounding the partner firm, and the type of training. We begin by determining whether, in fact, non-exclusive partners generate lower return-on-training than exclusive partners. We then consider whether additional moderating factors might attenuate that likelihood. We test our ideas using a multi-method approach involving cooperation from a large computer technology supplier. This study is focused on manufacturer-distributor partnerships, which are referred to as "partnerships" in the remainder of the paper.

\subsection{The Training-Agency Dilemma}

A quite extensive and impactful literature in marketing and allied disciplines has addressed the issue of whether and under what conditions firms should make investments in partners (Anderson and Weitz 1992; Brown, Dev, and Lee 2000; Heide and John 1988, 1990; Jap and Ganesan 2000; Rokkan, Heide, and Wathne 2003). This issue arises from the agency problem that the firm may be unable to monitor or compel partners to utilize those resources efficiently or to remain in the relationship long enough for the firm to recoup its investments.

These problems are exacerbated when the partner is not exclusive. Exclusivity is a restriction imposed by the manufacturer that prevents the sales partner from selling products from other suppliers (Bernheim and Whinston 1985). Research shows that non-exclusive partners are generally less committed and cooperative than exclusive partners, resulting in lower sales effort and output (Heide and John 1988; Palmatier, Dant, and Grewal 2007; Sengupta 1995).

The challenge of investing in partners is complicated further when the investment involves an intangible resource, such as knowledge, as opposed to tangible resources, such as a plant and equipment. Training is one key way that firms invest to improve partner knowledge. These investments bring three distinct challenges. First, the partner may fail to ascribe the training knowledge to the firm. This can occur because knowledge acquired through training becomes seamlessly interconnected with existing knowledge over time (Alba and Hasher 1983; Spaniol and Bayen 2002). When this happens, partners "recognize infor- 
mation, but not its source" (Johnson, Hashtroudi, and Lindsay (1993, p. 12). It can also happen because training knowledge becomes tacitly held (Nonaka and Takeuchi 1995). In this state, knowledge is not explicit and its linkage back to the firm is compromised.

Second, partners may not perceive the training to be useful. This may arise because partners have selling experience. It may also occur because partners think they know more than they do (Alba and Hutchinson 2000). In this miscalibrated state, there may be low motivation to process training information (Axtell, Maitlis, and Yearta, 1997; Guthrie and Schwoerer 1994).

Third, the intangible quality of knowledge means it can be applied to help competitors without the firm's awareness. This monitoring problem is true of many resources expended by the partner. However, monitoring how knowledge is used is particularly difficult because it is an intangible resource that is not depleted by use (Glazer 1991). In fact, if used by the partner on behalf of the firm, this may make the knowledge more accessible to help competitors. Finally, firm investments have been shown to serve as credible commitments that, in turn, increase partner commitment to the relationship (Anderson and Weitz 1992; Jap and Ganesan 2000; Palmatier et al. 2006).

This combination of factors results in what we term the training-agency dilemma. In this dilemma, the firm expends funds to train its sales partners with the goal to sell more of the firm's products. The sales return on these training investments is threatened by the features of knowledge and by non-exclusive partner's divided attention and loyalties noted above. However, the dilemma is created by two observations. First, research has shown that when firms invest in training their partners, these efforts have two important effects. Training can bind the partner to the firm by equipping the partner with the knowledge and tools to be successful in selling the firm's products (Mathieu 1991; Leach and Liu 2003). Training can also bond the partner to the firm by offering tools to support and develop the partner (Galunic and Anderson 2000). This means the partner is more committed to the firm relationship. Both outcomes reduce the agency problem. Second, the firm could, theoretically, not invest in training its nonexclusive salesforce. However, this would reduce the firm's ability to attract or retain such talent if non-exclusive partners must compete with exclusive partners receiving such training. This would leave the firm in a difficult position competing against larger and more motivated sales partners.

Therefore, despite the possibility that non-exclusive partners may not use training investments at all or they may use them to help competitors knowing or unknowingly, firms can not avoid making such investments. We seek to contribute to theory to guide the resolution of this dilemma. We begin by further substantiating the dilemma by predicting that non-exclusive partners are, on average, expected to generate lower sales return-on-training investments made by the firm. We then offer a set of conditions that mitigate this tendency. 


\subsection{Predictions}

We begin by defining key terms. Partner training refers to the partner's knowledge gains due to firm training. Partners can clearly learn in ways beyond training, including experiential learning from selling, learning from observing other salespeople, and learning through exposure to other sources of knowledge. We will use measures to control for these other sources of learning and for knowledge differences due to selection. Partner sales performance refers to the partner's sales of the firm's products.

\subsubsection{The Effect of Partner Exclusivity on Sales Return on Training In- vestments}

Research has shown that salesperson learning, in general, results in higher sales performance (Sujan, Sujan, and Bettman 1988; Weitz, Sujan, and Sujan 1986). However, there are a number of reasons to suspect that firms will not get the sales return they hope for when investing in non-exclusive partners. The training literature argues the learner's motivation to apply knowledge is the underlying mechanism that stimulates employees to use training knowledge (Axtell et al. 1997; Noe 1986). This motivation is likely to be lower for nonexclusive partners. Consistent with this, Heide and John (1988) show that distributors expend more sales effort when their partnership is more exclusive. Research has also found that distributors who are less dependent are also more likely to have a short-term relationship orientation and hence a focus on shortterm opportunistic gains (Lusch and Brown 1996). All of these problems can be viewed as manifestations of what agency theory calls "hidden actions" due to agent self-interests in post-contractual partnerships (Bergen et al. 1992). If these agency problems also exist in the training context, it implies that the application of partner training to help the firm should be higher in exclusive than in nonexclusive partnerships. Thus:

$\mathbf{H}_{1}$ : Partner training increases partner sales performance less when the partner is in a non-exclusive relative to an exclusive relationship.

\subsubsection{When Non-Exclusive Partners' Training Pays Off for the Firm}

We now investigate several conditions that may impact the training-agency dilemma for non-exclusive partners. Specifically, we identify factors that will weaken the prediction made in $\mathrm{H} 1$. Hence, we focus on factors that make the non-exclusive partners more likely to use training investments to sell firm products. Our prediction is that non-exclusive partner training will have a stronger effect on partner sales performance when a set of conditions are met. This means that the negative relationship in $\mathrm{H} 1$ is weakened.

We begin with a consideration of three factors concerned with the individual, the firm, and the broader sociocultural context. All of these can be viewed as 
partner selection strategies. Partner selection is an ex ante strategy that seeks to screen partners on criteria that are believed to predict behaviors valuable to the firm (Heide 1994; Stump and Heide 1996). We examine one individual difference variable (partner learning goal orientation) and two contextual conditions (partner firm professionalism and partner socio-cultural context) as factors that may make the non-exclusive partner a better steward of the firm's training investments. We observe these conditions in stewardship theory, which has been contrasted with agency theory (Davis, Schoorman, and Donaldson 1997). The fundamental assumption of stewardship theory is that agents will act as stewards when they are intrinsically motivated (as is the case for partners with a learning goal orientation), operating in organizational cultures that facilitate independent experts (as for professional firms), and in collectivistic as opposed to individualistic cultures (see Davis et al. 1997 for conceptual arguments). Figure 4.1 depicts how the moderating factors that follow affect the training-agency dilemma.

FIGURE 4.1 Conceptual Framework

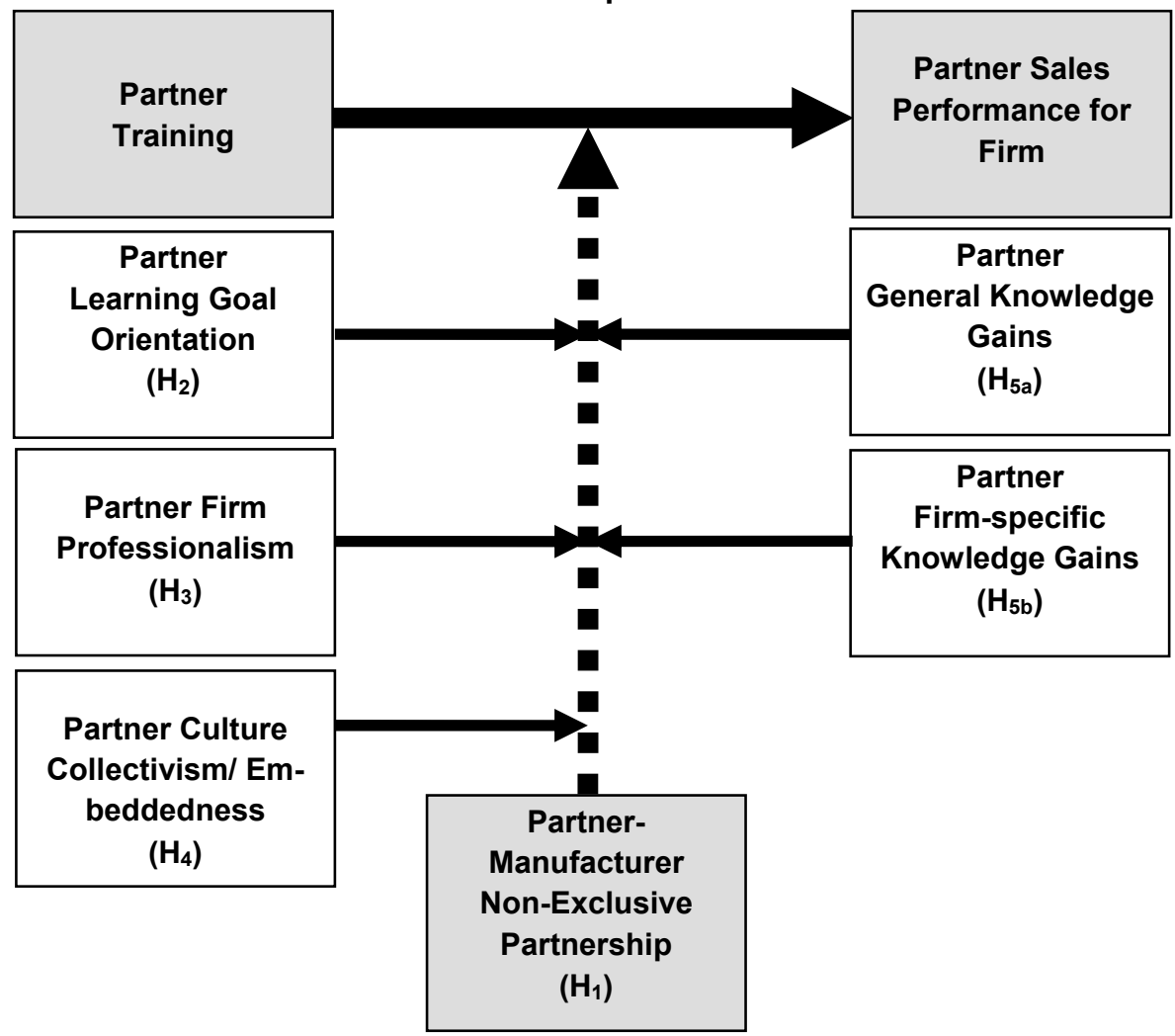


Partner learning goal orientation (LGO). Learning goal orientation has been studied among salespeople in the marketing literature (Kohli, Shervani, and Challagalla 1998; Sujan, Weitz, and Kumar 1994). People with a learning goal orientation are motivated to acquire knowledge and skills or to achieve mastery (Dweck and Leggett 1988; Ford et al. 1998). As noted by Sujan et al. (1994, p. 39), a learning goal "orients people to improve their abilities and master the tasks they perform." These researchers in turn find that learning goal orientation improves how hard (e.g., hours worked, persistence at selling) and how smart (e.g., planning, flexibility, and adaptability), the sales person worked. Working hard and smart, in turn, influenced sales performance. Kohli et al. (1998) fail to replicate the effects of learning orientation on performance. However, the authors argue that this may be due to the lack of opportunity to learn. Our study clearly offers salespeople the opportunity to learn. We also extend these two papers by using both subjective and objective assessments of sales performance to test the effect of learning goal orientation.

This literature also distinguishes learning orientation from a performance orientation, which reflects the salesperson's goal to achieve a positive evaluation of abilities and performance. Non-exclusive partners are not tied to any particular vendor. Instead, they are likely to be interested in performing on behalf of the distributor for whom they work. As such, a performance goal orientation is not likely to motivate a non-exclusive partner to apply training knowledge to help the firm that provided the knowledge. On the other hand, the high LGO nonexclusive partner may be more likely to do so for several reasons. First, the high LGO partner values training and hence may want to reciprocate by working harder on behalf of the firm that provided the training. Second, LGO has been shown to affect metacognition, or knowledge about one's knowledge (Ford et al. 1998). Ford and colleagues (1998) show that LGO increases knowledge monitoring. As such, high-LGO partners are more likely to remember the source of knowledge than low-LGO, making it more likely that these partners will apply this training knowledge for the firm. Hence,

$\mathbf{H}_{2}$ : Training of non-exclusive partners produces higher partner sales performance for the firm as learning goal orientation increases.

Partner firm professionalism. Professional control has been identified as an important source of resistance to opportunism by agents (Sharma 1997). Despite this, the literature in marketing has largely ignored this variable in understanding exchange relationships. Identified early on by Kotler and Connor 1977) as important to marketing, the force has been rarely studied. An exception is the study of the level of professionalism among marketing researchers and its effect on job satisfaction (Boyt, Lusch, and Naylor 2001).

The sociology and management literatures argue that professionalism is a trait of individuals and organizations that exerts considerable control over behavior (Parsons 1968). This trait is often a function of specialized training that distinguishes professionals from ordinary managers (Sharma 1997). 
Furthermore, professionalism is often associated with the provision of services. For example, law firms, consultancy firms, marketing research firms, and investment banks are typically considered professional firms. Professionalism tends to work in tandem with services because managers must be trusted to provide advice that is important to the success of others (e.g., legal or accounting advice) but that whose quality can not be easily judged by those using the service (Hall 1968). Professionalism is thus viewed as curbing the tendency for individual agents to behave opportunistically (Sharma 1997). For these reasons, professionals are often found to be more altruistic, belief in public service, a sense of calling to the field, autonomy to make independent decisions, and believe their training and knowledge puts them in a superior position to judge the quality of their work.

These traits combine to suggest that when non-exclusive partners work for firms that have more professional controls, they will be less likely to not use training knowledge provided by the firm or to use training knowledge opportunistically to help competitor firms. Thus:

$\mathbf{H}_{3}$ : Training of non-exclusive partners produces higher partner sales performance for the firm as partner firm professionalism increases.

Partner national culture collectivism/embeddedness. National cultures are comprised of various cultural dimensions, which represent shared ideas about what is valued, good, and desirable (Smith, Peterson, and Schwartz 2002). Marketing scholars have often examined the effect of these dimensions on manager and firm behaviors (Tse et al. 1988; Wuyts and Geyskens 2005). These dimensions reflect guiding principles for norms prescribing individual behavior and the organization of economic systems (Schwartz 1999). Although several different typologies have been described in the literature, Hofstede's (2001) classification including power distance, individualism-collectivism, masculinity-femininity, uncertainty avoidance, and long-term orientation has been used widely within and outside of marketing to explain cross-cultural differences (Steenkamp and Geyskens 2006).

The individualism-collectivism dimension describes "the relationship between the individual and the collectivity that prevails in a given society" (Hofstede 2001 , p. 209). Schwartz's (2007, p. 716) dimension of embeddedness, defined as "a normative emphasis in the culture on maintaining the status quo and restraining actions that might disrupt in-group solidarity or the traditional order" reflects this same idea. We focus on these cultural dimensions because they reflect how individuals relate to relationships and groups and hence are relevant to how partners are likely to apply firm training investments.

Both collectivism and embeddedness are expected to decrease the likelihood of opportunistic behavior by non-exclusive partners. In general, collectivistic firms perform better in close partnerships (Hofstede 2001). Additionally, individuals in collectivistic cultures are less likely to exhibit social loafing in group tasks when group performance is rewarded (Erez and Somech 1996). Finally, 
collectivism also results in strong customer and learning orientations (Yilmaz, Alpkan, and Ergun 2005), both of which may facilitate sales training. Thus, we propose that high collectivism and embeddedness induce non-exclusive partners to apply more training knowledge to benefit the firm. Hence:

$\mathbf{H}_{\mathbf{4}}$ : Training of non-exclusive partners produces higher partner sales performance for the firm relative to exclusive partners when the partner works in a national culture higher on qualities of collectivism/embeddedness.

Training knowledge type. Does provision of firm-specific or general knowledge influence whether or how the non-exclusive partner uses training knowledge on behalf of the firm? Firm-specific training knowledge is tailored to selling products from a specific manufacturer and hence is not likely to spill over to selling competitive brands. Anderson (1985) termed this brand-specific or special-purpose knowledge. Heide and John (1988, p. 22) describe this training as "...as nonsalvageable because a termination of the relationship would necessitate learning the specifics of another manufacturer's line." General training knowledge, on the other hand, can be used by the partner to improve their business in general and also for the benefit of the firm's competitors.

Non-exclusive partners may fail to use both types of knowledge because they lack motivation to apply what they have learned. On the other hand, nonexclusives may use firm-specific training to help the firm but use general training knowledge to help sell competitor products. Interestingly, the literature offers reasons to predict both types of knowledge should result in higher sales performance by the non-exclusive partner for the firm.

We first consider general training knowledge. On the one hand, general training knowledge has the ideal characteristics to be used by the non-exclusive partner to help competition. It is not tied to the firm and provides the partner with knowledge about the product category, the market, or the process of selling. On the other hand, general training knowledge may also generate partner commitment. Galunic and Anderson's (2000) study of insurance agents finds that agents given general knowledge about how to run their insurance businesses by parent firms are more committed to the firm. The authors argue that this is the case because partners view these investments as a helpful gesture by the firm to develop the agent. Reciprocating, agents work harder for the firm. Specifically, agents respond by "bonding themselves to the firm and thereby making it less likely that their skill sets will be applied to other firms, especially where those skill sets per se are transferable" (Galunic and Anderson 2000, p. 13). Whether these results generalize to non-exclusive partners is not clear.

$\mathbf{H}_{5 \mathbf{a}}$ : Training of non-exclusive partners produces higher partner sales performance for the firm relative to exclusive partners as general knowledge increases. 
Firm-specific training knowledge may produce the same effect for a different set of reasons. First, firm-specific knowledge "binds," as opposed to "bonds" the non-exclusive partner to the firm by equipping the partner to sell the firm's products (Galunic and Anderson 2000; Rokkan et al. 2003). Second, agency literature shows that when partners are the recipients of idiosyncratic investments, they become more dependent because it is more difficult for them to switch to another firm (Heide and John 1988). Thus:

$\mathbf{H}_{5 \mathbf{b}}$ : Training of non-exclusive partners produces higher partner sales performance for the firm relative to exclusive partners as firm-specific knowledge increases.

\subsection{Method}

\subsubsection{Study Context and Design}

This study was carried out in close collaboration with a leading computer technology manufacturer that uses an online portal to train sales partners. The online training program offers modules on a range of topics, including technical features of specific product lines, product category information, how to sell the firm's products, how to manage the customer relationship, and information about customers. The program was designed to be valuable to partners with a range of experience levels. Partner data, which we review later, offers evidence that partners with varying levels of experience participated in the program. All sales partners in the firm's network were invited to participate in the program. We address selection issues subsequently.

The program was designed so sales partners could freely choose the number and type of training modules they wished to access. Once selected, the modules offer information about a topic. The structure of the modules is similareach is comprised of several topics and several pages devoted to each topic. At the end of the module, the partner is asked to take a test comprised of five questions. These questions are simple and reflect the content of the module. There are no trick questions. However, the partner must get all the questions right before the module is counted as complete. The module may be repeated if the test is not passed. Upon successful completion of the module, points are awarded to the partner and accumulate in an account. These points can then be redeemed for prizes. All partners are aware that the firm has access to all training records and can observe their participation in the program over time.

The study utilized secondary data from the firm regarding both partner training levels and sales performance level. This was augmented with survey data collected directly from partners following the training. 


\subsubsection{Sample}

The sample for the study was the 1008 firm partners in Europe, NorthAmerica, Asia, and Australia, who completed the English-speaking training program between January, 2007 and December, 2007. This period was delineated so that the survey could be timed to ensure the training experience was still fresh in partner memories. All 1008 partners were sent an email invitation to participate in the study in January, 2008. Once agreed, partners clicked through to the survey. Of those contacted, 306 completed the survey, for a response rate of $30.3 \%$.

To examine the external validity of the sample and to probe for selection bias in training participation, we took the following steps. First, we compared 50 early and 50 late survey respondents on our study variables (Armstrong and Overton 1977). Early and late respondents showed no differences on any of the study variables, except for number of months in training, which shows that late respondents trained longer. Second, the firm sponsoring the study reports that overall $66 \%$ of its sales partners are non-exclusive, whereas in our sample this is $74 \%$, which is comparable. Third, the firm provided information about a random sample of European partner firms, the most highly represented continent in our sample, which did not participate in the training program. We compared our European firms involved in the training program $(n=450)$ with this sample $(n=$ $661)$ and found no differences on firm revenues $(t(1109)=-0.06, n s)$.

Given these tests, we believe our findings are generalizable to the firm's partners, in general, and to firm partners that did not participate in the training. Hence, our respondents do not reflect selection on important variables that may offer competing explanation for our findings. We address selection bias related to the choice to become non-exclusive subsequently.

Our final sample of 306 partners is detailed in Table 4.1. As is the norm in this industry, $79 \%$ of the respondents are male and the majority is younger than 40 years $(75.9 \%)$. In terms of geography, 31 countries are represented from four continents (Asia 16\%, Australia 24\%, Europe 38\%, and North America 21\%). Sales experience ranged from new to more than 7 years $(46.4 \%$ had more than 7 years experience) and the length of the partner relationship with the firm ranged from new to more than 7 years $(54.2 \%$ had been involved in the partnership 2 to 4 years). In total, 205 firms are represented in the sample, including some of the largest IT distributors in the world, such as Ingram Micro, Avnet, and Fujitsu. 
TABLE 4.1 Survey Respondent Characteristics

\begin{tabular}{|c|c|c|c|}
\hline Feature & Categories & $\mathbf{N}$ & $\%$ \\
\hline \multirow[t]{2}{*}{ Gender } & Male & 243 & 79.4 \\
\hline & Female & 63 & 20.6 \\
\hline Sales & 0-1 year & 30 & 9.8 \\
\hline \multirow[t]{4}{*}{ Experience } & $2-4$ years & 76 & 24.8 \\
\hline & $5-7$ years & 52 & 17.0 \\
\hline & More than 7 years & 142 & 46.4 \\
\hline & Don't know/ Missing & 6 & 2.0 \\
\hline Relationship & 0-1 year & 52 & 17.0 \\
\hline \multirow[t]{4}{*}{ Length } & $2-4$ years & 166 & 54.2 \\
\hline & $5-7$ years & 60 & 19.6 \\
\hline & More than 7 years & 26 & 8.5 \\
\hline & Don't know / Missing & 2 & .7 \\
\hline \multirow[t]{8}{*}{ Firm Type } & Indirect Partners & 22 & 7.2 \\
\hline & Resellers & 145 & 47.4 \\
\hline & Distributors & 66 & 21.6 \\
\hline & Software Vendors & 11 & 3.6 \\
\hline & Integrators & 18 & 5.9 \\
\hline & Direct Partners & 29 & 9.5 \\
\hline & Business Partners & 13 & 4.2 \\
\hline & Missing & 2 & .7 \\
\hline \multirow[t]{7}{*}{ Firm Size } & 0-5 employees & 9 & 2.9 \\
\hline & 6-20 employees & 0 & 0 \\
\hline & 21-50 employees & 68 & 22.2 \\
\hline & $51-100$ employees & 44 & 14.4 \\
\hline & 101-199 employees & 80 & 26.1 \\
\hline & $1000-10,000$ employees & 37 & 12.1 \\
\hline & Above 10,000 employees & 68 & 22.2 \\
\hline Months in & $1-3$ months & 85 & 27.8 \\
\hline \multirow[t]{4}{*}{ Training } & 4-6 months & 76 & 24.8 \\
\hline & 7-9 months & 111 & 36.3 \\
\hline & $10-12$ months & 24 & 7.8 \\
\hline & Missing & 10 & 3.3 \\
\hline
\end{tabular}




\begin{tabular}{|c|c|c|c|}
\hline Feature & Categories & $\mathbf{N}$ & $\%$ \\
\hline \multirow[t]{5}{*}{ Age } & $21-30$ & 92 & 30.1 \\
\hline & $31-40$ & 140 & 45.8 \\
\hline & $41-50$ & 51 & 16.7 \\
\hline & $51-60$ & 20 & 6.5 \\
\hline & Above 60 & 3 & 1.0 \\
\hline \multirow[t]{31}{*}{ Country } & Australia & 60 & 19.6 \\
\hline & Belgium & 11 & 3.6 \\
\hline & Canada & 34 & 11.1 \\
\hline & Croatia & 2 & .7 \\
\hline & Denmark & 9 & 2.9 \\
\hline & Finland & 3 & 1.0 \\
\hline & Germany & 17 & 5.6 \\
\hline & India & 18 & 5.9 \\
\hline & Indonesia & 5 & 1.6 \\
\hline & Ireland & 1 & .3 \\
\hline & Israel & 2 & .7 \\
\hline & Kazakhstan & 1 & .3 \\
\hline & Lithuania & 4 & 1.3 \\
\hline & Macedonia & 3 & 1.0 \\
\hline & Malaysia & 11 & 3.6 \\
\hline & Netherlands & 9 & 2.9 \\
\hline & N. Zealand & 14 & 4.6 \\
\hline & Norway & 4 & 1.3 \\
\hline & Philippines & 8 & 2.6 \\
\hline & Poland & 14 & 4.6 \\
\hline & Portugal & 1 & .3 \\
\hline & Romania & 2 & .7 \\
\hline & Singapore & 10 & 3.3 \\
\hline & Slovakia & 1 & .3 \\
\hline & Slovenia & 1 & .3 \\
\hline & Sri Lanka & 1 & .3 \\
\hline & Sweden & 3 & 1.0 \\
\hline & Thailand & 1 & .3 \\
\hline & UK & 23 & 7.5 \\
\hline & Ukraine & 1 & .3 \\
\hline & USA & 30 & 9.8 \\
\hline
\end{tabular}




\subsubsection{Independent Variables}

Appendix $E$ provides a detailed description of all the measures used in our study. In each case, we offer the items and the source of the measure, if it is adopted from prior literature.

Partner Training. Partner training was measured using secondary data. The measure was calculated by summing the number of completed training modules' pages read by a partner across all completed modules. In order to earn reward credits, the partner must take a test. Given this, one possibility is to use scores on tests as a measure of learning. However, the process was designed so that all of the questions had to be correct before the module was successfully completed. Hence, there is no variance in test scores since respondents had to obtain a $100 \%$ score before the module could be completed.

Partner Non-Exclusivity. This variable was measured using survey data. Specifically, respondents indicated whether they only sold the firm's brands or also sold competitor brands.

Partner Learning Goal Orientation. We use a scale adapted from Sujan et al. (1994) measuring the sales person's learning goal orientation. The measure focuses on how much the partner values knowledge and skill acquisition to improve sales performance.

Partner Firm Professionalism. We followed the literature in allocating more professional status to some partners than others. Often professionalism involves formal testing, such as a CPA exam or a bar exam. In other cases, the status of professionalism is conferred by the type of services offered by the firm. This variable is not a matter of partner perception. Instead, the status is a function of the social role played by the firm. Given this, partner professionalism was measured using secondary data from the firm which classifies each partner into one of the following roles: direct and indirect business partners, distributors, resellers, system integrators, independent software vendors, and consultants. We took three steps in making our classification. First, we reviewed the professionalism literature in sociology for direct evidence about what types of firms should be considered professional. Sharma (1997) describes consultancy firms as an example of a professional firm, since the partner provides a higher level of strategic advice and service beyond selling products. Second, we reviewed the websites for 100 of the partners to determine whether the partner firm's classification on the survey captured the partner firm's role as described on the site. We observed consistency in these classifications. Third, we spoke to the sponsoring firm and shared what we learned from the literature and choice of classifications. The firm agreed with our choices. Following this reasoning, we classify consultants as professionals (1) and resellers, distributors, software vendors, and integrators as non-professionals (0).

Cultural Collectivism/Embeddedness. Collectivism and embeddedness were measured using secondary data from Hofstede (2001) and Licht, Goldschmidt, and Schwartz (2007). Each set of authors has measured these cultural factors 
by surveying people in countries around the world. Answers are aggregated up to the level of country to generate a country-specific measure of each cultural factor. We formed our measure by combining Schwartz's embeddedness dimension and Hofstede's individualism dimension (which was recoded to reflect collectivism). The embeddedness question asked respondents to rate the importance of personal values where social order, respect for tradition, family security and wisdom represent embeddedness (Schwartz 1999). The individualism question asked respondents to rank work goals where training, physical conditions, and use of skills represented collectivism (Hofstede 2001). The two measures are strongly, but not perfectly, correlated $(r=0.62, p<.001)$.

We formed our measure by collecting the collectivism and embeddedness measures for each partner firm's country. Following recoding, we took the weighted average of the two country-level measures dimensions based on the factor scores of the standardized scale. This represents the relative importance of the two measures more accurately than taking the average. Nine countries were not studied in either Hofstede's or Schwartz's research and hence were excluded from this study $(n=28)$.

Specific and General Knowledge Gains. We distinguish firm-specific and general perceived knowledge gains by the partner. These perceived gains were measured using the survey. There were four types of knowledge contained in the training program: product, partnership program, market, and selling knowledge. We classified each as either firm-specific or general. Consider firm-specific knowledge, product knowledge (i.e., technical features of products) is specific to the manufacturer's products and can not be used to sell competitors' products, except to draw comparisons between products. Partnership knowledge (i.e., how the specific partnership with the sponsoring firm works, benefits, and requirement) is also firm-specific. Turning to general knowledge, we include market (i.e., information about customer needs and competitors) and selling knowledge (i.e., how to sell), which can be applied across products and markets.

Each of these knowledge types was measured on the survey. Specifically, respondents were asked to answer a series of questions that rate the amount of product, partnership, market, and product knowledge the partner acquired relative to before the training program. We measure knowledge gains subjectively for two reasons. First, objective gain measures would be confounded with our partner training measure. Second, general and specific knowledge cannot be clearly distinguished in the actual training. Instead, most modules consist of both general and specific knowledge. For example, selling strategies are often explained by showing how to sell a specific product. Using the survey data overcame both of these problems.

\subsubsection{Dependent Measures}

Perceived Sales Performance Improvement. Partners rated how much the training had influenced their sales performance for the firm on the survey. Spe- 
cifically, partners were asked "Compared to before the (XYZ) training, rate how each of the following changed as a result of the (XYZ) training: (i) Sales of (firm) products made to new customers; (ii) All other sales of (firm) products completed; and (iii) Sales of (firm) services." Questions were answered on a 7-point Likert scale anchored by "decreased a lot" and "increased a lot."

Actual Sales Performance. Actual sales performance is measured using salesperson data entries before, during, and after the training. Cheating on these entries is unlikely given they are audited against actual sales invoices by an independent firm.

\subsubsection{Covariates}

Market Turbulence refers to the rate of change in the composition of customers and their preferences (Jaworski and Kohli 1993). This environmental factor may influence the application of training to sales activities. If customer needs change and new customers are acquired often, salespeople need to adapt their selling activities and learn continually. Therefore, salespeople operating in turbulent markets are more motivated to learn and to apply knowledge. The construct was measured in the survey using the Joshi and Sharma (2004) scale, which was adapted from Jaworski and Kohli (1993).

Respondents indicated how many years of Sales Experience they have. This was measured by a categorical variable with the following categories: $0-1$ year, 2-4 years, 5-7 years and more than 7 years (Rapp et al. 2006). Sales experience has been shown to moderate the effect of salesperson knowledge on selling behaviors that impact performance (Rapp et al. 2006). In addition, experience may reduce the actual or perceived need for training. Using the same scale, we also asked how many years respondents worked in business in general, as denoted by Business Experience. We distinguish sales from business experience, because partners may have gained relevant experience in other jobs, which can be used to sell.

Research has shown that actual and perceived dependence may diverge, because dependence perceptions are likely to be biased (Corfman 1991; John and Robins 1994). Actual dependence is measured by Partner Non-Exclusivity (see earlier discussion). Perceived Dependence reflects the partner's perception that a replacement supplier firm is available (Kumar, Scheer, and Steenkamp 1995). This perceived dependency may influence the partner's commitment to the relationship and hence, improve training and its application to the firm's products.

Partnership Program Length is the number of years the sales partner has been involved in the partnership program. This signals the time partners had access to firm resources and support. Gender was included because perceptions of knowledge gains and performance may be systematically different for men versus women (Sharma, Levy, and Evanschitzky 2007). We also record the Age of the seller, because knowledge application abilities may vary with age as 
sellers develop routines. Hence, older sellers may be less likely to apply new knowledge.

\subsubsection{Measurement Model}

Table 4.2 presents descriptive statistics and correlations between the variables. We test normality violations by investigating skewness and kurtosis (Bollen 1989). Mardia's normalized estimate of multivariate kurtosis indicates the presence of significant multivariate kurtosis $(z=5.69, p<.05)$ (Mardia and Foster 1983). Hence, we correct for non-normality in the factor analysis using the Satorra-Bentler correction (SB, Satorra and Bentler 1988). 


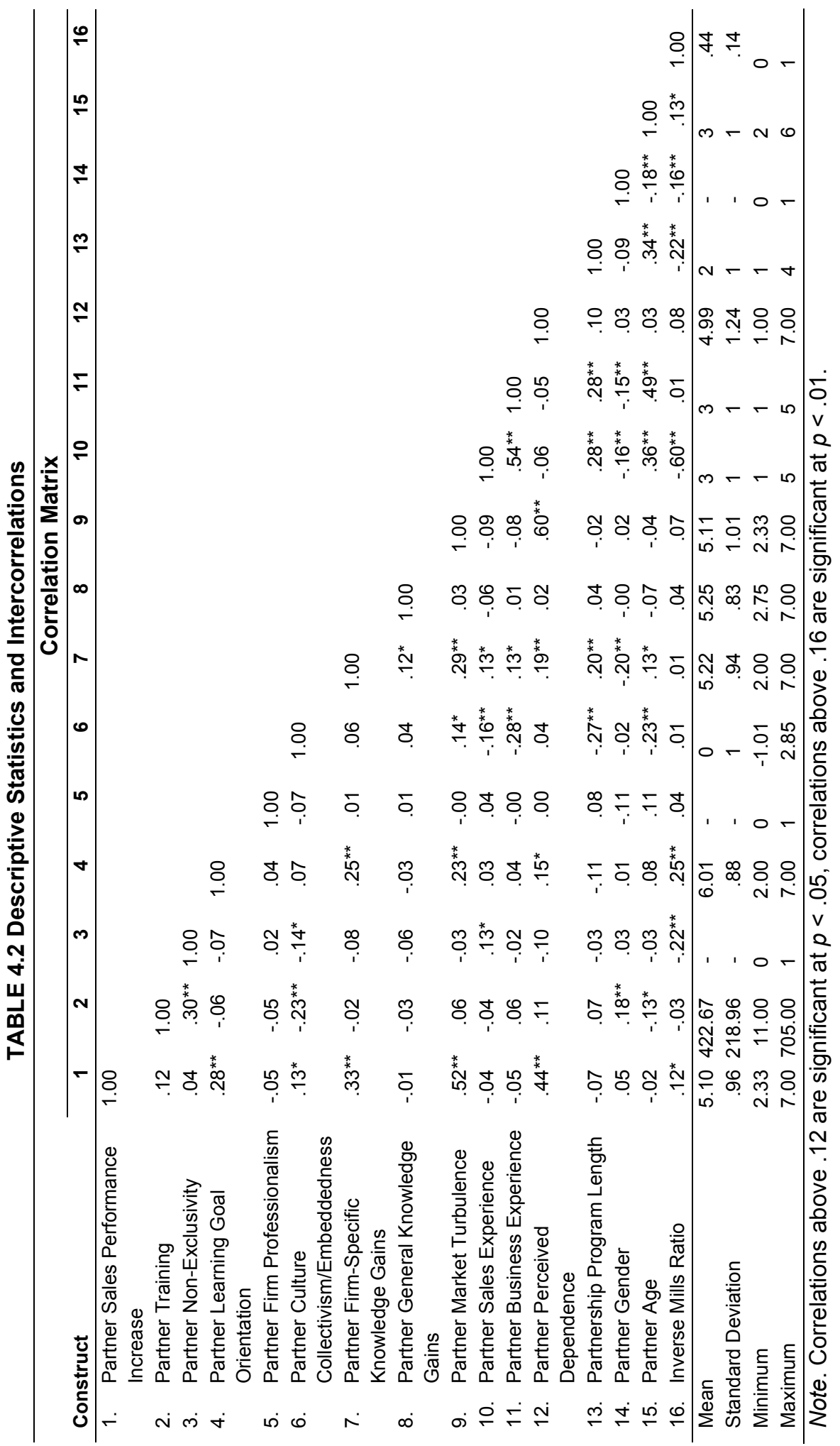


We also check for measurement invariance across cultures to ensure that questions were interpreted similarly across cultures. Although 31 countries are included in our sample, to test this issue, we divide our sample into three equal cultural groups based on the collectivism/embeddedness variable. This is necessary to ensure sufficient group size. In the remaining analyses, 31 countries will be distinguished. Tests for configural and metric invariance are conducted, because we are interested in predicting relationships instead of comparing means across cultures (Steenkamp and Baumgartner 1998). In each group, all factor loadings are significant and substantially different from zero, indicating that configural invariance is achieved (Steenkamp and Baumgartner 1998). In addition, the model specifying configural invariance shows an adequate fit, permitting inspection of metric invariance $\left(S B X^{2}(552)=722.60, p<.01\right.$, RMSEA $=.058$, SRMR $=.078, \mathrm{TLI}=.93, \mathrm{CFI}=.94)($ Vandenberg and Lance 2000). We check for partial metric invariance by freeing two items of different constructs, which have different loadings across groups $\left(S B \mathrm{X}^{2}(578)=760.07, p<.01\right.$, RMSEA = $.058, \mathrm{SRMR}=.086, \mathrm{TLI}=.93, \mathrm{CFI}=.93)$. This model is comparable to the configural measurement model $\left(S B \Delta \mathrm{X}^{2}(26)=35.76, n s\right)$, therefore partial metric invariance is achieved and groups can be aggregated into one model for the remaining analyses (Byrne, Shavelson, and Muthén 1989; Steenkamp and Baumgartner 1998; Vandenberg and Lance 2000).

All perceptual, individual-level measures are included in our final confirmatory factor analysis. All factor loadings were substantive (i.e., exceeding .49) and significant $(p<.001)$. Fit indices indicate a reasonable fit of the data $\left(S B X^{2}(174)\right.$ $=281.08, p<.01, \mathrm{RMSEA}=.045, \mathrm{SRMR}=.057, \mathrm{TLI}=.95, \mathrm{CFI}=.96)$. Construct reliabilities range between .97 and .99 , which indicates high convergent validity. Average variances extracted are between .91 and .96 and square roots exceed the construct correlations, indicating sufficient discriminant validity and no serious multicollinearity (Fornell and Larcker 1981). Construct reliabilities (CR) and average variances extracted (AVE) are reported in Appendix E.

\subsubsection{Selection Correction}

The partner's choice to become non-exclusive may be related to some of the antecedent and covariate variables in our study. Hence, it may be these variables and not exclusivity per se that is influencing our results. For example, individual characteristics such as age, gender, sales experience, learning goal orientation, and country might predict partner exclusivity. Additionally, partners with a great deal of experience might choose to be non-exclusive because their experience gives them a better chance at success. Following the two-step Heckman approach, we use these variables for calculating the Inverse Mills ratio which corrects for self-selection in exclusivity (Heckman 1979; Heckman et al. 1998). In the first stage, we regress the predictor variables on the choice to be exclusive or non-exclusive in a Probit model. The Inverse Mills ratio is recovered from this analysis and imported into our multi-level model. 


\subsubsection{Multilevel Model}

Our respondents are nested within countries, which means observations are not independent but may be affected by common country characteristics. Therefore, OLS estimates will be biased and standard errors will be incorrect. By using hierarchical linear modeling (HLM), we allow for missing data and specify the individual and country heterogeneity simultaneously (Raudenbush and Bryk 2002). ${ }^{3}$ We specify the model as follows:

Level 1:

$S P I_{\mathrm{ij}}=\beta_{0 \mathrm{j}}+\beta_{1 \mathrm{j}}\left(P T_{\mathrm{ij}}\right)+\beta_{2 \mathrm{j}}\left(P N E_{\mathrm{ij}}\right)+\beta_{3 \mathrm{j}}\left(P T_{\mathrm{ij}}{ }^{*} P N E_{\mathrm{ij}}\right)+\beta_{4 \mathrm{j}}\left(L G O_{\mathrm{ij}}\right)+\beta_{5 \mathrm{j}}\left(L G O_{\mathrm{ij}}\right.$ * $\left.P T_{\mathrm{ij}}\right)+\beta_{6 \mathrm{j}}\left(L G O_{\mathrm{ij}}{ }^{*} P N E_{\mathrm{ij}}\right)+\beta_{7 \mathrm{j}}\left(P R O F_{\mathrm{ij}}\right)+\beta_{8 \mathrm{j}}\left(P R O F_{\mathrm{ij}}\right.$ * $\left.P T_{\mathrm{ij}}\right)+\beta_{9 \mathrm{j}}\left(P R O F_{\mathrm{ij}}\right.$ * $\left.P N E_{\mathrm{ij}}\right)+$ $\beta_{10 \mathrm{j}}\left(G K G_{\mathrm{ij}}\right)+\beta_{11 \mathrm{j}}\left(I K G_{\mathrm{ij}}\right)+\beta_{12 \mathrm{j}}\left(G K G_{\mathrm{ij}} * P N E_{\mathrm{ij}}\right)+\beta_{13 \mathrm{j}}\left(G K G_{\mathrm{ij}} * P T_{\mathrm{ij}}\right)+\beta_{14 \mathrm{j}}\left(I K G_{\mathrm{ij}}\right.$ * $\left.P N E_{\mathrm{ij}}\right)+\beta_{15 \mathrm{j}}\left(I K G_{\mathrm{ij}}\right.$ * $\left.P T_{\mathrm{ij}}\right)+\beta_{16 \mathrm{j}}\left(L G \mathrm{O}_{\mathrm{ij}}\right.$ * $P T_{\mathrm{ij}}$ * $\left.P N E_{\mathrm{ij}}\right)+\beta_{17 \mathrm{j}}\left(P R O F_{\mathrm{ij}}\right.$ * $P T_{\mathrm{ij}}$ * $\left.P N E_{\mathrm{ij}}\right)+$ $\beta_{18 \mathrm{j}}\left(G K G_{\mathrm{ij}}{ }^{*} P T_{\mathrm{ij}}{ }^{*} P N E_{\mathrm{ij}}\right)+\beta_{19 \mathrm{j}}\left(I K G_{\mathrm{ij}} * P T_{\mathrm{ij}} * P N E_{\mathrm{ij}}\right)+\beta_{20 \mathrm{j}}\left(M T_{\mathrm{ij}}\right)+\beta_{21 \mathrm{j}}\left(S E_{\mathrm{ij}}\right)+\beta_{22 \mathrm{j}}\left(B E_{\mathrm{ij}}\right)$ $+\beta_{23 \mathrm{j}}\left(P D_{\mathrm{ij}}\right)+\beta_{25 \mathrm{j}}\left(P P L_{\mathrm{ij}}\right)+\beta_{27 \mathrm{j}}\left(G E_{\mathrm{ij}}\right)+\beta_{28 \mathrm{j}}\left(A G E_{\mathrm{ij}}\right)+\beta_{29 \mathrm{j}}\left(M I L L S_{\mathrm{ij}}\right)+r_{\mathrm{ij}}$.

Level 2:

(1) $\beta_{0 \mathrm{j}}=\mathrm{Y}_{00}+\mathrm{Y}_{01}\left(\mathrm{CE}_{\mathrm{j}}\right)+u_{0 \mathrm{j}}$;

(2) $\beta_{1 j}=\gamma_{10}+\gamma_{11}\left(C E_{j}\right)+u_{1 j}$;

(3) $\beta_{2 j}=\gamma_{20}+\gamma_{21}\left(C E_{j}\right)+u_{2 j}$; and

(4) $\beta_{3 j}=\gamma_{30}+\gamma_{31}\left(C E_{j}\right)+u_{3 j}$.

where $i$ and $j$ represent individuals and countries, respectively. The model variables are: sales performance increase (SPI), partner training (PT), partner non-exclusivity (PNE), learning-goal orientation (LGO), firm professionalism (PROF), general knowledge gains (GKG), firm-specific or idiosyncratic knowledge gains (IKG), and collectivism/embeddedness (CE). Covariates included in the model are market turbulence (MT), sales experience (SE), business experience (BE), perceived dependence (PD), partnership program length (PPL), gender (GE), and age (AGE). MILLS denotes the self-selection correction for exclusivity.

Error terms specify measurement error on the country (i.e., $u_{0 \mathrm{j}}$ ) and individual level (i.e., $r_{\mathrm{ij}}$ ), separately. In these equations we include all main effects and two-way interactions for correct estimation of the hypothesized three-way interactions. It is meaningful to investigate country effects in addition to individual effects in a multi-level model, because $15.28 \%$ of variance is explained at the

\footnotetext{
${ }^{3}$ The partners are also nested within firms. Hence, it is possible to nest within firms and countries in the multi-level model. However, given that our respondents are 306 partners that are part of 205 firms, the firm cluster size is only one in many cases. We exclude the firm level of the analysis, because of power concerns on the individual level (i.e., level 1). We did check the multi-level model by adding a firm random effect in addition to the country effect, but this did not change our results.
} 
country level (i.e., Intraclass Correlation Coefficient). HLM with maximum likelihood estimation was employed (Raudenbush and Bryk 2002). We have grand-mean centered all continuous predictors and estimate our models using SAS PROC MIXED (Singer 1998).

\subsection{Results}

\subsubsection{Partner Exclusivity and Sales Return on Training Investments: Perceived Sales Performance}

Before we consider our predictions, we begin by examining the training and sales performance levels of exclusive and non-exclusive partners. In general, we observe that non-exclusive partners learn significantly more than exclusive partners $\left(M_{\text {non }}=461.71\right.$ pages vs. $M_{\mathrm{ex}}=312.74$ pages, $\left.t(288)=-5.33, p<.001\right)$. Hence, non-exclusive partners were heavier users of the training investments offered by the firm. However, on average non-exclusive partners actually sell less per month than exclusive partners although this difference is not statistically significant $\left(M_{\text {non }}=\$ 68,484.49\right.$ vs. $\left.M_{\mathrm{ex}}=\$ 134,984.98, t(92)=1.59, n s, n=95\right)$. This initial evidence indicates that, indeed, non-exclusive partners cost the firm more in terms of training investments but that this investment is not recouped in firm sales. Hence, descriptively, the training-agency dilemma appears to be operating.

The moderating effect of partner non-exclusivity. We test our hypotheses using a nested-model approach. Table 4.3 contains the results of the full multilevel model. We report unstandardized coefficients, because variance is partitioned across levels of analysis.

First, we include all relevant main effects and two-way interactions. Next, we add the five predicted three-way interactions in the full model to test our hypotheses. Adding these interactions improves model fit $\left(\Delta x^{2}(5)=19.60, p<\right.$ .01).

In the full model, we find a significant main effect of partner training on sales performance increase $\left(\beta_{1 \mathrm{j}}=.0012, p<.01\right)$. Consistent with our predictions and at the heart of the training-agency dilemma, we find a significant negative interaction between partner non-exclusivity and partner training on partner sales increase $\left(\beta_{3 j}=-.0009, p<.05\right)$. Thus, $H_{1}$ is supported; the positive effect for training is weaker for non-exclusive partners. A follow-up OLS model involving the categorical exclusivity variable indicates that exclusive partners $(\beta=.26, p<$ $.05)$ apply knowledge, whereas non-exclusive partners do not $(\beta=.01, n s)$.

When non-exclusive partners' training pays off for the firm. We now consider possible conditions under which the significant negative interaction involving partner non-exclusivity and partner training on partner sales is weakened. As predicted in $\mathrm{H}_{2}$, we find a significant three-way interaction with learning goal orientation $\left(\beta_{16 \mathrm{j}}=.0009, p<.10\right)$. When non-exclusive partners 
have a learning goal orientation they are more likely to apply training to sell the firm's products.

Likewise, the three-way interaction including firm professionalism is also positive and significant $\left(\beta_{17 \mathrm{j}}=.0168, p<.05\right)$. This finding suggests that compared to their non-professional counterparts, professional non-exclusive partners are more likely to apply training to sell firm products. This supports $\mathrm{H}_{3}$.

There is also a significant three-way interaction involving training, nonexclusivity, and the collectivism/embeddedness of the national culture $\left(\gamma_{31}=\right.$ $.0016, p<.01)$. Non-exclusive partners in collectivistic/embedded cultures apply more of their training to sell firm products than their counterparts in individualistic cultures. This supports $\mathrm{H}_{4}$.

Finally, results indicate that general knowledge gains worsen the two-way interaction involving training $x$ non-exclusive status $\left(\beta_{110 \mathrm{j}}=-.0028, p<.01\right)$. Hence, in the presence of general training, non-exclusives sell less, not more, of the firm's products. This fails to support existing literature and our $\mathrm{H}_{5 a}$. On the other hand, results indicate a positive three-way interaction involving firmspecific knowledge gains $\left(\beta_{19 \mathrm{j}}=.0027, p<.01\right)$. This indicates that firm-specific training stimulates non-exclusive to sell higher levels of firm products. Thus, $\mathrm{H}_{5 b}$ is supported.

TABLE 4.3 Test of hypotheses: Partner Sales Performance Increase

\begin{tabular}{lll}
\hline & Predictor & Coefficient (SE) \\
\hline Intercept & $2.3569(.4684)$
\end{tabular}

Training-Agency Dilemma

Partner Training (PT)

Partner Non-Exclusivity (PNE)

$\mathrm{H}_{1} \mathrm{PT}^{*} \mathrm{PNE}$
$.0012(.0005)^{* * *}$

$.1719(.1313)^{*}$

$-.0009(.0006)^{* *}$

Individual Moderator

Partner Learning Goal Orientation

Partner Learning Goal Orientation*PT

$-.1784(.1324)^{*}$

Partner Learning Goal Orientation*PNE

$-.0006(.0005)$

$\mathbf{H}_{\mathbf{2}}$ Partner Learning Goal Orientation ${ }^{*} \mathrm{PT}^{\star} \mathrm{PNE}$

$.0148(.1463)$

$.0009(.0006)^{*}$

Firm Moderator

Partner Firm Professionalism

Partner Firm Professionalism*PT

$-5.2257(3.2057)^{*}$

Partner Firm Professionalism*PNE

$-.0158(.0095)^{\star *}$

$\mathbf{H}_{3}$ Partner Firm Professionalism ${ }^{\star} \mathrm{PT}^{\star} \mathrm{PNE}$

$5.0216(3.2175)^{*}$

$.0168(.0096)^{\star *}$

Cultural Moderator

Partner Collectivism/Embeddedness

$.0754(.1114)$ 
Partner Collectivism/Embeddedness ${ }^{*} \mathrm{PT}$

Partner Collectivism/Embeddedness*PNE

$\mathbf{H}_{4}$ Partner Collectivism/Embeddedness ${ }^{*} \mathrm{PT}{ }^{*} \mathrm{PNE}$

Knowledge Type Moderators

General Knowledge Gains

Firm-specific Knowledge Gains

General Knowledge Gains*PT

Firm-specific Knowledge Gains*PT

General Knowledge Gains*PNE

Firm-specific Knowledge Gains ${ }^{*} P N E$

$\mathbf{H}_{5 \mathbf{a}}$ General Knowledge Gains ${ }^{*} \mathrm{PT}^{*} \mathrm{PNE}$

$\mathbf{H}_{5 b}$ Firm-specific Knowledge Gains ${ }^{\star} \mathrm{PT}^{\star} \mathrm{PNE}$

Covariates

Market Turbulence

Sales Experience

Business Experience

Perceived Dependence

Partnership Program Length

Gender

Age

Inverse Mills Ratio

AIC/Log-likelihood
$-.0013(.0005)^{* * *}$

$-.0246(.1296)$

$.0016(.0006)^{\star * *}$

$$
\begin{aligned}
& .4843(.1974)^{* * *} \\
& -.0115(.1883) \\
& .0018(.0010)^{* *} \\
& -.0017(.0008)^{* *} \\
& -.2019(.2136) \\
& -.0296(.2076) \\
& -.0028(.0011)^{* * *} \\
& .0027(.0009)^{* * *}
\end{aligned}
$$

$.2821(.0687)^{\star * *}$

$.0381(.0648)$

$.0558(.0779)$

$.1642(.0533)^{* * *}$

$-.0411(.0685)$

$.0708(.1243)$

$-.0562(.0646)$

$.6093(.3868)$

Note. Significance of coefficients is based on one-tailed tests except for covariates. Table reports unstandardized regression coefficients with standard errors in parentheses. ${ }^{*} p<.10,{ }^{* *} p<.05,{ }^{* * *} p<.01$.

\subsubsection{Partner Exclusivity and Sales Return on Training Investments: Ac- tual Sales Performance}

We validate our results by investigating respondents' actual sales performance. The test uses a sub-sample of our survey respondents because some partner firms do not allow their salespeople to report sales performance to the manufacturer and for data reasons described in detail below. We were able to locate reasonably good data from 95 of our original 306 participants. This sample does not vary on any of the study variables. Hence, there are no selection concerns. In addition, respondents in this sub-sample who started training early versus late were identified using a median split. Although the early trainers trained more $(t(86)=4.02, p<.01)$, these groups did not differ significantly on obtained revenues $(t(92)=-.85, n s)$, perceived sales performance increase after training $(t(86)=.77, n s)$, specific knowledge gains $(t(91)=.52, n s)$, and general knowledge gains $(t(92)=1.10, n s)$. We begin by 
describing a growth model, which tracks sales performance over time, and follow with our results.

Growth model. In addition to estimating a multilevel model, a growth model using actual sales performance data is estimated with Mplus 5.2 (Muthén and Muthén 1988-2007). A three-level model is estimated in which the repeated measures of sales performance are positioned at level-1, and are then treated as nested within individuals (at level-2) and, subsequently nested within countries (at level-3). Growth modeling allows us to investigate sales performance change patterns over time before, during, and after training to delineate training effects on sales performance change for exclusive and non-exclusive partners. A baseline sales level was taken in December 2006, which is one month before the beginning of the training period. We measured changes in sales across this time period, knowing that individuals would begin and end training at different times. The last data point we could get from the manufacturer was November 2007. This is one month before some of the partners finished training. Hence, we eliminated partners that had not completed training by November 2007. Training occurs over the course of the year for most partners and performance increases are expected to accrue across this time, not just at the end. The growth model allows us to explain the change in actual sales performance that occurs during the training period while controlling for the time period in which partners trained.

We use monthly sales data, because this is spaced close enough to pick up sales performance change, and far enough to focus on performance development instead of explaining coincidental peaks. Only respondents who provided monthly sales for at least three months were included as this is the minimum number of observations needed to correctly estimate the growth curve (Willett 1989). Thus, we use a range of 3 to 12 measures of monthly sales performance for each sales partner. Enders (2004) suggests that missing data might cause reliability concerns unless the missing data is completely random. Little's MCAR test was non-significant and indicated that the missing data is random $\left(X^{2}(1483)\right.$ $=1440.35, n s)$ (Little 1988). All variables were standardized prior to model estimation.

Full-information maximum likelihood estimation (FIML) was used, which is appropriate for handling missing data in growth modeling (Cheung 2007; Enders 2001). The Yuan-Bentler $t^{2}$ test statistic was used to correct for nonnormality (Bentler and Yuan 1999). A linear slope shape was specified, because we assume that sellers in general improve their performance over time due to learning from training. The first month is set to zero, which implies that the intercept refers to December, 2006 period. This baseline model without predictors was tested against models with a quadratic and cubic slope (i.e., sshaped curve) as recommended by Bliese and Ployhart (2002). Both quadratic $\left(\Delta \mathrm{x}^{2}(1)=.004, n s\right)$ and cubic model $\left(\Delta \mathrm{x}^{2}(2)=-3.14, n s\right)$ did not fit significantly better than the more parsimonious linear model in the log-likelihood ratio tests, therefore the linear model was retained. 
In order to achieve model parsimony and to be able to incorporate all possible two-way interactions, the number of included covariates had to be restricted. Hence, only the conceptually and statistically most important covariates were retained (i.e., market turbulence, sales experience, business experience, perceived dependence, and partner program length). Additional variables related to training time were also included. Training Start specifies the month in which the first training module was completed. By controlling for this effect we take into account that respondents trained at different times of the year. Number of Months in Training indicates how long people trained, which might influence success. Finally, we include a Firm variable specifying the partner's firm to control for variability between firms related to firm size, product assortment, and sales territory. Effects are modeled on the slope of sales performance to test the hypotheses, because we are interested in explaining how training, exclusivity, and the moderating factors affect sales performance change. Some variables are modeled the sales performance intercept, because these affect the overall level of sales performance. ${ }^{4}$

Results. Similar to the multi-level analysis, we first include all relevant main effects and two-way interactions. Then we add the five predicted three-way interactions in our full growth model. Adding these interactions improves model fit $\left(\Delta \mathrm{x}^{2}(5)=43.50, p<.01\right)$.

Table 4.4 shows the results of the growth model analysis. Our objective is to explain change in individuals' sales performance by including time-invariant covariates. Results indicate a positive main effect for training on sales performance change $\left(\beta_{1 \mathrm{j}}=.019, p<.01\right)$ and a negative training-exclusivity interaction $\left(\beta_{3 j}=-.014, p<0.10\right)$, which validates $H_{1}$. In addition, results show a moderately significant positive three-way interaction involving learning goal orientation $\left(\beta_{16 \mathrm{j}}=.025, p<.10\right)$. This finding validates $\mathrm{H}_{2}$. Further, the three-way interaction with firm professionalism is significant and positive $\left(\beta_{17 j}=.149, p<\right.$ .10), validating $\mathrm{H}_{3}$. Unfortunately, the three-way interaction with collectivism/embeddedness is not significant, failing to support $\mathrm{H}_{4}$. However, the model does show a significant positive three-way interaction for firm-specific knowledge gains $\left(\beta_{19 \mathrm{j}}=.013, p<.05\right)$. This validates results for $\mathrm{H}_{5 \mathrm{a}}$. Finally, the general knowledge three-way interaction is significant and positive as well $\left(\beta_{18 \mathrm{j}}=\right.$ $.030, p<.05)$. Although this supports $\mathrm{H}_{5 \mathrm{~b}}$, the finding is in contrast to our previous analysis, in which we found a negative three-way interaction. Apparently non-exclusive sellers do not think they increase sales performance from as a result of general training knowledge, but, in fact, they do. We return to this point in our discussion.

\footnotetext{
${ }^{4}$ These relate to market conditions (i.e., market turbulence), sales partner resources (i.e., sales experience, business experience, and partner program length), perceived dependence, and the partner firm. These variables can affect sales performance irrespective of whether the partner trains.
} 
TABLE 4.4 Growth Model Results: Actual Change in Sales Performance

\section{Growth Model}

Predictor

Intercept

Slope

Training-Agency Dilemma

Partner Training (PT)

Partner Non-Exclusivity (PNE)

$\mathrm{H}_{1} \mathrm{PT}{ }^{*} \mathrm{PNE}$

$.019(.008)^{\star * *}$

$-.029(.008)^{* * *}$

$-.014(.009)^{*}$

Individual Moderator

Partner Learning Goal Orientation

$-.001(.020)$

Partner Learning Goal Orientation*PT

$-.020(.019)$

$.006(.020)$

Partner Learning Goal Orientation*PNE

$.025(.017)^{*}$

$\mathbf{H}_{\mathbf{2}}$ Partner Learning Goal Orienta-

tion*PT*PNE

Firm Moderator

Partner Firm Professionalism

$-.235(.171)^{*}$

Partner Firm Professionalism*PT

$-.140(.091)^{*}$

Partner Firm Professionalism*PNE

$.255(.154)^{* *}$

$\mathrm{H}_{3}$ Partner Firm Professionalism ${ }^{\star} \mathrm{PT}{ }^{*} \mathrm{PNE}$

$.149(.094)^{*}$

Cultural Moderator

Partner Collectivism/ Embeddedness

$-.006(.008)$

Partner Collectivism/ Embeddedness* ${ }^{*} T$

$.005(.013)$

Partner Collectivism/ Embeddedness ${ }^{*}$ PNE

$.018(.009)^{\star *}$

$\mathrm{H}_{4}$ Partner Collectivism/ Embedded-

$-.007(.014)$

ness ${ }^{*} P T^{*} P N E$

Knowledge Type Moderators

General Knowledge Gains

$-.002(.007)$

Firm-specific Knowledge Gains

$-.047(.017)^{* \star *}$

General Knowledge Gains ${ }^{*} \mathrm{PT}$

$-.015(.006)^{* * *}$

Firm-specific Knowledge Gains*PT

$-.035(.015)^{\star \star}$

General Knowledge Gains*PNE

$.013(.010)$

Firm-specific Knowledge Gains*PNE

$\mathbf{H}_{5 \mathrm{a}}$ General Knowledge Gains ${ }^{*} \mathrm{PT}^{*} \mathrm{PNE}$

$.057(.020)^{\star * *}$

$.030(.017)^{\star *}$

$\mathbf{H}_{5 b}$ Firm-specific Knowledge Gains ${ }^{*} \mathrm{PT}^{*} \mathrm{PNE}$

$.013(.008)^{* *}$

Covariates

Month of Training Start

$.003(.007)$

Number of Months Trained

$-.002(.006)$

Market Turbulence

$-.004(.079)$

Sales Experience

$.041(.031)^{*}$

$-.001(.005)$ 
Business Experience

Perceived Dependence

Partnership Program Length

Firm

AIC/Log-likelihood

$1799.2 /-864.6$

Note. Significance of coefficients is based on one-tailed tests except for covariates. Table reports unstandardized regression coefficients with standard errors in parentheses. Intercept and slope columns denote whether effects are modeled on sales performance intercept or slope. ${ }^{*} p<.10,{ }^{* *} p<$ $.05,{ }^{* * *} p<.01$.

We estimated an alternative growth model using dummy variables denoting the month prior to each respondent's training as the starting point of their sales performance slope. Model results are directionally equivalent to the original model. However, the original growth model produces a significantly better model fit $\left(\Delta x^{2}(20)=56.80, p<.01\right)$.

\subsection{Discussion}

\subsubsection{Summary of Findings}

This study investigates the existence of and solutions for the trainingagency dilemma. In this common situation, firms face the problem of needing to invest in training non-exclusive partners. However, non-exclusive partners are expected to be less likely to use training to sell the firm's products and to use the training to sell competitor products as well. Yet, firms must often invest in these non-exclusive partners to ensure their salesforces are competitive and to ensure they are large enough to cover important territories.

Across both perceived and actual sales gains, we find that the relationship between training and firm sales is weaker for non-exclusive partners than exclusive partners. We also observe that the non-exclusive partner's tendency to use training knowledge to help the firm is improved: (i) when the partner has a learning goal orientation, (ii) when the partner is part of a professionalized, as opposed to a non-professionalized, firm; and (iii) when the partner is from a country with a collectivistic/embedded, as opposed to individualistic, culture. We also find that, as expected, firm-specific training binds the partner to the firm and increases the return-on-training investments. Our findings related to general training are mixed. For perceived sales gains, higher general training worsens the negative two-way interaction between training and partner non-exclusivity. However, for actual sales gains, general training does mitigate the negative twoway interaction. 


\subsubsection{Theoretical and Managerial Implications}

This research attempts to contribute to agency and transaction cost analysis literature as well as the salesperson literature in marketing. A key issue in the agency and transaction cost literature is how to design, manage, and monitor relationships with agents outside the firm to reduce opportunistic behavior. We contribute to the literature by focusing on investments in training independent agents that the firm hopes will payoff in terms of firm sales. Although the literature has addressed training investments conceptually, aside from Galunic and Anderson (2000), we are not aware of other literature in marketing that has examined the firm's return on training investments when facing independent and non-exclusive agents. We contribute to this literature by demonstrating that training investments do, indeed payoff at lower rates for non-exclusive agents. However, selecting agents, ex ante, on the basis of important individual, firm, and cultural criteria can mitigate those risks and generate positive returns on training investments. These findings contribute to the burgeoning literature on opportunism in principal-agent relationships in the transaction cost literature in marketing (Heide and John 1988; Heide, Wathne, and Rokkan 2007; Jap and Anderson 2003; Mishra et al. 1998; Rokkan et al. 2003).

Prior literature has suggested that ensuring goal congruence is more important when there are potentially higher levels of opportunism in the relationship (Bergen et al. 1992; Jap and Anderson 2003). As such, it is likely that as partner firm professionalism and partner collectivistic culture increase, the agency problem weakens and partners apply what they have learned from the firm for the benefit of the firm. Our study does not directly test for the presence of this mediating process. Future research could consider this and other mediating explanations for the effect of our moderating effects.

Our focus on the role of professionalism as an important social control that curbs partner opportunism is actually quite novel in the marketing literature. This factor has received more attention in the broader organizational literature. Professional control curbs opportunism because partners seek to uphold a larger social contract or expectation they embraced when they assumed the professional role. We measure professionalism at the firm level. However, future research could measure it as a belief system at the individual partner level or as reflected in specialized training or education that the partner has invested in to assume the professional role. These investments and resulting beliefs may vary at the individual level and hence could examine whether the social control is exerted at both the individual and/or firm level. Professionalism can be lost by partners if they betray expected norms for behavior. Given the investments in achieving professional status, partners should strive to maintain this status. This is especially true given our results-professional sales partners do, in fact, offer firms a greater training ROI. If this is expected by sellers and they select professional sales partners as a result, this increases the power of professionalism as a tool for curbing opportunistic behavior. Given these possibilities, we recom- 
mend that professionalism is more widely researched and more directly measured in the channels literature.

Considering the role of culture, our results support a strategy of selecting non-exclusive partners from collectivistic cultures rather than from individualistic cultures. This is consistent with Wuyts and Geyskens (2005) who find that collectivistic firms are more likely to perform better in partnerships. This finding also supports the observed tendency for Japanese manufacturers, operating in a more collectivistic culture, to introduce fewer safeguards on their outsourced relationships because the institutional environment serves as a check on opportunistic behavior (Bensaou and Anderson 1999). We examined culture at the country level. Future research may examine heterogeneity within cultures reflecting the degree to which individuals adopt the larger set of cultural norms and values.

Previous salesperson literature has examined the effect of a salesperson's existing knowledge on performance (Sujan et al. 1988) or salesperson's goal orientation on sales performance (Kohli et al. 1998; Sujan et al. 1994). In contrast, our research examined the conditions under which salespeople apply new training knowledge to improve performance. This focus fills an important gap in the literature given how common it is for firms to make such training investments with the hope of improving sales performance. Importantly, we observe for both perceived and actual sales performance that training does have a positive effect. However, all of this lift appears to be coming from exclusive salespeople; nonexclusive salespeople evince no change in sales following training. Our findings point to the critical role of learning goal orientation in reversing this tendency of non-exclusive partners. The problem is that learning-oriented non-exclusive partners may not be very performance or outcome-oriented, which may reduce their actual sales performance. Our results indicate that learning goal orientation in general has a negative (for perceptions of sales performance) and null (for actual sales performance) effect. This means that firms must worry that selecting partners with a high learning goal orientation to avoid the training-agency dilemma could inadvertently depress sales levels from these partners. One strategy is to screen for sales partners high on both performance orientation and learning goal orientation. Research indicates that these traits can co-occur in some people (Sujan et al. 1994).

Our findings suggest that firms can explicitly manage training investments for salespeople. As an important knowledge asset, training does, overall, improve sales. Past research has indicated mixed results for training. However, in a sales context, this marketing knowledge does appear to payoff. Yet, as our discussion has reviewed, these payoffs are not uniform. Hence, research should follow our direction in attempting to identify the conditions under which training knowledge generates the greatest return on investment. Part of the challenge in this research is observing the application of knowledge. Better process measures may help. For example, Eisenhardt (1989) recommends the use of beepers that randomly ask informants to report behavior. This could be 
expanded to include reporting the knowledge or ideas that are guiding behavior. Given that research has shown that output monitoring reduces opportunism while behavior monitoring increases opportunism (Heide et al. 2007), this approach could be used in a field study to ferret out the effects of such tools on the quality of measures as well as performance on these measures.

Using indicators of actual sales, we find that both general and specific training knowledge help non-exclusives perform better for the firm. It is interesting that non-exclusive partners' perceptions of their sales performance are only higher for firm-specific, not general training. This may be a function of the way in which general training knowledge is integrated by the salesperson. Specifically, given its general applicability, we suspect that sales partners remember the information but not the source. Hence, there is a positive effect on actual sales, but this effect is so generalized that the salesperson does not notice it and does not attribute it to firm training. Based on Galunic and Anderson (2000) and our findings, we recommend that firms attempt to brand this training. This means that although it is general to the partner's work, it may be more likely to be ascribed to the firm. When this happens, partner commitment should increase (Galunic and Anderson 2000).

\subsubsection{Limitations and Issues for Further Research}

This study has some limitations, which highlight opportunities for future research. First, because we do not have a measure of the partner's sales of competitor product, we can not know for certain that low performing partners are behaving opportunistically. We only know how their sales performance levels are changing over time both in terms of perceptions and actual sales. Second, our sample was limited to partners working with one specific manufacturer. Future research should examine whether our results hold in other industries and for smaller manufacturers. We have cooperated with one of the market leaders in computer technology, which might have inflated the relationship between learning and performance due to more sales opportunities (i.e., the manufacturer has many product lines, is diversified, and has a large existing customer base).

In addition, we have only investigated the effect of a single training program. The fact that a training program runs over an extended period of time, such as a number of years, might impact training effectiveness. On the one hand, partners might become more efficacious in applying training knowledge over time. On the other hand, partners might get tired of training and apply less. An interesting research topic would be to study effects of training duration versus frequency (i.e., taking several trainings simultaneously) on training effectiveness.

Finally, in this research we measure knowledge gains subjectively. This eliminates the problem of the partner forgetting how much was learned. However, knowledge calibration research has shown that these knowledge perceptions may be biased (Alba and Hutchinson 2000). Hence, partners may be under confident or over confident, which might influence how training is applied. Future 
research could introduce alternative measures of training, including training time that may be a more objective indicator of actual knowledge acquired.

\subsection{Conclusion}

Nowadays, many manufacturers cooperate with an independent sales force. In order to increase sales and customer satisfaction, firms invest heavily in sales training. We found that firms face a training-agency dilemma when non-exclusive partners are trained. On the one hand, these partners need to train to be effective at selling for the firm. On the other hand, firms might help competitors by training non-exclusive partners, thereby hurting their own market position. The results show that training content (i.e., type of knowledge gained) and selection solutions can be used to solve the dilemma. 

Chapter 5

Conclusion 


\subsection{Introduction}

The overall aim of this dissertation is to examine effects of external parties' knowledge development on self-efficacy beliefs and performance. In this dissertation, we show that firms can be "earning-by-learning". That is, firms that commit to educating customers will reap benefits in terms of more repeat customers, customer profitability (when customers' investment profits increase), and higher sales. This chapter starts with a brief recap of the findings of the three studies, whereas the following sections focus on the discussion and conclusion, answering the research question posed in the introduction of this dissertation. Finally, we provide a set of recommendations for further research.

\subsection{Discussion}

Customers and business partners are increasingly actively involved in service production and sales processes. Consumers need to adapt to these new and demanding service roles in order to achieve satisfactory service performance. This dissertation focuses on knowledge development as key process to foster effective adaptation. Further, we attempt to identify mechanisms that facilitate this process.

First, we consider the role of self-efficacy during service production as this is a key requirement for effective role adjustment. The study focuses on identifying antecedents and consequences of customer self-efficacy. We show that information source evaluations, i.e., credibility and argument quality, instead of amount of search affect self-efficacy for novice consumers. In general, consumers use these evaluations selectively; for credibility consumers rely mainly on the third-party source to form self-efficacy, whereas for argument quality the firm source has the strongest effects. An interesting individual characteristic to consider in this context is consumers' role engagement, which is broader than just involvement and motivation, but also encompasses enjoyment, interest, and challenge. This characteristic not only affects self-efficacy directly, but also impacts the effect of source evaluations.

Additionally, self-efficacy is an important factor in the development and translation of customer knowledge into performance and various service evaluations. Especially the finding that self-efficacy increases usage intentions is important for firms, as this study focuses on novice consumers in particular. This implies that in order to lock-in customers and convert them to regular service users, building customers' self-efficacy is a key success factor firms should focus on. In short, when customers believe they are good at a service task, it enhances the likelihood of them being willing to do it again in the future.

Secondly, the dissertation focuses on consumers' reactions in terms of selfefficacy to multiple information sources. Although previous studies have looked at self-efficacy change during performance cycles, we test whether new 
information instead of performance can result in self-efficacy change or updating as well. In general, longitudinal studies using repeated measures assume that different individuals develop the same way over time (e.g., Bolton 1998; Kim and Malhotra 2005). We investigate empirically whether this is the case for selfefficacy updating during information search and find that it is not. Consumers actually respond differently to information in terms of self-efficacy change, for some an increase in their confidence concerning their ability occurs, while others decrease, and/ or do not change their beliefs at all. The underlying mechanisms explaining different change patterns are experience and effort. Relatively inexperienced consumers spend high task effort, increase self-efficacy, and reach high performance compared to the other groups. This is reflected in their level of intrinsic motivation. Experienced consumers either spend medium or low effort. The former group does not update self-efficacy and reaches relatively high performance, whereas the latter decreases self-efficacy and reaches low performance. Thus, inexperienced consumers can overcome their lack of experience with effort and do well in complex services. For firms this is important to know if they introduce new service formats. Not only educating, but also motivating customers is necessary to achieve good service performance.

Finally, we investigate training effectiveness in B2B settings. Firms frequently outsource their sales function to other companies. Because they rely on these sales partners firms invest heavily in sales training programs to foster customer knowledge development. However, although it is necessary to train partners, these partners might not apply training knowledge or even use it to sell for competitors. In this study we find evidence that non-exclusive partners, i.e., partners who sell various (competing) brands, apply less knowledge for the firm than exclusive partners. Several conditions can help solve this problem; individual, relational, firm, and cultural characteristics increase knowledge application for non-exclusive partners especially. These characteristics were selected, because they have been shown to increase commitment, motivation, and decrease opportunistic behavior. Specifically, we find that non-exclusive partners can be trusted to apply what they have learned when (1) training is idiosyncratic to the manufacturer; (2) the partner is involved in a long-term relationship with the manufacturer; (3) the partner is affiliated with a firm that has a strong professional affiliation; and (4) the partner operates in a collective/embedded national culture. In general, both selection and socialization approaches are effective for increasing the likelihood that firms will achieve sales returns on training investments. These findings are likely to help firms make strategic training investments in exclusive and nonexclusive partners as well as to identify nonexclusive partners to maximize training ROI.

\subsection{What Learning Was Earned?}

The results of these three empirical studies lead to one overall conclusion; the effect of knowledge development on performance differs across individuals. 
That is, for some individuals information search or training leads to high performance, whereas for others it does not. Consumer heterogeneity exists in effects of knowledge development due to a variety of factors. We distinguish several moderators across studies, which impact the knowledge development process. A relevant question is therefore what general mechanisms underlie the effectiveness of customer knowledge development, which is discussed next.

The overall research question proposed in the first chapter of this dissertation is as follows: What mechanisms account for the effectiveness of customer knowledge development for facilitating external parties' performance? After studying performance implications of information search and training, there is one mechanism that affects the impact of information or training in each of the three empirical studies. The underlying mechanism driving the effectiveness of knowledge for facilitating performance in the studies included in this dissertation seems to be motivation. Various motivational constructs positively impact the effect of knowledge development on different outcomes.

Engagement, which is concerned with effort, enthusiasm, and challenge, creates a stronger impact of credibility on self-efficacy, specifically third-party and peer credibility, which in turn increases performance and service evaluations. However, the impact of argument quality is decreased under high engagement, implying that highly engaged consumers are less influenced by the sources' content when forming self-efficacy. This seems counterintuitive given that argument quality has been conceptualized as a central cue, which should have stronger effects under high cognitive processing. However, novices, the focus of this study, lack the ability to evaluate argument quality and to process centrally (Chen and Chaiken 1999), so it makes sense to use argument quality less than credibility to form self-efficacy. Highly engaged consumers realize their lack of ability.

Next, we focus on the effect of reading new information in general on selfefficacy, irrespective of the source evaluations and order in which the sources were presented. Effort is an important explanatory factor why some consumers increase self-efficacy during information search and consequently achieve high performance, whereas others do not. Effort has been related to intrinsic motivation in the literature and is often used as a proxy for motivation. The findings show that the consumers who increase self-efficacy during search, resulting in highest self-efficacy and performance after viewing three information sources, are indeed higher intrinsically motivated than the other consumers.

Finally, a training problem associated with non-exclusive sales partners was delineated, as the study shows these partners are less likely to apply knowledge from training. Non-exclusive partners are in general more likely to behave opportunistically and less committed to the partnership. The conditions which alleviate this problem all evolve around increasing motivation to apply knowledge for nonexclusive partners in particular. Specifically, the conditions decrease the likelihood of opportunistic behavior and create higher partnership commitment. 
This dissertation attempts to contribute to knowledge on the effectiveness of motivational mechanisms. In a recent paper on motivation theory, Locke and Latham (2004) outline research directions to build theories of work motivation. These authors recommend two important directions for extending theory, namely understanding self-motivation and understanding the relationship between motivation and knowledge. The authors note that for a better understanding of the former new insights in self-efficacy building are critical. For the latter, research on how motivation governs knowledge utilization is one of the core issues. In this dissertation we aim to extend literature on self-efficacy formation and knowledge utilization in particular. In both processes the inclusion of motivation in the studies explains differential effects on performance across individuals.

\subsection{Directions for Future Research}

Specific suggestions for future research have been discussed at the end of each empirical study. However, we would like to point out some general directions for future research in the area of self-efficacy in coproduction services, and agency challenges in marketing partnerships.

In this dissertation we have investigated the relevance of self-efficacy in services. Although we find effects of self-efficacy on performance, we have not investigated long-term consequences of self-efficacy. It would be interesting to investigate long-term loyalty and revenue consequences of producing services with highly efficacious customers. This would extend current insights on the role of self-efficacy in services. In addition, a long-term perspective on the formation of self-efficacy could yield interesting insights. Here, we focus on one information search process and do not incorporate repeated service experiences. It is likely that effects of antecedents on self-efficacy change when consumers gain service experience. Specifically, we predict that the effects of source evaluations will decrease, whereas experience effects should be stronger.

Self-efficacy updating during information search gives rise to several research questions. These evolve around how best to communicate with each consumer segment and how to motivate the small group that does not spend effort and reaches low performance. Should online content be tailored to consumer experience, effort and self-efficacy? By measuring how much time consumers typically spend on reading information from the web site, content can be added or decreased. In addition, does it pay off to maintain a relationship with customers, who spend low effort and do not perform sufficiently to be satisfied with the service? Or might it be more prudent not to invest in educating this group?

Finally, we examine a training problem, which firms that collaborate with an external sales force face. Although we prove the existence of the dilemma and delineate mitigating conditions, several questions remain. A strategic decision firms should make is whether to make equal knowledge investments in all types of sales partners. Although we show that non-exclusive partners are generally 
less likely to utilize knowledge, certain types of non-exclusive partners do better than others. A related question would be whether customizing training content and incentives works best for specific partners; what is the best combination of training and rewards? Another interesting question is when to collaborate with non-exclusive versus exclusive partners. Although literature generally suggests that exclusive partners should be preferred because firms can control these partners better, other literature suggests that non-exclusive partners are better able to respond to changing demands and have stronger customer relationships. This strategic decision might depend on market conditions and product characteristics, which to our knowledge have not been investigated in marketing so far.

\subsection{A Final Thought}

Current marketing thought has put forward the notion that everything is service, including goods, which are described as bundles of services. As firms focus on providing service, knowledge becomes a crucial resource to build sustainable competitive advantage. Further, customers are becoming "partial employees" by being actively involved in service production. This dissertation attempts to contribute to the marketing literature by investigating the actual effect of knowledge on performance of these partial B2C and B2B employees. Our findings provide guidelines to firms and customers, who are starting to explore new service and partnering formats. Overall, educating customers really does pay off for firms. In turn, customers who are motivated to learn will do well. The general take-away is that it is imperative that both firms and customers put in sufficient effort to make these types of services and sales processes successful. 


\section{ApPEndix A}

\section{Screen Prints, Chapter 2 and Chapter 3}

\section{FIGURE A1 Firm Source Homepage}

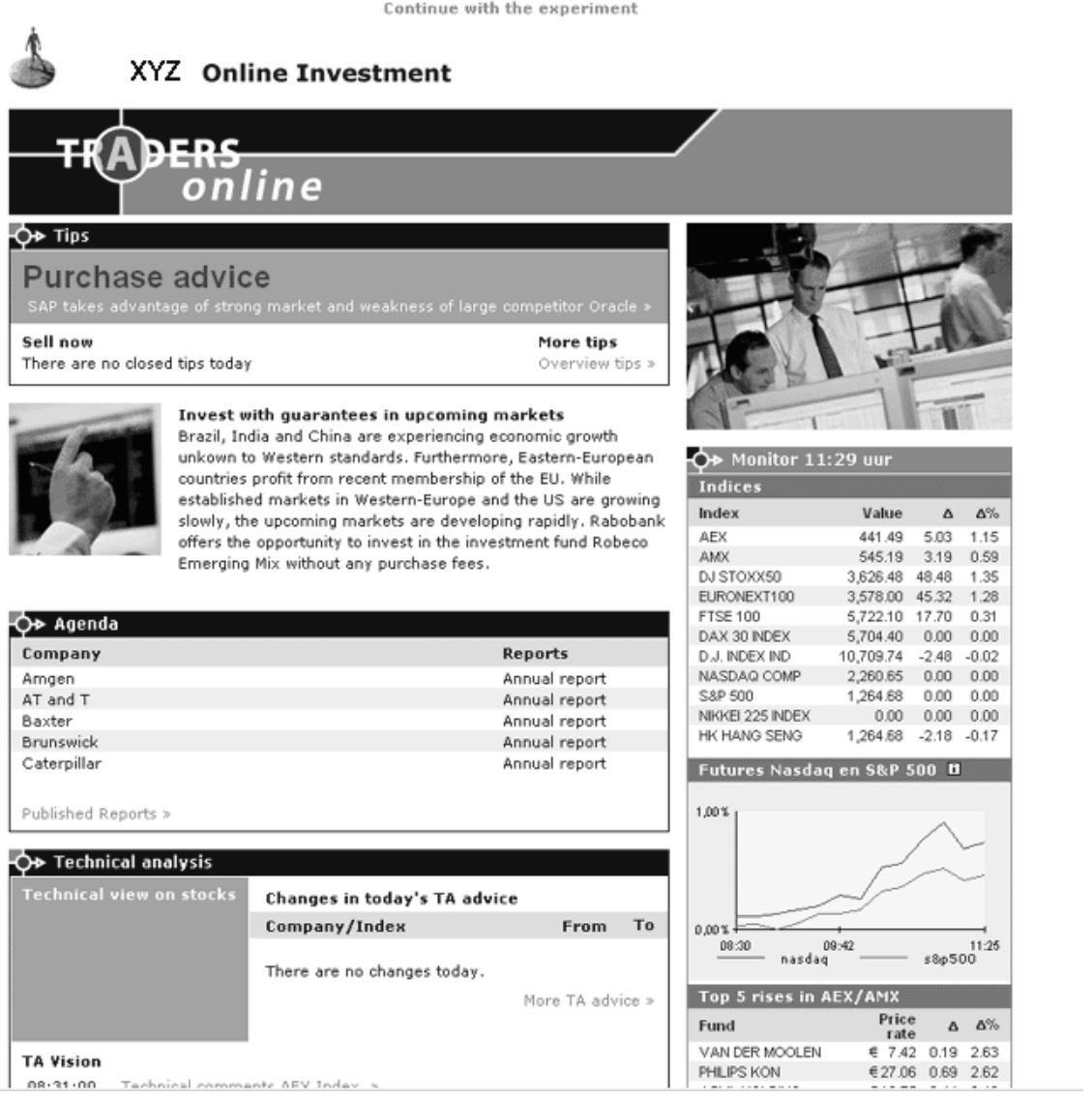


FIGURE A2 Third-Party Source Homepage

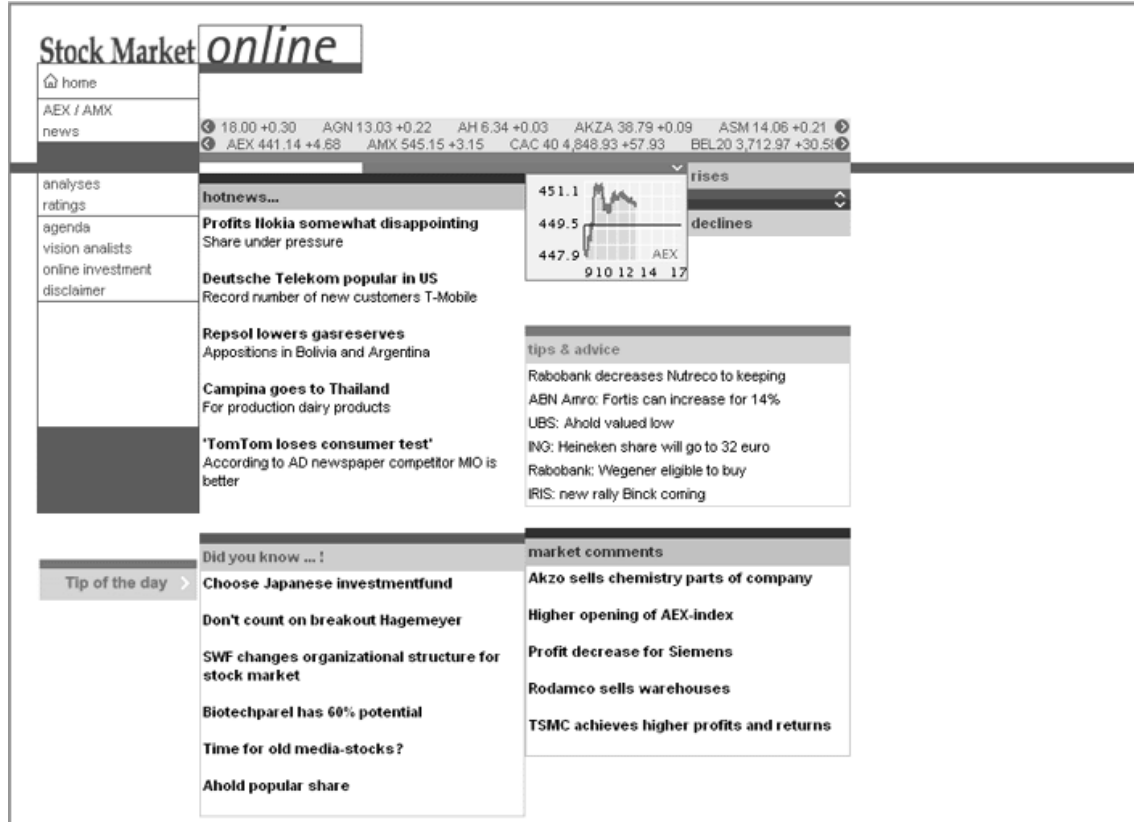


FIGURE A3 Peer Source Homepage

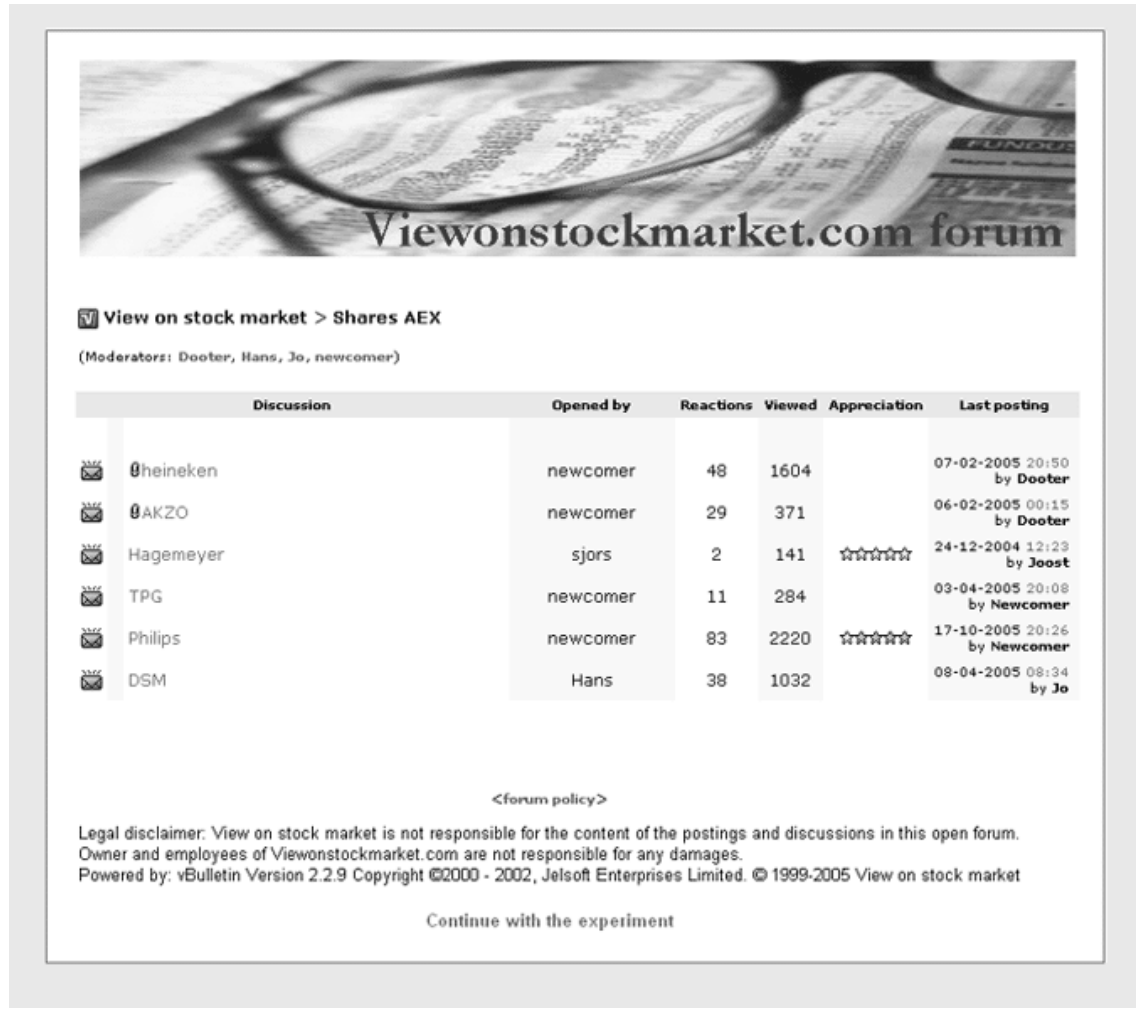




\section{APPENDIX B}

\section{Operationalizations, Chapter 2}

TABLE B1 Measures and Items

\begin{tabular}{|c|c|c|}
\hline Measures and Items (CR; AVE) & $\begin{array}{l}\text { Standardized } \\
\text { Loadings } \\
\text { F T P }\end{array}$ & Source \\
\hline Credibility & & Newell and \\
\hline $\begin{array}{l}(\mathrm{CR}=.94 ; \mathrm{AVE}=.63)(\mathrm{CR}=.95 ; \mathrm{AVE}= \\
.64)(\mathrm{CR}=.95 ; \mathrm{AVE}=.65)\end{array}$ & & $\begin{array}{l}\text { Goldsmith } \\
(2001)\end{array}$ \\
\hline $\begin{array}{l}\text { XYZ has a great amount of experience in } \\
\text { stock trading. }\end{array}$ & .81 .78 .80 & \\
\hline $\mathrm{XYZ}$ is skilled in stock trading. & .79 .81 .84 & \\
\hline$X Y Z$ has great expertise in stock trading. & .84 .84 .84 & \\
\hline$X Y Z$ has much experience in stock trading. & .77 .78 .78 & \\
\hline $\begin{array}{l}\mathrm{XYZ} \text { is a good repository of knowledge } \\
\text { about stock trading. }\end{array}$ & .83 .81 .85 & \\
\hline I trust $X Y Z$ in matters of stock trading. & .78 .82 .81 & \\
\hline $\begin{array}{l}\text { XYZ makes truthful claims about stock } \\
\text { trading. }\end{array}$ & .70 .74 .73 & \\
\hline$X Y Z$ is honest about stock trading. & .76 .77 .77 & \\
\hline $\begin{array}{l}\text { I believe what } X Y Z \text { tells me about stock } \\
\text { trading. }\end{array}$ & .78 .79 .77 & \\
\hline $\begin{array}{l}\mathrm{XYZ} \text { is a trustworthy source about stock } \\
\text { trading. }\end{array}$ & .85 .84 .84 & \\
\hline Argument Quality & & Bailey and \\
\hline $\begin{array}{l}(\mathrm{CR}=82 ; \mathrm{AVE}=.61)(\mathrm{CR}=.85 ; \mathrm{AVE}= \\
.65)(\mathrm{CR}=.84 ; \mathrm{AVE}=.63)\end{array}$ & & $\begin{array}{l}\text { Pearson } \\
(1983)\end{array}$ \\
\hline \multicolumn{3}{|l|}{$\begin{array}{l}\text { Please rate the content of the } X Y Z \text { Web } \\
\text { site on the following scales, as in: "The } \\
\text { information from this source is . ." }\end{array}$} \\
\hline Incomplete - Complete & .68 .73 .75 & \\
\hline Inconsistent - Consistent & .84 .82 .78 & \\
\hline Inaccurate - Accurate & .82 .85 .85 & \\
\hline $\begin{array}{l}\text { Self-Efficacy } \\
(\mathrm{CR}=.92 ; \mathrm{AVE}=.67)(\mathrm{CR}=.92 ; \mathrm{AVE}= \\
.66)(\mathrm{CR}=.93 ; \mathrm{AVE}=.68)\end{array}$ & & $\begin{array}{l}\text { Adapted } \\
\text { from Web- } \\
\text { ster and }\end{array}$ \\
\hline After reading information from $X Y Z$, please & & Martocchio \\
\hline
\end{tabular}


state your expectations right now about the

$A B C$ service.

I believe that purchasing stocks via $A B C$

.87 .86 .85

Investment is a task on which I can perform well.

I believe it is possible for me to use $A B C$

.85 .84 .88

Investment at the level I would like.

I can master trading stocks via $A B C$ In-

vestment.

I believe I can trade stocks via ABC In-

.78 .76 .77

.84 .85 .85

vestment as well as I would like.

I am certain I can trade stocks via ABC

.86 .8486

Investment well.

I think my performance in trading stocks via

.69 .72 .72

$A B C$ Investment is optimal.

Perceived Financial Performance

Singh

(1 - 7, Very Low - Very High)

(1993)

$(\mathrm{CR}=.87 ; \mathrm{AVE}=.70)$

How would you rate yourself in terms of

.89

what you have achieved in the stock trad-

ing task (i.e., purchasing stocks)?

How do you rate yourself in terms of your

reached goals while doing the stock trading

task?

How would you estimate your performance

relative to other respondents doing the

stock trading task?

Perceived Value

(1 - 7, Very Low - Very High)

Harris and

Goode

$(\mathrm{CR}=.84 ; \mathrm{AVE}=.73)$

(2004)

Overall, the value of $A B C$ Investment

service to me is ...

Compared to what I had to give up, the

overall ability of $A B C$ Investment to satisfy

my wants and needs is ... 
Usage Intentions

$(\mathrm{CR}=.97 ; \mathrm{AVE}=.90)$
Agarwal and Karahanna (2000)

If it would be possible, I plan to use a similar service from my bank in the future. If it would be possible, I intend to start using a similar service from my bank in the future.

If it would be possible, I expect my use of a similar service from my bank to start in the future.

\section{Role Engagement}

(1 - 7, Not At All - To A Large Degree) $(\mathrm{CR}=.84 ; \mathrm{AVE}=.54)$

Based on Kahn (1990) and Salanova, Agut, and Peiro (2005)

To what degree do you think the task was interesting?

To what extent do you feel the task was challenging?

How satisfying was working with the task

itself?

How much did you enjoy working on this task?

I exerted a lot of energy when executing this task.

(1 - 7, Strongly Disagree - Strongly Agree)

Online Experience

(No - Yes, for. . . . years)
Adapted

from

Balasubramanian, Konana, and Menon (2003)

Have you ever traded stocks online before? 
Offline Experience (No - Yes, for. . . . years)

Have you ever traded stocks offline before?

\section{Information Search}

Amount of search was measured by recording the number of seconds respondents spent on each web site.

Note. ${ }^{\text {a }}$ Standardized loadings relate to the firm, third-party, and peer source when applicable, where $F$ corresponds with firm, $T$ with third-party, and $P$ with peer source. 7-point Likert scales ranging from "Strongly Disagree" to "Strongly Agree" were used unless indicated otherwise.
Adapted

from

Balasubramanian, et al. (2003) 


\section{APPENDIX C}

\section{Operationalizations, Chapter 3}

\section{TABLE C1 Measures and Items}

Measures and Items
Self-Efficacy
$(\alpha=.90)(\alpha=.93)(\alpha=.94)(\alpha=.94)$
After reading information from $X Y Z$, please state
your expectations right now about the ABC service.
I believe that purchasing stocks via $X Y Z$ Investment
is a task on which I can perform well.
I believe it is possible for me to use XYZ Investment
at the level I would like.
I can master trading stocks via $X Y Z$ Investment.
I believe I can trade stocks via XYZ Investment as
well as I would like.
I am certain I can trade stocks via XYZ Investment
well.
I think my performance in trading stocks via $X Y Z$
Investment is optimal.

\section{Online Experience}

(No - Yes, for. . . . years)

Have you ever traded stocks online before?

Effort

$(\alpha=.87)$

I exerted a lot of energy when executing this task.

I did not spend much time when executing this task.

(R)

I did not try very hard during this task. (R)

I put a lot of effort into this situation.

\section{Performance}

We employ the investment profits two months after the investment decision was made and correct it for the overall market development.
Adapted from Webster

and Martocchio (1992)
Adapted from Balasubramanian, Konana, and

Menon (2003)

Mohr and Bitner (1995) 


\section{Credibility}

$(\alpha=.95)(\alpha=.95)(\alpha=.95)$

Source $X$ has a great amount of experience in stock trading.

Source $X$ is skilled in stock trading.

Source $X$ has great expertise in stock trading.

Source $X$ has much experience in stock trading.

Source $X$ is a good repository of knowledge about stock trading.

I trust source $X$ in matters of stock trading.

Source $X$ makes truthful claims about stock trading.

Source $X$ is honest about stock trading.

I believe what source $X$ tells me about stock trading.

Source $X$ is a trustworthy source about stock trading.

\section{Time Spent}

We record in seconds how much time respondents spend on the web sites.

\section{Pages Read}

We also record the number of pages respondents read during search.

\section{Intrinsic Motivation}

(1 - 7, Not At All - To A Large Degree)

$(\alpha=.86)$

To what degree do you think the task was interesting?

To what extent do you feel the task was challenging?

How satisfying was working with the task itself?

How much did you enjoy working on this task?

\section{Source Quality}

(1 - 7, Very Bad - Excellent)

Please rate the content of the $X Y Z$ Web site on the following scale, as in: "The information from this source is ..."

Very Bad - Excellent

Note. $\mathrm{R}=$ reverse coded. 7-point Likert scales ranging from "Strongly Disagree" to "Strongly Agree" were used unless indicated otherwise.
Newell and Goldsmith

(2001)
Debowski, Wood, and

Bandura (2001) 


\section{APPENDIX D}

\section{Instructions, Chapter 3}

\section{Please read the following situation carefully:}

Imagine that you plan to invest 1500 Euros and you have decided to invest this in shares by using [BANK SERVICE]. Therefore, your task consists of purchasing stocks online via [BANK SERVICE].

[BANK SERVICE] consists of a web site where you can trade stocks yourself. On the web site you can view information about the stock market, investment funds and a demo showing how to purchase stocks via the web site. You can also take a look at selected funds and fill out your personal goal-risk profile to get personalized advice. You can always look at the help page or call the help desk during working hours. Since you have to decide where to invest your money in, you want to have more information about shares you can invest your money in. For simplicity, we only take the Dutch AEX stock index into account. You will find information about shares from 3 information sources later in this experiment. 


\section{APPENDIX E}

\section{Operationalizations, Chapter 4}

\section{TABLE E1 Measures and Items}

Measures and Items

Partner Sales Performance Increase (new scale)

(1 - 7, Decreased a lot - Increased a lot)

$(\mathrm{CR}=.99, \mathrm{AVE}=.96)$

Compared to before (firm) training:

Sales of $X Y Z$ products made to new customers after the $X Y Z$ training.

All other sales of $X Y Z$ products completed after the $X Y Z$ training.

Sales of $X Y Z$ services after the $X Y Z$ training.

\section{Actual Change in Sales Performance}

We employ the amount sold in US Dollars by each respondent in a particular month ranging from December 2006 to November 2007 using list prices set by the manufacturer.

\section{Partner Training}

Total number of pages read by respondents during training.

\section{Partner Non-Exclusivity}

$(0=$ Yes, 1 = No $)$

Do you only sell (firm) products?

\section{Learning Goal Orientation}

(Sujan et al. 1994) $(\mathrm{CR}=.98, \mathrm{AVE}=.91)$

It is worth spending a lot of time learning new approaches for dealing with customers.

An important part of being a good salesperson is continually improving your sales skills.

It is important for me to learn from each selling experience I have.

\section{Firm Professionalism}

( 0 = Not Professional, $1=$ Professional $)$

We employing the company classification provided by the manufacturer, consultants and business partners are coded as professionals, whereas other partners (i.e., resellers, distributors, software vendors and integrators) are not. 


\section{Collectivism/Embeddedness}

(Hofstede 2001; Licht, Goldschmidt, and Schwartz 2007)

We employ a combination of country ratings for embeddedness (Schwartz) and individualism (Hofstede) provided in these sources.

\section{Firm-Specific Training Knowledge Gains}

(Flynn and Goldsmith 1999; Rapp et al. 2006) (CR = .99 AVE = .95)

As a result of the $X Y Z$ training:

I know more about the $X Y Z$ partnership program compared to most other sales representatives. (partnership knowledge)

I feel very knowledgeable about $X Y Z$ products, services and solutions. (product knowledge)

I am one of the experts on XYZ products, services and solutions in my own company. (product knowledge)

I know more about $\mathrm{XYZ}$ products, services and solutions compared to most other sales representatives. (product knowledge)

I really know a lot when it comes to specifications and applications of $X Y Z$ products, services and solutions. (product knowledge)

\section{General Training Knowledge Gains}

(Luo, Slotegraaf, and Pan 2006; Norman 2004; Rapp et al. 2006) (CR = .98,

AVE $=.93$ )

As a result of the $X Y Z$ training:

I can keep abreast of the marketing strategies of our competitors. (market knowledge)

I have improved brand image building skills. (how-to-sell knowledge)

I am better at making sense of customers' current and potential needs. (how-tosell knowledge)

I communicate effectively with my customers. (how-to-sell knowledge)

\section{Market Turbulence}

(Joshi and Sharma 2004) (CR = .97, AVE = .91)

Customers' preferences for product features have changed quite a bit over time. We are witnessing demand for our products from customers who never bought them before.

New customers tend to have product-related needs that are different from those of our existing customers.

\section{Sales Experience}

(Rapp et al. 2006) ( $0-1$ years, $2-4$ years, $5-7$ years, More than 7 years) I have been working in sales for ... 


\section{Business Experience}

(Rapp et al. 2006) ( $0-1$ years, $2-4$ years, $5-7$ years, More than 7 years) I have been working in business for ...

\section{Perceived Dependence}

(Kumar, Scheer, and Steenkamp 1995) (CR = .98, AVE = .95)

It would be difficult for us to find other suppliers who could provide us with products of comparable quality.

Our total costs of switching to a competing manufacturer's line would be prohibitive.

It would be difficult for our firm to replace the sales and profits generated from this supplier's line.

\section{Partnership Program Length}

( $0-1$ years, $2-4$ years, $5-7$ years, More than 7 years) How long have you been a member of the relationship program?

Note. ${ }^{*}$ indicates the item was dropped because of high modification indices in the confirmatory factor analysis. 7-point Likert scales ranging from "Strongly Disagree" to "Strongly Agree" were used unless indicated otherwise. 


\section{REFERENCES}

A

Agarwal, Ritu and Elena Karahanna (2000), "Time Flies When You're Having Fun: Cognitive Absorption and Beliefs About Information Technology Usage," MIS Quarterly, 24 (December), 665-94

Ahearne, Michael, John Mathieu and Adam Rapp (2005), "To Empower or Not to Empower Your Sales Force? An Empirical Examination of the Influence of Leadership Empowerment Behavior on Customer Satisfaction and Performance," Journal of Applied Psychology, 90 (September), 945-55.

Alba, Joseph W. and Lynn Hasher (1983), "Is Memory Schematic?," Psychological Bulletin, 93 (March), 203-31.

---- and J. Wesley Hutchinson (1987), "Dimensions of Consumer Expertise," Journal of Consumer Research, 13 (March), 411-53.

---- and ---- (2000), "Knowledge Calibration: What Consumers Know and What They Think They Know," Journal of Consumer Research, 27 (September), 123-56.

Anderson, Erin (1985), "The Salesperson as outside Agent or Employee: A Transaction Cost Analysis," Marketing Science, 4 (Summer), 234-54.

---- and Barton Weitz (1992), "The Use of Pledges to Build and Sustain Commitment in Distribution Channels," Journal of Marketing Research, 29 (February), 18-34.

Anderson, James C., Håkan Håkansson, and Jan Johansson (1994), "Dyadic Business Relationships Within a Business Network Context," Journal of Marketing, 58 (October), 1-15.

Armstrong, J. Scott and Terry S. Overton (1977), "Estimating Nonresponse Bias in Mail Surveys," Journal of Marketing Research, 14 (August), 396-402.

Arrow, Kenneth J. 1985. The economics of agency. In J. W. Pratt and R. J. Zeckhauser (eds.), Principals and agents: The structure of business. Boston: Harvard Business School Press.

Ashforth, Blake E. and Alan M. Saks (1996), "Socialization Tactics: Longitudinal Effects on Newcomer Adjustment," Academy of Management Journal, 39 (February), 149-78.

Axtell, Carolyn M., Sally Maitlis, and Shawn K. Yearta (1997), "Predicting immediate and longerterm transfer of training," Personnel Review, 26 (3), 201-13

B

Bailey, James E. and Sammy W. Pearson (1983), "Development of a Tool for Measuring and Analyzing Computer User Satisfaction," Management Science, 29 (May), 530-45.

Balasubramanian, Sridhar, Prabhudev Konana and Nirup M. Menon (2003), "Customer Satisfaction in Virtual Environments: A Study of Online Investing," Management Science, 49 (July), 871-89.

Bandura, Albert (1997), Self-efficacy. The Exercise of Control. New York: W. H. Freeman and Company.

---- and Daniel Cervone (1986), "Differential Engagement of Self-Reactive Influences in Cognitive Motivation," Organizational Behavior and Human Decision Processes, 38 (August), 92113.

---- and Forest J. Jourden (1991), "Self-Regulatory Mechanisms Governing the Impact of Social Comparison on Complex Decision Making," Journal of Personality and Social Psychology, 60 (June), 941-51.

---- and Edwin A. Locke (2003), "Negative Self-Efficacy and Goal Effects Revisited," Journal of Applied Psychology, 88 (February), 87-99. 
Bank of America (2007), "Self-Directed Investing," (accessed November 15, 2007), [available at http://www.bankofamerica.com/hub/index.cfm?template= wealthmanagement].

Barber, Brad M. and Terrance Odean (2002), "Online Investors: Do the Slow Die First?" The Review of Financial Studies, 15 (2), 455-87.

Baron, Reuben M. and David A. Kenny (1986), "The moderator-mediator variable distinction in social psychological research: Conceptual, strategic, and statistical considerations," Journal of Personality and Social Psychology, 51 (December), 1173-82.

Basu, Amiya K., Rajiv Lal, V. Srinivasan, and Richard Staelin (1985), "Salesforce Compensation Plans: An Agency Theoretic Perspective," Marketing Science, 4 (Fall), 267-91.

Bauer, Talya N., Todd Bodner, Berrin Erdogan, Donald M. Truxillo and Jennifer S. Tucker (2007), "Newcomer adjustment during organizational socialization: A meta-analytic review of antecedents, outcomes, and methods," Journal of Applied Psychology, 92 (May), 70721.

Beatty, Sharon E. and Scott M. Smith (1987), "External Search Effort: An Investigation Across Several Product Categories," Journal of Consumer Research, 14 (June), 83-95.

Bendapudi, Neeli and Robert P. Leone (2003), "Psychological Implications of Customer Participation in Co-Production," Journal of Marketing, 67 (January), 14-28.

Bensaou, M., and Erin Anderson (1999), "Buyer-Supplier Relations in Industrial Markets: When Do Buyers Risk Making Idiosyncratic Investments?" Organization Science, 10 (July/August) 460-81.

Bentler, Peter M. and Ke-Hai Yuan (1999), "Structural Equation Modeling with Small Samples: Test Statistics," Multivariate Behavioral Research, 34 (2), 181-97.

Bergen, Mark, Shantanu Dutta, and Orville C. Walker, Jr. (1992), "Agency Relationships in Marketing: A Review of the Implications and Applications of Agency and Related Theories," Journal of Marketing, 56 (July), 1-24.

Bernheim, B. Douglas and Michael D. Whinston (1985), "Common marketing agency as a device for facilitating collusion," Rand Journal of Economics, 16 (Summer), 269-81.

Bettencourt, Lance A., Amy L. Ostrom, Stephen W. Brown, and Robert I. Roundtree (2002), "Client Co-Production in Knowledge-Intensive Business Services," California Management Review, 44 (Summer), 100-28.

Bickart, Barbara and Robert M. Schindler (2001), "Internet Forums as Influential Sources of Consumer Information," Journal of Interactive Marketing, 15 (Summer), 31-40.

Bitner, Mary Jo, William T. Faranda, Amy R. Hubbert, and Valarie A. Zeithaml (1997), "Customer contributions and roles in service delivery," International Journal of Service Industry Management, 8 (3), 193-205.

Biyalogorsky, Eyal, William Boulding, and Richard Staelin (2006), "Stuck in the Past: Why Managers Persist with New Product Failures," Journal of Marketing, 70 (April), 108-21.

Bliese, Paul D. and Robert E. Ployhart (2002), "Growth Modeling Using Random Coefficient Models: Model Building, Testing, and Illustrations," Organizational Research Methods, 5 (October), 362-87.

Bobbitt, L. Michelle and Pratibha A. Dabholkar (2001), "Integrating Attitudinal Theories to Understand and Predict Use of Techonology-Based Self-Service," International Journal of Service Industry Management, 12 (5), 423-50.

Bollen, Kenneth A. (1989), Structural Equations with Latent Variables. New York: John Wiley \& Sons.

Bolton, Ruth N. (1998), "A Dynamic Model of the Duration of the Customer's Relationship with a Continuous Service Provider: The Role of Satisfaction," Marketing Science, 17 (1), 45-65.

Boyle, David, Sherry Clarke and Sarah Burns (2006), "Aspects of Co-production: The implications for work, health, and volunteering," (accessed November 15, 2007), [available at http://www.neweconomics.org/gen/uploads/sc3fcz45lpnoi055rdrini3n22022007122759.pdf] 
Boyt, Thomas E., Robert F. Lusch, and Gillian Naylor (2001), "The Role of Professionalism in Determining Job Satisfaction in Professional Services," Journal of Service Research, 3 (May), 321-30.

Brown, James R., Chekitan S. Dev, Dong-Jin Lee (2000), "Managing Marketing Channel Opportunism: The Efficacy of Alternative Governance Mechanisms," Journal of Marketing, 64 (April), 51-65.

Brown, Steven P., Eli Jones and Thomas W. Leigh (2005), "The Attenuating Effect of Role Overload on Relationships Linking Self-Efficacy and Goal Level to Work Performance," Journal of Applied Psychology, 90 (September), 972-79.

BusinessWeek (2007), "Social Networking Hits Investing," (accessed November 15, 2007), [available at http://www.businessweek.com/investor/content/aug2007/pi20070820_780840.htm?campai gn_id=rss_null].

Byrne, Barbara M., Richard J. Shavelson, and Bengt Muthén (1989), "Testing for the equivalence of Factor Covariance and Mean Structures: The Issue of Partial Measurement In-

C variance," Psychological Bulletin, 105 (May), 456-66.

Celly, Kirti Sawhney and Gary L. Frazier (1996), "Outcome-Based and Behavior-Based Coordination Efforts in Channel Relationships," Journal of Marketing Research, 33 (May), 200-10.

Celsi, Richard L. and Jerry C. Olson (1988), "The Role of Involvement in Attention and Comprehension Processes," Journal of Consumer Research, 15 (September), 210-24.

Cervone, Daniel and Barton W. Palmer (1990), "Anchoring Biases and the Perseverance of Self-Efficacy Beliefs," Cognitive Therapy and Research, 14 (August), 401-16.

Chen, Serena and Shelly Chaiken (1999), "The Heuristic-Systematic Model in Its Broader Context," in Dual-Process Theories in Social Psychology, S. Chaiken and Y. Trope, eds. New York: The Guilford Press, 73-96.

Chen, Gilad, Stanley M. Gully, Jon-Andrew Whiteman, and Robert N. Kilcullen (2000), "Examination of Relationships Among Trait-Like Individual Differences, State-Like Individual Differences, and Learning Performance," Journal of Applied Psychology, 85 (December), 835-47.

Cheung, Mike W.-L. (2007), "Comparison of Methods of Handling Missing Time-Invariant Covariates in Latent Growth Models Under the Assumption of Missing Completely at Random," Organizational Research Methods, 10 (October), 609-34.

Chiou, Wen-Bin and Chin-Sheng Wan (2007), "The Dynamic Change of Self-Efficacy in Information Searching on the Internet: Influence of Valence of Experience and Prior SelfEfficacy," The Journal of Psychology, 141 (November), 589-603.

Compeau, Deborah R. and Christopher A. Higgins (1995), "Computer self-efficacy: Development of a measure and initial test," MIS Quarterly, 19 (June), 189-211.

Corfman, Kim P. (1991), "Perceptions of Relative Influence: Formation and Measurement," Journal of Marketing Research, 28 (May), 125-36.

D

Dabholkar, Pratibha A. (1994), "Incorporating Choice into an Attitudinal Framework: Analyzing Models of Mental Comparison Processes," Journal of Consumer Research, 21 (June), 100-18.

---- (1996), "Consumer Evaluations of New Technology-Based Self-Service Options: An Investigation of Alternative Models of Service Quality," International Journal of Research in Marketing, 13, 29-51. 
----, L. Michelle Bobbitt, and Eun-Ju Lee (2003), "Understanding Consumer Motivation and Behavior Related to Self-Scanning in Retailing," International Journal of Service Industry Management, 14 (1), 59-95.

---- and Richard P. Bagozzi (2002), "An Attitudinal Model of Technology-Based Self-Service: Moderating Effects of Consumer Traits and Situational Factors," Journal of the Academy of Marketing Science, 30 (Summer), 184-201.

Darley, William K. (1999), "The Relationship of Antecedents of Search and Self-Esteem to Adolescent Search Effort and Perceived Product Knowledge," Psychology and Marketing, 16 (August), 409-27.

Davis, James H., F. David Schoorman, and Lex Donaldson (1997), "Toward A Stewardship Theory of Management," Academy of Management Review, 22 (1), 20-47.

DeCarlo, Lawrence T. (1997), "On the Meaning and Use of Kurtosis," Psychological Methods, 2 (3), 292-307.

Deshpandé, Rohit and Gerald Zaltman (1982), "Factors Affecting the Use of Market Research Information: A Path Analysis," Journal of Marketing Research, 19 (February), 14-31.

Dweck, Carol S. and Ellen L. Leggett (1988), "A Social-Cognitive Approach to Motivation and Personality," Psychological Review, 95 (2), 256-73.

Dyer, Jeffrey H. and Nile W. Hatch (2006), "Relation-Specific Capabilities and Barriers to Knowledge Transfers: Creating Advantage through Network Relationships," Strategic Management Journal, 27 (8), 701-19.

----, Prashant Kale, and Harbir Singh (2001), "How To Make Strategic Alliances Work," MIT Sloan Management Review, 42 (Summer), 37-43.

E

Enders, Craig K. (2001), "The Performance of the Full Information Maximum Likelihood Estimator in Multiple Regression Models with Missing Data," Educational and Psychological Measurement, 61 (October), 713-40.

---- (2004), "The Impact of Missing Data on Sample Reliability Estimates: Implications for Reliability Reporting Practices," Educational and Psychological Measurement, 64 (June), 419-36.

Eisenhardt, Kathleen (1989), "Building Theories from Case Study Research," Academy of Management Review, 14 (4), 532-50.

Erez, Miriam and Anit Somech (1996), "Is Group Productivity Loss the Rule or the Exception? Effects of Culture and Group-Based Motivation," Academy of Management Journal, 39 (December), 1513-37.

ES Research Group (2008), "2008 Sales Training Vendor Guide," http://www.esresearch.com/e/home/document.php?dA=Sales_Training_Vendor_Guide_20 08 (Accessed June 2008).

Eyring, James D., Debra Steele Johnson, and David J. Francis (1993), "A Cross-Level Units-ofAnalysis Approach to Individual Differences in Skill Acquisition," Journal of Applied Psychology, 78 (October), 805-14.

$\mathbf{F}$

Feldman, Daniel Charles (1976), "A Contingency Theory of Socialization," Administrative Science Quarterly, 21 (September), 433-52.

Flynn, Leisa Reinecke and Ronald E. Goldsmith (1999), "A Short, Reliable Measure of Subjective Knowledge," Journal of Business Research, 46, 57-66.

Ford, Kevin J., Eleanor M. Smith, Daniel A. Weissbein, Stanley M. Gully, and Eduardo Salas (1998), "Relationships of Goal Orientation, Metacognitive Activity, and Practice Strategies with Learning Outcomes and Transfer," Journal of Applied Psychology, 83 (2), 218-33. 
Fornell, Claes and David F. Larcker (1981), "Evaluating Structural Equation Models with Unobservable Variables and Measurement Error," Journal of Marketing Research, 18 (February), 39-50.

Forrester Research (2002), "E-Learning Plays a Key Role in Effective Customer Service Agent Training", (Accessed September 2008) [Available at http://www.forrester.com/Research/LegacylT/Excerpt/ $0,7208,27594,00 . \mathrm{html}]$.

Freidson, Eliot (1984), "The Changing Nature of Professional Control," Annual Review of Sociology, 10 (August), 1-20.

Furse, David H., Girish N. Punj, and David W. Stewart (1984), "A Typology of Individual Search Strategies Among Purchasers of New Automobiles," Journal of Consumer Research, 10 (March), 417-31.

G

Galunic, D. Charles and Erin Anderson (2000), "From Security to Mobility: Generalized Investments in Human Capital and Agent Commitment," Organization Science, 11 (January/February), 1-20.

Gist, Marilyn E. (1987), "Self-Efficacy: Implications for Organizational Behavior and Human Resource Management," Academy of Management Review, 12 (July), 472-85.

---- and Terence B. Mitchell (1992), "Self-Efficacy: A Theoretical Analysis of its Determinants and Malleability," Academy of Management Review, 17 (April), 183-211.

----, Catherine Schwoerer, and Benson Rosen (1989), "Effects of Alternative Training Methods on Self-Efficacy and Performance in Computer Software Training," Journal of Applied Psychology, 74 (December), 884-91.

Glazer, Rashi (1991), "Marketing in an Information-Intensive Environment: Strategic Implications of Knowledge as an Asset," Journal of Marketing, 55 (October), 1-19.

Goodwin, Cathy (1988), "'I Can Do It Myself:' Training the Service Consumer to Contribute to Service Productivity," Journal of Services Marketing, 2 (Fall), 71-8.

Guthrie, James P. and Catherine E. Schwoerer (1994), "Individual and Contextual Influences on Self-Assessed Training Needs," Journal of Organizational Behavior, 15 (September), 40522.

$\mathbf{H}$

Hall, Richard H. (1968), "Professionalization and Bureaucratization," American Sociological Review, 33 (1), 92-104.

Harris, Lloyd C. and Mark M. H. Goode (2004), "The four levels of loyalty and the pivotal role of trust: a study of online service dynamics," Journal of Retailing, 80 (Summer), 139-58.

Hartline, Michael D. and O. C. Ferrell (1996), "The Management of Customer-Contact Service Employees: An Empirical Investigation," Journal of Marketing, 60 (October), 52-70.

Hawkins, Scott A. and Stephen J. Hoch (1992), "Low-Involvement Learning: Memory without Evaluation," Journal of Consumer Research, 19 (September), 212-25.

Heckman, James J. (1979), "Sample Selection Bias as a Specification Error," Econometrica, 47 (January), 153-62.

----, Hidehiko Ichimura, Jeffrey Smith, and Petra Todd (1998), "Characterizing Selection Bias Using Experimental Data," Econometrica, 66 (September), 1017-98.

Hedeker, Donald and Robert D. Gibbons (2006), Longitudinal Data Analysis. Hoboken, NJ: John Wiley and Sons.

Heide, Jan B. (1994), "Interorganizational Governance in Marketing Channels," Journal of Marketing, 58 (January), 71-85.

---- and George John (1988), "The Role of Dependence Balancing in Safeguarding TransactionSpecific Assets in Conventional Channels," Journal of Marketing, 52 (January), 20-35. 
---- and ---- (1990), "Alliances in Industrial Purchasing: The Determinants of Joint Action in Buyer-Supplier Relationships," Journal of Marketing Research, 27 (February), 24-36.

--- and Kenneth H. Wathne (2006), "Friends, Businesspeople, and Relationship Roles: A Conceptual Framework and a Research Agenda," Journal of Marketing, 70 (July), 90-103.

----, ----, and Aksel I. Rokkan (2007), "Interfirm Monitoring, Social Contracts, and Relationship Outcomes," Journal of Marketing Research, 44 (August), 425-33.

Hill, Thomas, Nancy D. Smith and Millard F. Mann (1987), "Role of Efficacy Expectations in Predicting the Decision to Use Advanced Technologies: The Case of Computers," Journal of Applied Psychology, 72 (May), 307-13.

Hoch Stephen J. (1984), "Hypothesis Testing and Consumer Behavior: "If It Works, Don't Mess With It," Advances in Consumer Research, 11 (1), 478-83.

---- and John Deighton (1989), "Managing What Consumers Learn from Experience," Journal of Marketing, 53 (April), 1-20.

Hofstede, Geert (2001), Culture's Consequences. Comparing Values, Behaviors, Institutions, and Organizations Across Nations ( $2^{\text {nd }}$ ed.), Thousand Oaks: Sage Publications.

Hogarth, Robin M. and Hillel J. Einhorn (1992), "Order effects in belief updating: The beliefadjustment model," Cognitive Psychology, 24 (January), 1-55.

I

Investment Company Institute (2007), "Trends in Ownership of Mutual Funds in the United States, 2007," Research Fundamentals, 16 (November), 1-12.

Jacoby, Jacob (1984), "Comments: Perspectives on Information Overload," Journal of Consumer Research, 10 (March), 432-35.

---- and J. Edward Russo (1984), "Product Familiarity and Learning New Information ," Journal of Consumer Research, 11 (June), 542-50.

Jap, Sandy D. and Erin Anderson (2003), "Safeguarding Interorganizational Performance and Continuity Under Ex Post Opportunism," Management Science, 49 (December), 16841701.

---- and Shankar Ganesan (2000), "Control Mechanisms and the Relationship Life Cycle: Implications for Safeguarding Specific Investments and Developing Commitment," Journal of Marketing Research, 37 (May), 227-45.

Jaworski, Bernard J. and Ajay K. Kohli (1993), "Market Orientation: Antecedents and Consequences," Journal of Marketing, 57 (July), 53-70.

J.D. Power (2006), "Online Trading Investor Satisfaction Survey," (accessed November 15, 2007), [available at http://www.jdpower.com/finance/ratings/online_investment/index.asp].

Johar, Gita Venkataramani, Jaideep Sengupta, and Jennifer L. Aaker (2005), "Two Roads to Updating Brand Personality Impressions: Trait Versus Evaluative Inferencing," Journal of Marketing Research, 42 (November), 458-69.

John, Oliver P. and Richard W. Robins (1994), "Accuracy and Bias in Self-Perception: Individual Differences in Self-Enhancement and the Role of Narcissism," Journal of Personality and Social Psychology, 66 (January), 206-19.

Johnson, Eric J., Steven Bellman, and Gerald L. Lohse (2003), "Cognitive Lock-In and the Power Law of Practice," Journal of Marketing, 67 (April), 62-75.

Johnson, Marcia K., Shahin Hashtroudi, and Stephen D. Lindsay (1993), "Source monitoring," Psychological Bulletin, 114 (July), 3-28.

de Jong, Ad, Ko de Ruyter and Martin Wetzels (2006), "Linking Employee Confidence to Performance: A Study of Self-Managing Service Teams," Journal of the Academy of Marketing Science, 34 (September), 576-87. 
Joshi, Ashwin W. and Sanjay Sharma (2004), "Customer Knowledge Development: Antecedents and Impact on New Product Performance," Journal of Marketing, 68 (October), 4759.

K

Kahn, William A. (1990), "Psychological Conditions of Personal Engagement and Disengagement At Work," Academy of Management Journal, 33 (December), 692-724.

Kelley, Scott W., James H. Donnelly Jr., and Steven J. Skinner (1990), "Customer Participation in Service Production and Delivery," Journal of Retailing, 66 (Fall), 315-35.

----, Steven J. Skinner, and James H. Donnelly Jr. (1992), "Organizational Socialization of Service Customers," Journal of Business Research, 25 (November), 197-214.

Kempf, Deanna S. and Robert E. Smith (1998), "Consumer Processing of Product Trial and the Influence of Prior Advertising: A Structural Modeling Approach," Journal of Marketing Research, 35 (August), 325-38.

Kim, Sung S. and Naresh K. Malhotra (2005), "A Longitudinal Model of Continued IS Use: An Integrative View of Four Mechanisms Underlying Postadoption Phenomena," Management Science, 51 (May), 741-55.

Klein, Lisa R. and Gary T. Ford (2003), "Consumer Search for Information in the Digital Age: An Empirical Study of Prepurchase Search For Automobiles," Journal of Interactive Marketing, 17 (Summer), 29-49.

Kohli, Ajay K., Tasadduq A. Shervani, and Goutam N. Challagalla (1998), "Learning and Performance Orientation of Salespeople: The Role of Supervisors," Journal of Marketing Research, 35 (May), 263-74.

Konana, Prabhudev and Sridhar Balasubramanian (2005), "The Social-Economic-Psychological model of technology adoption and usage: an application to online investing," Decision Support Systems, 39 (May), 505-24.

Kotler, Philip, and Richard A. Connor, Jr. (1972), "Marketing Professional Services," Journal and Marketing, 42 (January), 71-76.

Kowalchuk, Rhonda K., H. J. Keselman, James Algina, and Russell D. Wolfinger (2004), "The Analysis of Repeated Measurements with Mixed-Model Adjusted F Tests," Educational \& Psychological Measurement, 64 (April), 224-42.

Kumar, Nirmalya, Lisa K. Scheer, and Jan-Benedict E. M. Steenkamp (1995), "The Effects of Perceived Interdependence on Dealer Attributes," Journal of Marketing Research, 32 (August), 348-56.

$\mathbf{L}$

Laczniak, Russell N. and Darrel D. Muehling (1990), "Delayed Effects of Advertising Moderated by Involvement," Journal of Business Research, 20, 263-77.

Leach, Mark P. and Annie H. Liu (2003), "Investigating Interrelationships among Sales Training Evaluation Methods," Journal of Personal Selling and Sales Management, 23 (Fall), 32739.

Leuven, Edwin, Hessel Oosterbeek, Randolph Sloof, and Chris van Klaveren (2005), "Worker Reciprocity and Employer Investment in Training," Econometrica, 72, 137-49.

Li, Fuzhong, Terry E. Duncan, Susan C. Duncan, and Alan Acock, (2001), "Latent Growth Modeling of Longitudinal Data: A Finite Growth Mixture Modeling Approach," Structural Equation Modeling, 8 (January), 493-530.

Licht, Amir N., Chanan Goldschmidt, and Shalom H. Schwartz (2007), "Culture rules: The foundations of the rule of law and other norms of governance," Journal of Comparative Economics, 35 (December), 659-88.

Lindsley, Dana H., Daniel J. Brass, and James B. (1995), "Efficacy-Performance Spirals: A Multilevel Perspective," Academy of Management Review, 20 (July), 645-78. 
Littell, Ramon C., George A. Milliken, Walter W. Stroup, Russell D. Wolfinger, and Oliver Schabenberger (2006), SAS for Mixed Models. Cary, NC: SAS Institute Inc.

Little, Roderick J. A. (1988), "A Test of Missing Completely at Random for Multivariate Data with Missing Values," Journal of the American Statistical Association, 83 (December), 11981202.

Lo, Yungtai, Nancy R. Mendell, and Donald B. Rubin (2001) "Testing the number of components in a normal mixture," Biometrika, 88 (3), 767-78.

Locke, Edwin A. and Gary P. Latham (2004), "What Should We Do About Motivation Theory? Six Recommendations for the Twenty-First Century," Academy of Management Review, 29 (July), 388-403.

Looney, Clayton Arlen, Joseph S. Valacich, Peter A. Todd, and Michael G. Morris (2006), "Paradoxes of Online Investing: Testing the Influence of Technology on User Expectancies," Decision Sciences, 37 (May), 205-46.

Lubke, Gitta H. and Bengt Muthén (2005), "Investigating Population Heterogeneity With Factor Mixture Models," Psychological Methods, 10 (March), 21-39.

Luo, Xueming, Rebecca J. Slotegraaf, and Xing Pan (2006), "Cross-Functional "Coopetition": The Simultaneous Role of Cooperation and Competition Within Firms," Journal of Marketing, 70 (April), 67-80.

Lusch, Robert F. and James R. Brown (1996), "Interdependency, Contracting, and Relational Behavior in Marketing Channels," Journal of Marketing, 60 (October), 19-38.

----, Stephen L. Vargo, and Matthew O'Brien (2007), "Competing through service: Insights from service-dominant logic," Journal of Retailing, 83 (1), 5-18.

M

Mardia, Kanti V. and K. Foster (1983), "Omnibus tests of multinormality based on skewness and kurtosis," Communication in Statistics, 12 (2), 207-21.

Mathwick, Charla, Caroline Wiertz, and Ko de Ruyter (2008), "Social Capital Production in a Virtual P3 Community," Journal of Consumer Research, 34 (April), 832-49.

McKee, Daryl, Christina S. Simmers and Jane Licata (2006), "Customer Self-Efficacy and Response to Service," Journal of Service Research, 8 (February), 207-20.

Menon, Geeta, Priya Raghubir, and Norbert Schwarz (1995), "Behavioral Frequency Judgments: An Accessibility-Diagnosticity Framework," Journal of Consumer Research, 22 (September), 212-28.

Meuter, Matthew L., Amy L. Ostrom, and Robert I. Roundtree (2000), "Self-Service Technologies: Understanding Customer Satisfaction with Technology-Based Service Encounters," Journal of Marketing, 64 (July), 50-64.

----, ----, Mary Jo Bitner, and Robert Roundtree (2003), "The influence of technology anxiety on consumer use and experiences with self-service technologies," Journal of Business Research, 56 (November), 899-906.

----, Mary Jo Bitner, Amy L. Ostrom, and Stephen W. Brown (2005), "Choosing Among Alternative Service Deliver Modes: An Investigation of Customer Trial of Self-Service Technologies," Journal of Marketing, 69 (April), 61-83.

Mishra, Dabi Prasad, Jan B. Heide, and Stanton G. Cort (1998), "Information Asymmetry and Levels of Agency Relationships," Journal of Marketing Research, 35 (August), 277-95.

Mitchell, Terence R., et al. (1994), "Predicting Self-Efficacy and Performance During Skill Acquisition," Journal of Applied Psychology, 79 (August), 506-17.

Mohr, Lois A. and Mary Jo Bitner (1995), "The Role of Employee Effort in Satisfaction with Service Transactions," Journal of Business Research, 32 (March), 239-52.

Moorthy, Sridhar, Brian T. Ratchford, and DebabrataTalukdar (1997), "Consumer Information Search Revisited: Theory and Empirical Analysis," Journal of Consumer Research, 23 (March), 263-77. 
Morrison, Elizabeth W. and Jeffrey B. Vancouver (2000), "Within-Person Analysis of Information Seeking: The Effects of Perceived Costs and Benefits," Journal of Management, 26 (1), 119-37.

Murray, Keith B. (1991), "A Test of Services Marketing Theory: Consumer Information Acquisition Activities," Journal of Marketing, 55 (January), 10-25.

Murray, Kyle B. and Gerald Häubl (2007), "Explaining Cognitive Lock-In: The Role of SkillBased Habits of Use in Consumer Choice," Journal of Consumer Research, 34 (June), 7788.

Muthén, Bengt (2004), "Latent Variable Analysis: Growth Mixture Modeling and Related Techniques for Longitudinal Data," In The SAGE Handbook of Quantitative Methodology for the Social Sciences, David Kaplan ed. Newbury Park: Sage Publications, 345-68.

Muthén, Bengt and Shedden, Kerby (1999), "Finite mixture modeling with mixture outcomes using the EM algorithm," Biometrics, 55 (June), 463-69.

Muthén, Linda K. and Bengt O. Muthén (1988-2007), Mplus User's Guide ( $5^{\text {th }}$ ed.). Los Angeles, CA: Muthén and Muthén.

$\mathbf{N}$

Nagin, Daniel S. (1999), "Analyzing Developmental Trajectories: A Semi-Parametric GroupBased Approach," Psychological Methods, 4 (June), 139-57.

Newell, Stephen J. and Ronald E. Goldsmith (2001), "The development of a scale to measure perceived corporate credibility," Journal of Business Research, 52 (June), 235-47.

Newman, Joseph W. and Richard Staelin (1972), "Prepurchase Information Seeking for New Cars and Major Household Appliances," Journal of Marketing Research, 9 (August), 24957.

Noe, Raymond A. (1986), "Trainees' Attributes and Attitudes: Neglected Influence on Training Effectiveness," The Academy of Management Review, 11 (October), 736-49.

Nonaka, Ikujiro and Hirotaka Takeuchi (1995), The Knowledge-Creating Company: How Japanese Companies Create the Dynamics of Innovation. New York: Oxford University Press.

Noortgate, Wim Van den and Patrick Onghena (2006), "Analysing repeated measures data in cognitive research: A comment on regression coefficient analyses," European Journal of Cognitive Psychology, 18 (6), 937-52.

Norman, Patricia M. (2004), "Knowledge Acquisition, Knowledge Loss, and Satisfaction in High Technology Alliances," Journal of Business Research, 57, 610-19.

Odean, Terrance (1998), "Are Investors Reluctant to Realize Their Losses?" The Journal of Finance, 53 (October), 1775-98.

Overall, John, Chul Ahn, C. Shivakumar and Yallapa Kalburgi (1999), "Problematic Formulations of SAS PROC.MIXED Models for Repeated Measurements," Journal of Biopharmaceutical Statistics, 9 (January), 189-216.

Oyedele, Adesegun and Penny M. Simpson (2007), "An Empirical Investigation of Consumer Control Factors on Intentions to Use Selected Self-Service Technologies," International Journal of Service Industry Management, 18 (3), 287-306.

$\mathbf{P}$

Palmatier, Robert W., Rajiv P. Dant, Dhruv Grewal, and Kenneth R. Evans (2006), "Factors Influencing the Effectiveness of Relationship Marketing: A Meta-Analysis," Journal of Marketing, 70 (October), 136-53.

----, Rajiv P. Dant, and Dhruv Grewal (2007), "A Comparative Longitudinal Analysis of Theoretical Perspectives of Interorganizational Relationship Performance," Journal of Marketing, 71 (October), 172-94. 
Parsons, Talcott (1968), "Professions," in International Encyclopedia of the Social Sciences, D. Sills, ed. vol. XII, New York: Maximillan, Free Press, 536-47.

Pavlou, Paul A. and Mendel Fygenson (2006), "Understanding and Predicting Electronic Commerce Adoption: An Extension of the Theory of Planned Behavior," MIS Quarterly, 30 (March), 115-43.

Petty, Richard E., John T. Cacioppo, and Rachel Goldman (1981), "Personal involvement as a determinant of argument-based persuasion," Journal of Personality and Social Psychology, 41 (November), 847-55.

----, ----, and David Schumann (1983), "Central and Peripheral Routes to Advertising Effectiveness: The Moderating Role of Involvement," Journal of Consumer Research, 10 (September), 135-46.

---- and Duane T. Wegener (2006), The Elaboration Likelihood Model: Current Status and Controversies. New York: The Guilford Press.

Prahalad, C. K. and Venkat Ramaswamy (2004), "Co-Creation Experiences: The Next Practice in Value Creation," Journal of Interactive Marketing, 18 (Summer), 5-14.

Priester, Joseph R. and Richard E. Petty (1995), "Source Attributions and Persuasion: Perceived Honesty as a Determinant of Message Scrutiny," Personality and Social Psychology Bulletin, 21 (June), 637-54.

Purohit, Devavrat and Joydeep Srivastava (2001), "Effect of Manufacturer Reputation, Retailer Reputation, and Product Warranty on Consumer Judgments of Product Quality: A Cue Diagnosticity Framework," Journal of Consumer Psychology, 10 (3), 123-34.

$\mathbf{R}$

Rapp, Adam, Michael Ahearne, John Mathieu, and Niels Schillewaert (2006), "The impact of knowledge and empowerment on working smart and working hard: The moderating role of experience," International Journal of Research in Marketing, 23 (September), 279-93.

Ratchford, Brian T., Myung-Soo Lee, and Debabrata Talukdar (2003), "The Impact of the Internet on Information Search for Automobiles," Journal of Marketing Research, 40 (May), 193-209.

Raudenbush, Stephen W. and Anthony S. Bryk (2002), Hierarchical Linear Models: Applications and Data Analysis Methods. Thousand Oaks, CA: Sage Publication.

Rokkan, Aksel I., Jan B. Heide, and Kenneth H. Wathne (2003), "Specific Investments in Marketing Relationships: Expropriation and Bonding Effects," Journal of Marketing Research, 40 (May), 210-24.

Ross, William T., Erin Anderson, and Barton Weitz (1997), "Performance in Principal-Agent Dyads: The Causes and Consequences of Perceived Asymmetry of Commitment to the Relationship," Management Science, 43 (May), 680-704.

Russo, J. Edward, Margaret G. Meloy, and Victoria Husted Medvec (1998), "Predecisional Distortion of Product Information," Journal of Marketing Research, 35 (November), 438-52.

S

Salanova, Marisa, Sonia Agut, and José María Peiró (2005), "Linking Organizational Resources and Work Engagement to Employee Performance and Customer Loyalty: The Mediation of Service Climate," Journal of Applied Psychology, 90 (November), 1217-27.

Sanbonmatsu, David M. and Frank R. Kardes (1988), "The Effects of Physiological Arousal on Information Processing and Persuasion," Journal of Consumer Research, 15 (December), 379-85.

----, ----, David C. Houghton, Edward A. Ho, and Steven S. Posavac (2003), "Overestimating the Importance of the Given Information in Multiattribute Consumer Judgment," Journal of Consumer Psychology, 13 (3), 289-300.

Saks, Alan M. and Monica Belcourt (2006), "An Investigation of Training Activities and Transfer of Training in Organizations," Human Resource Management, 45 (Winter), 629-48. 
Satorra, Albert and Peter M. Bentler (1988), "Scaling Corrections for Chi-square Statistics in Covariance Structure Analysis," American Statistical Association 1988 Proceedings of the Business and Economic Sections, 308-13.

Schwartz, Shalom H. (1999), "A Theory of Cultural values and Some Implications for Work," Applied Psychology: An International Review, 48 (January), 23-47.

---- (2007), "Universalism Values and the Inclusiveness of Our Moral Universe," Journal of Cross-Cultural Psychology, 38 (November), 711-28.

Schwarzkopf, David L. (2007), "Investors' attitudes toward source credibility," Managerial Auditing Journal, 22 (1), 18-33.

Seijts, Gerard H., Gary P. Latham, Kevin Tasa, and Brandon W. Latham (2004), "Goal Setting and Goal Orientation: An Integration of Two Different Yet Related Literatures," Academy of Management Journal, 47 (2), 227-39.

Selnes, Fred and James Sallis (2003), "Promoting Relationship Learning," Journal of Marketing, 67 (July), 80-95.

Sengupta, Sanjit (1995), "Some Antecedents of Exclusivity in Bilateral Interorganizational Relationships," Marketing Letters, 6 (January), 33-44.

Sharma, Anurag (1997), "Professional as Agent: Knowledge Asymmetry in Agency Exchange," Academy of Management Review, 22 (July), 758-98.

Sharma, Arun, Michael Levy, Heiner Evanschitzky (2007), "The Variance in Sales Performance Explained by the Knowledge Structures of Salespeople," Journal of Personal Selling and Sales Management, 27 (Spring), 169-81.

Shea, Christine M. and Jane M. Howell (2000), "Efficacy-Performance Spirals: An Empirical Test," Journal of Management, 26 (4), 791-812.

Singer, Judith D. (1998), "Using SAS PROC MIXED to Fit Multilevel Models, Hierarchical Models, and individual Growth Models," Journal of Educational and Behavioral Statistics, 24 (Winter), 323-55.

Singh, Jagdip (1993), "Boundary role ambiguity: Facets, determinants, and impacts," Journal of Marketing, 57 (April), 11-31.

Slovic, Paul, and Lichtenstein, Sarah (1971), "Comparison of Bayesian and Regression Approaches to the Study of Information Processing in Judgment," Organizational Behavior and Human Performance, 6, 649-744.

Smith, Peter B., Mark F. Peterson, and Shalom H. Schwartz (2002), "Cultural Values, Sources of Guidance, and their Relevance to Managerial Behavior: A 47-Nation Study," Journal of Cross-Cultural Psychology, 33 (2), 188-208.

Smudde, Peter M. (2005), "Blogging, Ethics and Public Relations: A Proactive and Dialogic Approach," Public Relations Quarterly, 50 (3), 34-38.

Spaniol, Julia and Ute J. Bayen (2002), "When is Schematic Knowledge Used in Source Monitoring?," Journal of Experimental Psychology: Learning, Memory, and Cognition, 28 (July), 631-51.

Stajkovic, Alexander D. and Fred Luthans (1998), "Self-efficacy and work-related performance: A meta-analysis," Psychological Bulletin, 124 (September), 240-61.

Stapel, Diederik A. and Hart Blanton (2004), "From Seeing to Being: Subliminal Social Comparisons Affect Implicit and Explicit Self-Evaluations," Journal of Personality and Social Psychology, 87 (October), 468-81.

Steckel, Joel, et al. (2005), "Choice in Interactive Environments," Marketing Letters, 16 (December), 309-20.

Steenkamp, Jan-Benedict E. M. and Hans Baumgartner (1998), "Assessing Measurement Invariance in Cross-National Consumer Research," Journal of Consumer Research, 25 (June), 78-90.

---- and Inge Geyskens (2006), "How Country Characteristics Affect the Perceived Value of Web Sites," Journal of Marketing, 70 (July), 136-50. 
Stone, Dan N. (1994),"Overconfidence in Initial Self-efficacy Judgments: Effects on Decision Processes and Performance," Organizational Behavior and Human Decision Processes, 59 (September), 452-74.

Stump, Rodney L. and Jan B. Heide (1996), "Controlling Supplier Opportunism in Industrial Relationships," Journal of Marketing Research, 33 (November), 431-41.

Sujan, Harish, Mita Sujan, and James R. Bettman (1988), "Knowledge Structure Differences Between More Effective and Less Effective Salespeople," Journal of Marketing Research, 25 (February), 81-6.

----, Barton A. Weitz, and Nirmalya Kumar (1994), "Learning Orientation, Working Smart, and Effective Selling," Journal of Marketing, 58 (July), 39-52.

$\mathbf{T}$

Tax, Stephen S., Mark Colgate, and David E. Bowen (2006), "How to Prevent Your Customers From Failing," MIT Sloan Management Review, 47 (Spring), 30-38.

The Economist (2007), "Beyond Loyalty: Meeting the Challenge of Customer Engagement," (accessed November 15, 2007), [available at http://www.adobe.com/engagement/pdfs/partl.pdf].

Toothaker, Larry E (1993), Multiple Comparsion Procedures. Quantitative Applications in the Social Sciences. Sage University Paper Nr. 89. Thousand Oaks: Sage Publications.

Tse, David K., Kam-hon Lee, Ilan Vertinsky, and Donald A. Wehrung (1988), "Does Culture Matter? A Cross-Cultural Study of Executives' Choice, Decisiveness, and Risk Adjustment in International Marketing," Journal of Marketing, 52 (October), 81-95.

V

Vancouver, Jeffrey B. and Laura N. Kendall (2006), "When Self-Efficacy Negatively Relates to Motivation and Performance in a Learning Context,' Journal of Applied Psychology, 91 (September), 1146-53.

----, Charles M. Thompson, E. Casey Tischner, and Dan J. Putka (2001), 'Two Studies Examining the Negative Effect of Self-Efficacy on Performance," Journal of Applied Psychology, 87 (June), 506-16.

----, ---- and Amy A. Williams (2001), "The Changing Signs in the Relationships Among SelfEfficacy, Personal Goals, and Performance," Journal of Applied Psychology, 86 (August), 605-20.

----, Kristen M. More, and Ryan J. Yoder (2008), "Self-Efficacy and Resource Allocation: Support for a Nonmonotonic Discontinuous Model," Journal of Applied Psychology, 93 (January), 35-47.

Vandenberg, Robert J. and Charles E. Lance (2000), "A Review and Synthesis of the Measurement Invariance Literature: Suggestions, Practices, and Recommendations for Organizational Research," Organizational Research Methods, 3 (January), 4-70.

Vargo, Stephen L. and Robert F. Lusch (2004), "Evolving to a New Dominant Logic for Marketing," Journal of Marketing, 68 (January), 1-17. 
W

Wang, Alex (2006), "Advertising Engagement: A Driver of Message Involvement on Message Effects," Journal of Advertising Research, 46 (December), 355-68.

Wang, Guangping, and Richard G. Netemeyer (2002), "The Effects of Job Autonomy, Customer Demandingness, and Trait Competitiveness on Salesperson Learning, Self-efficacy, and Performance," Journal of the Academy of Marketing Science, 30 (Summer), 217-28.

Ward, James C. and Amy L. Ostrom (2006), "Complaining to the Masses: The Role of Protest Framing in Customer-Created Complaint Web Sites," Journal of Consumer Research, 33 (September), 220-30.

Webster, Jane and Joseph J. Martocchio (1992), "Microcomputer playfulness: Development of a measure with workplace implications," MIS Quarterly, 16 (June), 201-26.

Wedel, Michel and Wayne S. DeSarbo (1995), "A Mixture Likelihood Approach for Generalized Linear Models," Journal of Classification, 12 (March), 21-55.

Weitz, Barton A., Harish Sujan, and Mita Sujan (1986), "Knowledge, Motivation, and Adaptive Behavior: A Framework for Improving Selling Effectiveness," Journal of Marketing, 50 (October), 174-91.

Willett, John B. (1989), "Some Results On Reliability For The Longitudinal Measurement Of Change: Implications For The Design Of Studies Of Individual Growth," Educational and Psychological Measurement, 49, 587-602.

Wu, Chenghuan and David R. Shaffer (1987), "Susceptibility to Persuasive Appeals as a Function of Source Credibility and Prior Experience With the Attitude Object," Journal of Personality and Social Psychology, 52 (4), 677-88.

Wuyts, Stefan and Inge Geyskens (2005), "The Formation of Buyer-Supplier Relationships: Detailed Contract Drafting and Close Partner Selection," Journal of Marketing, 69 (October), 103-17.

$\mathbf{x}$

Xie, Chunyan, Richard P. Bagozzi, and Sigurd V. Troye (2008), "Trying to prosume: toward a theory of consumers as co-creators of value," Journal of the Academy of Marketing Science, 36 (Spring), 109-22.

$\mathbf{Y}$

Yeo, Gillian B. and Andrew Neal (2006), "An Examination of the Dynamic Relationship Between Self-Efficacy and Performance Across Levels of Analysis and Levels of Specificity," Journal of Applied Psychology, 91 (September), 1088-101.

---- and ---- (2008), "Subjective Cognitive Effort: A Model of States, Traits, and Time," Journal of Applied Psychology, 93 (3), 617-31.

Yilmaz, Cengiz, Lutfihak Alpkan, and Ercan Ergun (2005), "Cultural determinants of customerand learning-oriented value systems and their joint effects on firm performance," Journal of Business Research, 58 (October), 1340-52.

z

Zauberman, Gal (2003), "The Intertemporal Dynamics of Consumer Lock-In," Journal of Consumer Research, 30 (December), 405-19.

Zhu, Zhen, Cheryl Nakata, K. Sivakumar, and Dhruv Grewal (2007), "Self-service technology effectiveness: the role of design features and individual traits," Journal of the Academy of Marketing Science, 35 (Winter), 492-506. 


\section{SAMENVATTING}

\section{Inleiding}

Bedrijven werken steeds vaker samen met externe partijen, zoals klanten en werknemers van andere bedrijven, voor het (mede-)uitvoeren van hun dienstenprocessen. Hierdoor kunnen diensten beter toegesneden worden op de individuele wensen van de klant wat ervoor zorgt dat deze bedrijven competitief voordeel behalen. Bedrijven zijn tevens actief bezig hun klanten en partners op te leiden waardoor de prestatie van deze groepen verder verbetert. Een voorbeeld van een dergelijke dienst is het verkopen van je eigen huis via http://www.makelaarsland.nl, dat een alternatief biedt voor de traditionele verkoopmakelaar en de laatste jaren steeds populairder wordt. De verkoper zorgt zelf voor de foto's van het huis met bijbehorende verkooptekst en de rondleiding van potentiële kopers. Makelaarsland taxeert de woning, zorgt ervoor dat tekst en foto's op Internet te vinden zijn, en begeleidt de verkoper tijdens het proces. Op de web site van makelaarsland is uitgebreide informatie en zijn handige links te vinden om de klanten te helpen. Naast het uitbesteden van taken aan de klant besteden bedrijven ook steeds vaker diensten uit aan andere bedrijven, zoals onafhankelijke distributeurs die producten van een fabrikant verkopen.

Behalve lagere kosten en diensten op maat kleven er ook nadelen aan deze vorm van dienstverlening. Er ontstaan vaker problemen die tot ontevredenheid van de klant leiden en veel partnerschappen tussen bedrijven falen of worden voortijdig beëindigd. Oorzaken van deze problemen zijn onder andere de onervarenheid en het gebrek aan kennis van de externe partij. Deze dissertatie gaat daarom in op de vraag hoe dit type dienstverlening tot een succes gemaakt kan worden. Hiertoe richt het onderzoek zich zowel op klanten als op medewerkers van andere bedrijven. De nadruk in de drie empirische studies ligt op het verbeteren van de prestatie van de klant of partner door middel van het ontwikkelen van kennis met behulp van het aanbieden van informatie en training. De centrale onderzoeksvraag van deze dissertatie luidt als volgt: Welke mechanismen zijn van invloed op de effectiviteit van kennisontwikkeling van klanten in termen van de prestatie van deze externe partners?

Om deze vraag te beantwoorden gaan we in de eerste studie in op de vorming van taakspecifiek zelfvertrouwen, of self-efficacy, tijdens het zoeken van informatie en de gevolgen hiervan voor dienstenevaluaties. In de tweede studie wordt onderzocht hoe consumenten hun self-efficacy veranderen nadat ze een informatiebron hebben bekeken. Tot slot wordt in de derde studie gekeken naar hoe werknemers gemotiveerd worden om nieuwe kennis van training toe te passen op hun verkoopactiviteiten. 


\section{Antecedenten en Consequenties van Self-Efficacy}

In hoofdstuk 2, het eerste empirische hoofdstuk, identificeren wij antecedenten en consequenties van self-efficacy tijdens het zoeken van informatie door nieuwe klanten. Online beleggen via een Nederlandse bank is gekozen als onderzoekscontext. Door middel van een online survey aan studenten is onderzocht hoe self-efficacy wordt beïnvloed door de evaluaties van informatiebronnen. Drie verschillende websites, namelijk die van de bank, een online beleggingsmagazine, en een online beleggersforum, zijn aselect voorgelegd aan de respondenten. Deze werden vervolgens beoordeeld op hun betrouwbaarheid en kwaliteit van de beleggingsinformatie. Respondenten gaven ook aan hoeveel self-efficacy, of vertrouwen in hun capaciteiten om online te beleggen via de site van de bank, zij na aanleiding van de aangeboden informatie hadden. $\mathrm{Na}$ het bekijken van de drie bronnen evalueerden de respondenten de online beleggingsdienst en namen ze een fictieve beleggingsbeslissing.

Uit de studie blijkt dat betrouwbaarheid van de bron en kwaliteit van de aangeboden informatie belangrijke voorspellers zijn van self-efficacy en dat deze effecten niet in dezelfde mate toe te schrijven zijn aan de drie aangeboden bronnen. Hoe lang respondenten zochten naar informatie blijkt verassend genoeg niet van belang voor hun self-efficacy. Het positieve effect van betrouwbaarheid op self-efficacy is vooral terug te voeren op de betrouwbaarheid van de onafhankelijke partij, en dat van informatie kwaliteit vooral op die van het bedrijf. Deze effecten worden respectievelijk versterkt of verzwakt door hoge betrokkenheid van de klant. Self-efficacy beïnvloedt op zijn beurt gepercipieerde prestatie, de waarde van de dienst, en gebruiksintenties.

\section{Updatingpatronen van Self-Efficacy Tijdens het Zoeken naar Informatie}

Hoofdstuk 3 gaat in op de ontwikkeling van self-efficacy tijdens het zoeken van informatie. Als consumenten nieuwe informatie tot hun beschikking hebben, maken zij onbewust de afweging of ze hun self-efficacy wel of niet veranderen. Deze studie gaat in op het veranderen van self-efficacy naar aanleiding van informatie. Eerder onderzoek heeft aangetoond dat self-efficacy mentaal bijgewerkt wordt na een prestatie of een taak, dit onderzoek toont aan dat dit ook het geval is na het lezen van taakinformatie. De studie laat tevens zien dat niet iedereen hetzelfde op informatie reageert: voor sommigen heeft nieuwe informatie een positief effect op self-efficacy, voor anderen een negatief effect, en voor een groot deel van de consumenten heeft het geen effect. Welk type bron op dat moment is gelezen, maakt daarbij niet uit. Deze verschillende updatingpatronen kunnen worden verklaard door verschillen in ervaring en inspanning. De groep die zijn self-efficacy verhoogt tijdens het zoeken van informatie, heeft de minste ervaring en spendeert veel inspanning aan het zoeken. De andere twee groepen hebben meer ervaring, maar de groep die negatief reageert op de informatie in termen van self-efficacy spendeert de laagste inspanning aan het zoeken. Deze 
groep behaalt ook een veel lagere objectieve prestatie dan de andere twee groepen.

\section{De Pay-off van Kennisinvesteringen in Partners}

In plaats van consumenten richt hoofdstuk 4 zich op werknemers van andere bedrijven. De relatie tussen fabrikant en zijn distributeurs staat centraal. Fabrikanten investeren veel in training van medewerkers van distributeurs. Vaak verkopen deze distributeurs een portfolio met producten van de fabrikant en zijn concurrenten, iets wat wij non-exclusiviteit hebben genoemd. Dit type partner is minder afhankelijk van de fabrikant en daardoor meestal minder gemotiveerd om hard te werken voor de fabrikant. Dit brengt een groot probleem met zich mee: hoewel fabrikanten de verkopers wel moeten trainen omdat ze van hen afhankelijk zijn, kunnen non-exclusieve partners deze kennis ook gebruiken om producten van concurrenten te verkopen. Dit noemen wij het training-agency dilemma. Door middel van een online survey aan verkooppartners van een multinationale fabrikant van computertechnologie zijn de effecten van een salestraining op de verkoop van producten van de fabrikant geanalyseerd.

De studie toont aan dat non-exclusieve partners inderdaad minder kennis van training omzetten in hogere prestaties dan exclusieve partners. Wij identificeren een aantal condities die dit probleem verminderen. Kennistoepassing van non-exclusieve partners wordt verhoogd door het aanbieden van fabrikantspecifieke kennis. Als non-exclusieve partners veel algemene kennis opdoen, die zij kunnen gebruiken om te verkopen voor andere bedrijven, denken zij dat ze niet meer zijn gaan verkopen voor de fabrikant ook al is dat in werkelijkheid wel het geval. Tevens zijn verschillende contextuele condities van invloed; als een nonexclusieve partner veel belang hecht aan het leren van nieuwe dingen, zorgt dat voor een hogere kennistoepassing, net als het werken in een professioneel bedrijf gericht op dienstverlening (zoals een consultancy bureau in plaats van een distributeur of reseller), en het werken in een cultuur waar de nadruk op het belang van het collectief in plaats van het individu wordt gelegd.

\section{Conclusie}

Uit de drie empirische studies zijn een aantal algemene conclusies te trekken. Ten eerste reageren mensen anders op informatie en heeft meer informatie of kennis niet altijd positieve effecten. Ten tweede blijkt motivatie een belangrijke rol te spelen in de effectiviteit van taakinformatie op prestaties. In de drie studies hebben betrokkenheid, inspanning, en condities die opportunistisch gedrag verlagen een grote (soms indirecte) impact op prestaties. Ten derde kunnen bedrijven door het aanbieden van informatie via hun website of via training de prestatie van hun klanten en partners verbeteren. Dit gebeurt op een directe manier door het verbeteren van vaardigheden en het verhogen van kennis, maar 
ook indirect door middel van mechanismen zoals het verhogen van self-efficacy en motivatie.

De resultaten die beschreven zijn in dit proefschrift geven meer inzicht in het samenspel van informatie, persoonlijkheidskenmerken, en situationele factoren die de effectiviteit van kennisontwikkeling bij klanten en partners beïnvloeden. Voor bedrijven geeft dit proefschrift suggesties voor betere klantensegmentatie op basis van motivatie, ervaring, en eventueel bedrijfscontext. De studies geven tevens richtlijnen voor het aanbieden en structureren van informatie of training aan klanten. 


\section{Curriculum Vitae}

Jacqueline van Beuningen was born on the $1^{\text {st }}$ of September 1981 in Nijmegen, The Netherlands. She attended secondary school at the Dominicus College in Nijmegen and graduated in 1999. In September 1999, she started studying Toegepaste Communicatiewetenschap (i.e., Communication Studies) at the faculteit Gedragswetenschappen at the University of Twente. After specializing in Marketing Communications, she received her Masters degree (cum laude) in June 2004.

She joined the Department of Marketing at Maastricht University in August 2004 to do a PhD. She was a consortium fellow at the AMA Sheth Foundation Doctoral Consortium in 2007. During the spring semester of 2008, she was a visiting $\mathrm{PhD}$ at the Fuqua School of Business at Duke University. She has presented her work at several international conferences. She is the winner of the 2007 Sheth European doctoral award competition, and is 2nd place winner in the 2008 dissertation competition organized by the AMA/ Relationship Marketing SIG and CBIM Georgia State University. She has also received an honorable mention in the 2007 ISBM Dissertation Support Award Competition at Penn State University.

Currently, she works as a Postdoctoral Researcher at the Department of Marketing at Maastricht University. Her research interests lie in the area of cognitive and information processing and learning in vertical networks. 